\author{
Aus der Abteilung Neurologie \\ (Prof. Dr. med. M. Bähr) \\ im Zentrum Neurologische Medizin \\ der Medizinischen Fakultät der Universität Göttingen
}

\title{
Untersuchung von Proteomveränderungen im Synaptosom von Patienten mit sporadischer Creutzfeldt-Jakob-Krankheit
}

\author{
INAUGURAL - Dissertation \\ zur Erlangung des Doktorgrades \\ der Medizinischen Fakultät \\ der Georg-August-Universität zu Göttingen
}

\author{
vorgelegt von \\ Martin Nowak \\ aus \\ Haldensleben
}

Göttingen 2012 
Dekan: Prof. Dr. med. M. Schön

I. Berichterstatterin: Prof. Dr. med. I. Zerr

II. Berichterstatter/in: Prof. Dr. Dresbach

III. Berichterstatter/in: Prof. Dr. Crozier

Tag der mündlichen Prüfung: 27.03.2013 
Die Ergebnisse dieser Arbeit wurden auf der Prion 2010 in Salzburg und der 9. Göttinger Tagung der Neurowissenschaftlichen Gesellschaft als Poster vorgestellt. 


\section{Inhaltsverzeichnis}

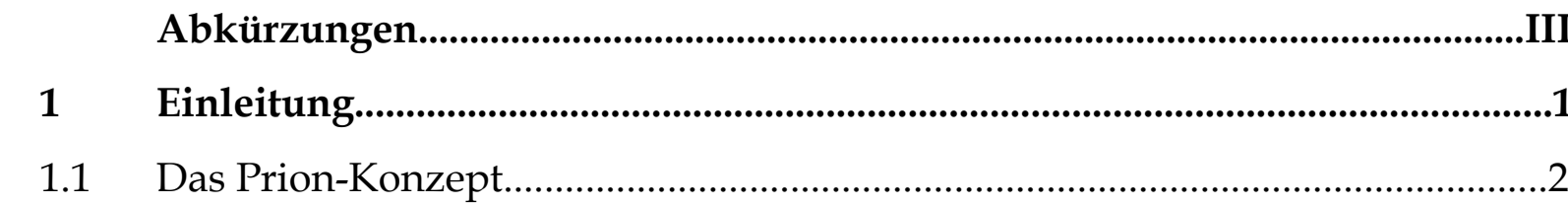

1.1.1 Auf der Suche nach dem Erreger - Protein-only-Hypothese.......................2

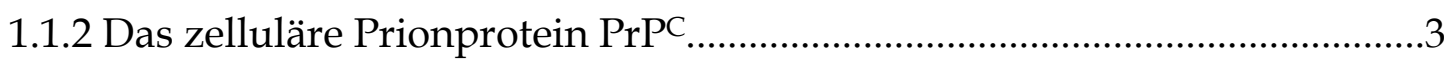

1.1.2.1 Die Struktur des $\mathrm{PrPC}^{\mathrm{C}}$....................................................................

1.1.2.2 Die Funktion von $\mathrm{PrPC}^{2}$..................................................................

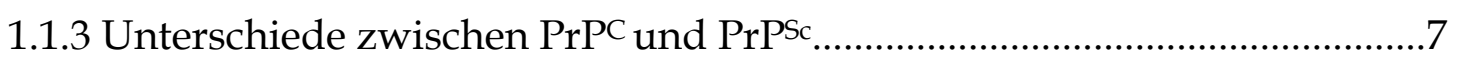

1.2 Prionenerkrankungen bei Menschen................................................................

1.2.1 Sporadische Formen.....................................................................................

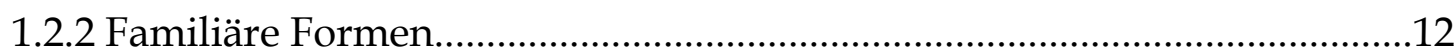

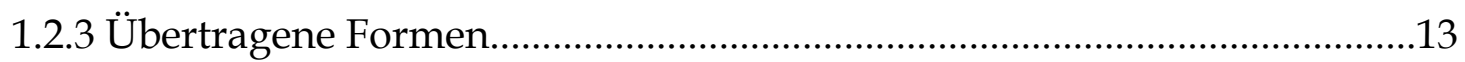

1.3 Neurodegenerative Prozesse und Prionen................................................................14

1.3.1 Gewinn, Verlust oder Änderung der Funktion des PrP?............................14

1.3.2 Krankheitsbeginn an den Synapsen...........................................................15

1.3.3 Synaptosomen ..........................................................................................15

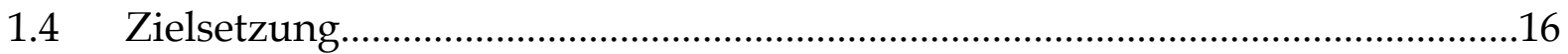

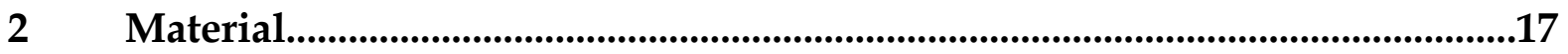

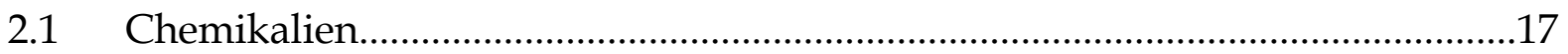

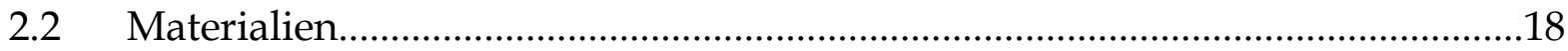

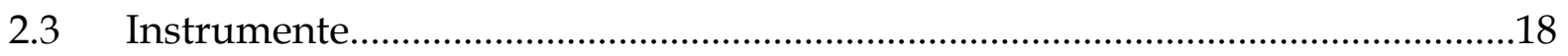

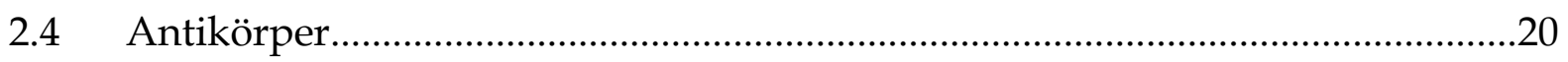

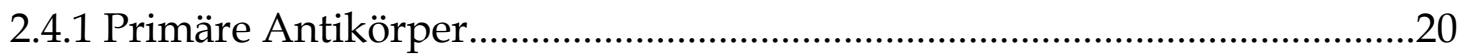

2.4.2 Sekundäre Antikörper.................................................................................20

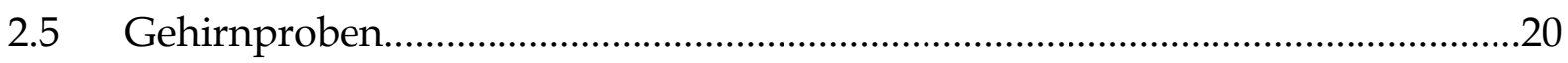

2.6 Puffer und Lösungen............................................................................22

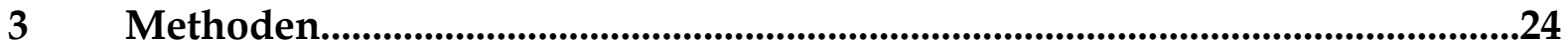

3.1 Isolation von Synaptosomen aus humanem Gehirngewebe...............................24

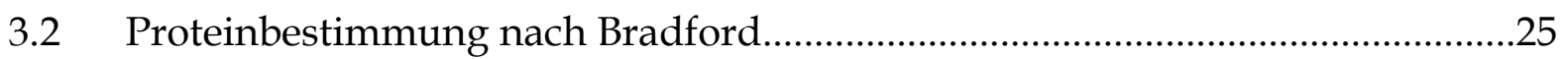

3.3 SDS-Polyacrylamidgelelektrophorese (SDS-PAGE) ...........................................25 


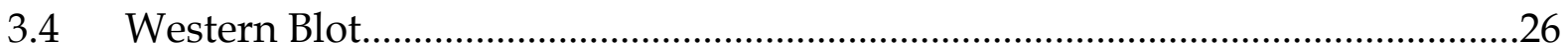

3.5 Zweidimensionale Gelelektrophorese...........................................................27

3.5.1 Probenvorbereitung für die erste Dimension.............................................28

3.5.1.1 Präzipitation...................................................................................28

3.5.1.2 Proteinmarkierung mit CyDyes....................................................28

3.5.2 Erste Dimension: Isoelektrische Fokussierung...............................................29

3.5.3 Äquilibrierung der Proteine für die zweite Dimension................................30

3.5.4 Zweite Dimension: SDS-PAGE....................................................................30

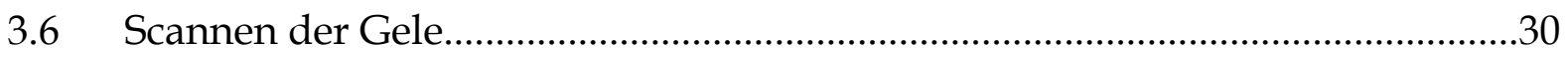

3.7 Kolloidale Coomassie-Brilliant-Blau-Färbung........................................................31

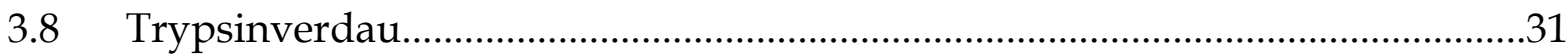

3.9 Massenspektrometrische Untersuchung..........................................................32

3.10 Vergleich und statistische Auswertung....................................................................33

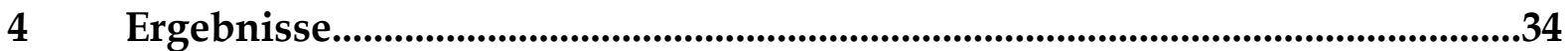

4.1 Nachweis der korrekten Isolierung der Synaptosomen..........................................34

4.2 Ergebnisse der Proteomanalyse: allgemeine Bemerkungen...................................34

4.3 Proteine mit Einfluss auf Zellstruktur und Stofftransport....................................41

4.4 Proteine mit Einfluss auf Zellstoffwechsel und Energiestoffwechsel................42

4.5 Proteine mit Einfluss auf Apoptose und oxidativen Stress..................................43

4.6 Proteine mit Einfluss auf Proteinfaltung (Chaperon-Proteine) ………………....44

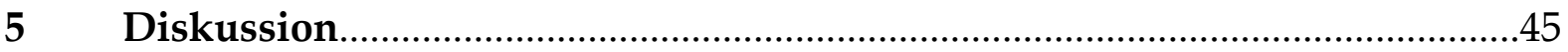

5.1 Proteine mit Einfluss auf Zellstruktur und Stofftransport.................................45

5.2 Proteine mit Einfluss auf Zellstoffwechsel und Energiestoffwechsel.................48

5.3 Proteine mit Einfluss auf Apoptose und oxidativen Stress..................................49

5.4 Proteine mit Einfluss auf Proteinfaltung (Chaperon-Proteine)...........................50

5.5 Gemeinsamkeiten und Unterschiede zwischen den Subtypen............................51

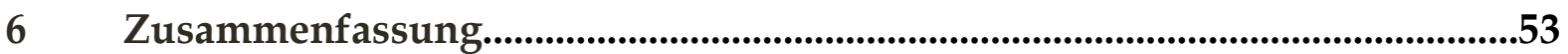

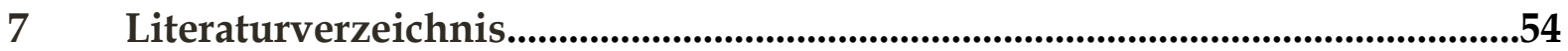




\section{Abkürzungen}

\begin{tabular}{|c|c|}
\hline Abb. & Abbildung \\
\hline $\mathrm{ACN}$ & Acetonitril \\
\hline AMBIC & Ammoniumbikarbonat \\
\hline APS & Ammoniumpersulfat \\
\hline $\mathrm{ATP}$ & Adenosintriphosphat \\
\hline BSA & Bovines Serumalbumin \\
\hline BSE & Bovine Spongiforme Enzephalopathie \\
\hline${ }^{\circ} \mathrm{C}$ & Grad Celsius \\
\hline CBBG & Coomassie-Brilliant-Blau G-250 \\
\hline CDK5 & Cyclin-dependent kinase 5 \\
\hline CHAPS & (3-(3-Cholamidopropyl)-Dimethylammonio)-1- \\
\hline & Propansulfonsäure \\
\hline CJK & Creutzfeldt-Jakob-Krankheit \\
\hline $\mathrm{cm}$ & Zentimeter \\
\hline $2 \mathrm{D}$ & zweidimensional \\
\hline DIGE & Fluorescence Difference Gel Electrophoresis \\
\hline $\mathrm{dd}_{\mathrm{H}} \mathrm{O}$ & doppeltdestilliertes Wasser \\
\hline${ }_{\mathrm{d}} \mathrm{H}_{2} \mathrm{O}$ & destilliertes Wasser \\
\hline DTT & Dithiothreitol \\
\hline ECL & Erhöhte Chemilumineszenz \\
\hline ER & Endoplasmatisches Retikulum \\
\hline fCJK & familiäre Creutzfeldt-Jakob-Krankheit \\
\hline$x g$ & Erdschwerebeschleunigung \\
\hline g & Gramm \\
\hline GFAP & Glial Fibrillary Acidic Protein \\
\hline GSS & Gerstmann-Sträussler-Scheinker-Syndrom \\
\hline $\mathrm{H}_{2} \mathrm{O}_{2}$ & Wasserstoffperoxid \\
\hline Hsp & Hitzeschockprotein \\
\hline IAA & Iodacetamid \\
\hline iCJK & iatrogene Creutzfeldt-Jakob-Krankheit \\
\hline
\end{tabular}




\begin{tabular}{|c|c|}
\hline IEF & isoelektrische Fokussierung \\
\hline IgG & Immunglobulin Gamma \\
\hline IS & Internal Standard \\
\hline $\mathrm{kDa}$ & Kilodalton \\
\hline 1 & Liter \\
\hline M & Molar \\
\hline $\mathrm{mA}$ & Milliampere \\
\hline $\mathrm{mg}$ & Milligramm \\
\hline$\mu \mathrm{g}$ & Mikrogramm \\
\hline $\mathrm{ml}$ & Milliliter \\
\hline$\mu l$ & Mikroliter \\
\hline $\mathrm{mM}$ & Millimolar \\
\hline$\mu \mathrm{M}$ & Mikromolar \\
\hline $\mathrm{mm}$ & Millimeter \\
\hline MRT & Magnetresonanztomographie \\
\hline $\mathrm{NADH}$ & reduziertes Nicotinamid-Adenin-Dinukleotid \\
\hline NDK & Kontrollgruppe \\
\hline ng & Nanogramm \\
\hline $\mathrm{nm}$ & Nanometer \\
\hline NOS & Stickstoffmonoxid-Synthase \\
\hline NSE & Neuronenspezifische Enolase \\
\hline PBS & Phosphat-gepufferte Salzlösung \\
\hline pg & Pikogramm \\
\hline $\mathrm{pI}$ & Isoelektrischer Punkt \\
\hline PRNP & menschliches Prionproteingen \\
\hline Prnp & Prionproteingen der Maus \\
\hline Prnp $0 / 0$ & Prionproteingen der Maus knockout \\
\hline $\operatorname{PrP}$ & Prionprotein \\
\hline $\operatorname{PrPC}$ & zelluläres Prionprotein \\
\hline PrPSc & abnormes Prionprotein, Scrapie-Prionprotein \\
\hline PVDF & Polyvinylidenfluorid \\
\hline Q-TOF & Quadropol-time-of-Flight \\
\hline
\end{tabular}




\begin{tabular}{l|l} 
rpm & $\begin{array}{l}\text { Umdrehungen pro Minute } \\
\text { S2 }\end{array}$ \\
sCJK & $\begin{array}{l}\text { sporolische Proteinfraktionen } \\
\text { SDS }\end{array}$ \\
SDS-PAGE & SDS-Polyacrylamidgelelektrophorese \\
Sy & Synaptosomenfraktionen \\
TEMED & N,N,N',N'-Tetramethylethylendiamin \\
TFA & Trifluoressigsäure \\
Tris & Tris(hydroxymethyl)-aminomethan \\
TSE & Transmissible spongiform encephalopathy \\
Tween-20 & Polyoxyethylen(20)-sorbitan-monolaurat \\
V & Volt \\
vCJK & neue Variante der Creutzfeldt-Jakob-Krankheit \\
Vh & Voltstunden \\
Vol & Volumen \\
ZNS & Zentralnervensystem
\end{tabular}




\section{Einleitung}

Die Creutzfeldt-Jakob-Krankheit gehört zu einer Gruppe von neurodegenerativen Erkrankungen, die auch als Übertragbare Spongiforme Enzephalopathien (transmissible spongiform encephalopathy, kurz TSE) bezeichnet werden. Diese können bei Menschen und Tieren auftreten. Entsprechend der Protein-only-Hypothese von Stanley B. Prusiner (Prusiner 1998) sind die Erreger der TSEs proteinhaltige infektiöse Partikel, die Prionen genannt werden (Prion für proteinaceous infectious particle). Histologisch sind TSEs durch charakteristische Veränderungen im Gehirn gekennzeichnet. Dazu zählen eine reaktive Gliose, neuronaler Zellverlust, Spongiose und Ablagerungen des pathologisch gefalteten Scrapie-Prionproteins auf $\left(\mathrm{PrPs}^{\mathrm{Sc}}\right)$ (Abb. 1).

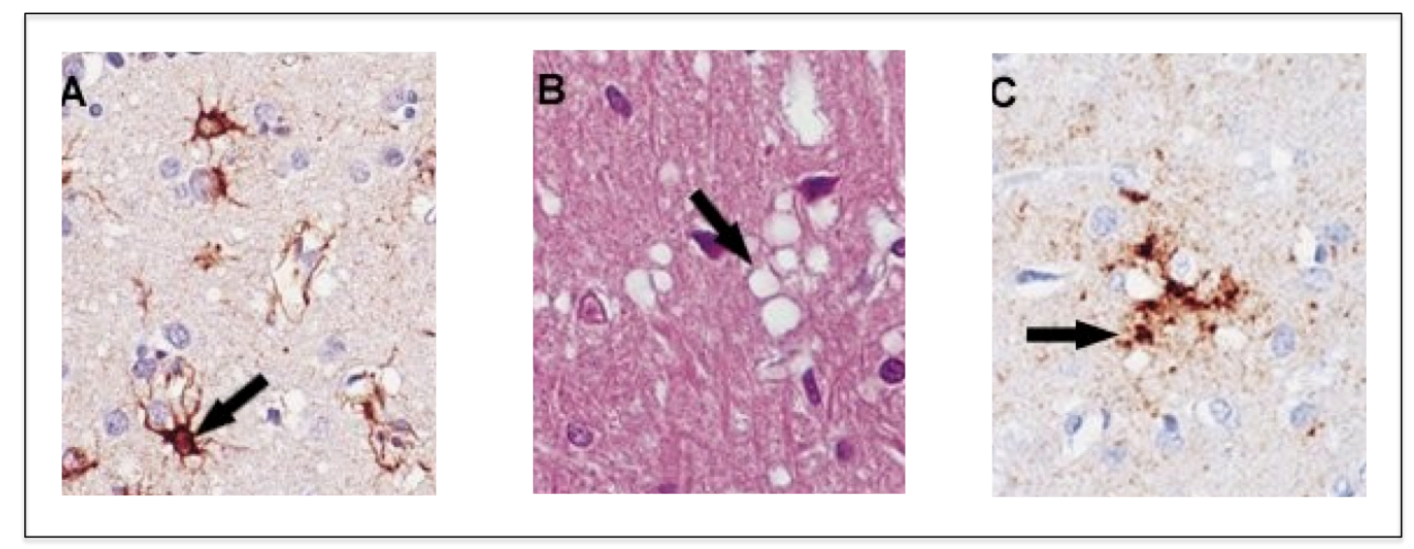

Abbildung 1. Die histologischen Merkmale der TSEs. A) Der Pfeil zeigt auf einen aktivierten Astrozyten, welcher eine hypertrophe Morphologie und eine verstärkte Immunreaktivität des für diesen Zelltyp spezifischen Intermediärfilamentes GFAP (glial fibrillary acidic protein) aufweist. B) Der Pfeil kennzeichnet die Vakuolisierung des Gehirns, die als Spongiose bezeichnet wird. C) Der Pfeil deutet auf PrPsc-Ablagerungen hin. Bildquelle adaptiert von Glatzel and Aguzzi (2001, S. 245).

Die dadurch resultierende Degeneration des Gehirns kann sich entsprechend der betroffenen Region in typischen klinischen Symptomen äußern. Dazu zählen Myoklonien, extrapyramidalmotorische Bewegungsstörungen und eine sich schnell entwickelnde Demenz (Masters et al. 1979; Collinge 2001). Die Einzelheiten des pathologischen Mechanismus, die zur Entwicklung des Krankheitsbildes führen sind bis heute noch unzureichend erforscht. Bisher war es noch nicht möglich eine 
erfolgversprechende Therapie $\mathrm{zu}$ finden. Neuere Forschungsergebnisse deuten daraufhin, dass die Erkrankung zu einem frühen Zeitpunkt an den Synapsen im Gehirn beginnt. Dies geschieht weit vor dem Auftreten der typischen klinischen Symptome, sodass die Hoffnung besteht, durch frühes Erkennen und Behandlung der Erkrankung den pathologischen Prozess aufhalten zu können (Mallucci et al. 2007; Mallucci 2009; Gray BC et al. 2009).

\subsection{Das Prion-Konzept}

\subsubsection{Auf der Suche nach dem Erreger - Protein-only-Hypothese}

Die Suche nach dem Erreger der transmissiblen spongiformen Enzephalopathien gestaltete sich sehr schwierig und ist bis heute ohne eindeutigen Erfolg. Erste Aufzeichnungen von Scrapie gibt es seit 1732 und über Creutzfeldt-Jakob seit 1920. Dennoch hat es bis 1967 gedauert, als Tikvah Alper feststellte, dass selbst nach intensiver DNA- und RNA-schädigender Strahlung Hirnextrakte von Scrapieinfizierten Schafen ihre Infektiosität nicht verloren. Dies bedeutete im Umkehrschluss, dass der Erreger keine Erbinformation besitzt und somit kein Virus oder Plasmid sein kann (Alper et al. 1967; Prusiner 1982). 1967 wurde erstmals beschrieben, dass es sich beim krankheitsauslösenden Agens um ein Protein handeln könnte, was sich autokatalytisch repliziert (Griffith 1967). Trotz dieser neuen Erkenntnisse war es zu dieser Zeit nicht vorstellbar, dass es sich um ein Protein als Krankheitsauslöser handeln könnte. Es wurde weiter an der bis dahin bekannten slow-virus-Theorie festgehalten, die eine Übertragung durch eine neue Virus-Art nach langer Inkubationszeit postulierte (Gajdusek et al. 1966). Die Hypothese von Proteinen als Erreger wurde von Stanley Prusiner in den Siebzigern weiterentwickelt. In seinen Versuchen konnte er die Infektiosität von Scrapie-infizierten Hirnextrakten durch denaturierende Substanzen verringern und kam so auch zur Annahme, dass Proteine ein essentieller Bestandteil des Erregers sein müssen (Prusiner et al. 1981). 1982 führte Prusiner den Begriff „Prion“ ein, was als Abkürzung für den englischen Ausdruck proteinaceous infectious particle steht (Prusiner 1982), um es von anderen Pathogenen abzugrenzen. So unterscheiden sich Prionen von anderen infektiösen Agenzien durch das Fehlen von DNA oder RNA. Dadurch zeigt sich eine Resistenz 
gegenüber einer Vielzahl von toxischen Einflüssen wie zum Beispiel Hitze, UV- und Röntgenstrahlung, Formaldehyd oder Psoralen (Pattison 1965; Alper et al. 1966; Bellinger-Kawahara et al. 1987). Mitte der achtziger Jahre gelang es, dass krankmachende Protein aus Scrapie-infizierten Hamsterhirnen zu isolieren (Bolton et al. 1982; Prusiner et al. 1982). Seitdem wurde das Protein Prionprotein (PrP) genannt. Durch die Bestimmung der Aminosäuresequenz am N-terminalen Ende des Prionproteins (Prusiner et al. 1984) war es möglich durch DNA-Sonden das Prionproteingen aufzuspüren (Oesch et al. 1985). Anders als erwartet, ließ sich das PrP-Gen bei erkrankten und nicht-erkrankten Hamstern und Mäusen nachweisen (Chesebro et al. 1985; Oesch et al. 1985; Basler et al. 1986). Da es nun sicher war, dass tierische Lebewesen PrP exprimieren, ohne dabei zu erkranken, kam man zu dem Schluss, dass es eine nicht infektiöse Form $\operatorname{PrPC}^{\mathrm{C}}$ (cellular prion protein) und eine infektiöse Form PrPsc (scrapie prion protein) geben muss. PrPC und $\mathrm{PrPSc}$ unterscheiden sich in unterschiedlich großen Anteilen an $\alpha$-Helices und $\beta$-FaltblattStrukturen und den damit verbundenen neuen biochemischen Eigenschaften (Pan et al. 1993).

\subsubsection{Das zelluläre Prionprotein PrPC}

\subsubsection{Die Struktur des PrPC}

Das zelluläre Prionprotein $\operatorname{PrPC}$ (cellular prion protein) ist ein Sialoglykoprotein der Zellmembran (Rac 2006), das hochkonserviert im Genom aller bisher untersuchten Säugetiere vorkommt (Levin 2007). Beim Menschen ist das Prionproteingen auf dem kurzen Arm des Chromosom 20 lokalisiert und besteht aus 253 Aminosäuren (Puckett et al. 1991).

Durch Kernspinresonanzspektroskopie-Studien (nuclear magnetic resonance, kurz NMR) konnte die räumliche Struktur des Proteins dargestellt werden (Abb. 2). 


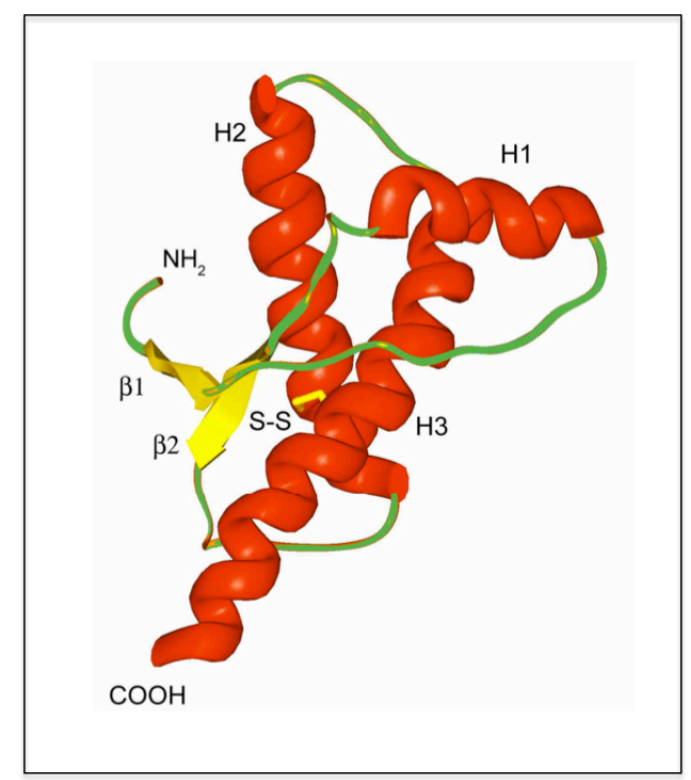

Abbildung 2. NMR-Struktur des rekombinanten PrPC. Der globuläre Teil des PrPC gliedert sich in drei $\alpha$-Helices (H1, H2 und H3) sowie zwei antiparallele $\beta$-Faltblätter ( $\beta 1$ und $\beta 2$ ). Bildquelle adaptiert von Porps (2008, S. 11).

PrPC besteht aus einer flexiblen N-terminalen Domäne und einer gefalteten Cterminalen Domäne (Riek et al. 1996; Zahn et al. 2000). Der hochbewegliche NTerminus enthält eine fünfmalige Wiederholungssequenz von 8 Aminosäuren, was als Oktarepeat-Domäne bezeichnet wird, die auch eine hohe Affinität für Kupfer (II)Ionen hat. Der gefaltete C-Terminus besteht aus $3 \alpha$-helikalen Abschnitten und einem Abschnitt mit antiparalleler $\beta$-Faltblatt-Struktur (Riek et al. 1996). Weiterhin hat der C-terminale Teil zwei Asparagin-Reste, die Zuckerseitenketten tragen können (Endo et al. 1989). Außerdem besitzt das Protein zwei Cystein-Reste, die eine Disulfidbrücke bilden können, welche die zweite und dritte $\alpha$-Helix stabilisiert (Turk et al. 1988) (Abb. 3). 


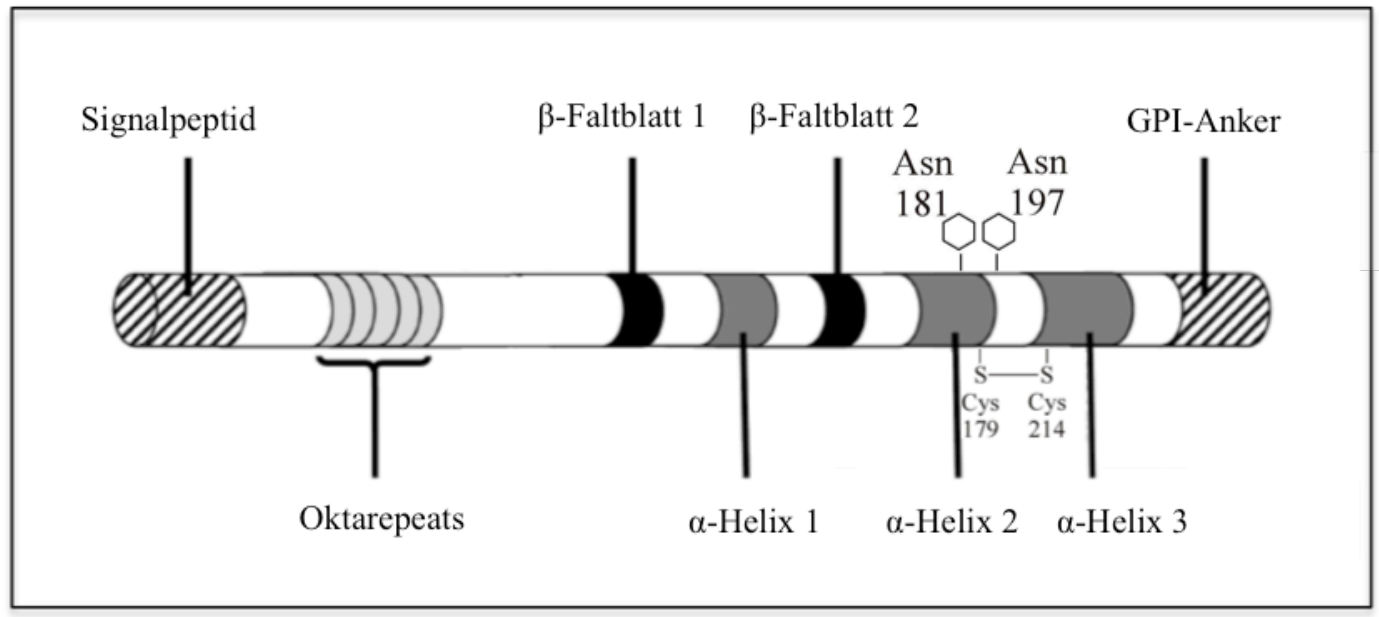

Abbildung 3. Schematische Darstellung der Primärsequenz des PrPC. Die Grundstruktur des $\mathrm{PrPC}$ ist weiß, die Oktarepeat-Region hellgrau dargestellt. Die $\beta$-Faltblatt-Strukturen im Protein sind durch schwarze und die $\alpha$-Helices durch dunkelgraue Abschnitte gekennzeichnet. Das Signalpeptid (gestreift) wird während der Prozessierung abgespalten. S-S: Disulfidbrücke, Cys: Cystein, Asn: Asparagin und Oligosaccharidketten. Bildquelle adaptiert von Levin $(2007$, S. 12).

PrPc kann in un-, mono- oder diglykosylierter Form vorliegen, wodurch das Molekulargewicht zwischen $27 \mathrm{kDa}$ und $36 \mathrm{kDa}$ variiert (Abb. 4).

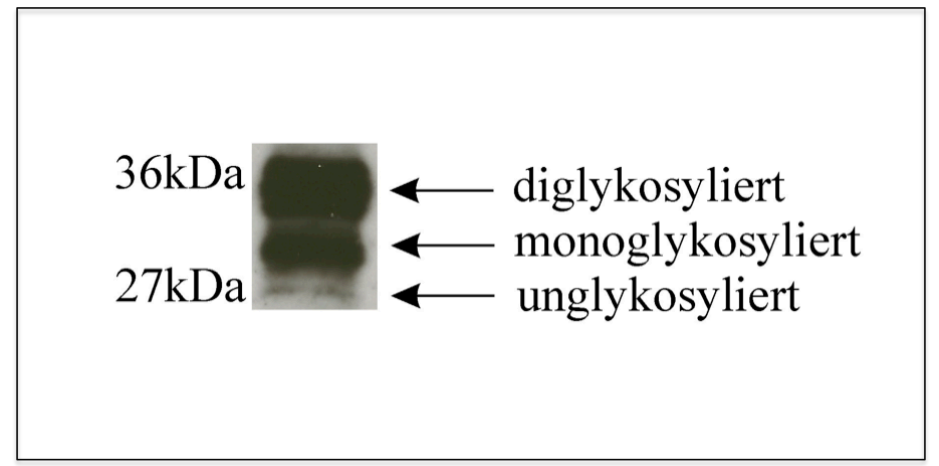

Abbildung 4. Darstellung des Western Blot-Profils des PrPC. Die 3 Banden zeigen die un-, mono- und diglykosylierte Form des Proteins. Bildquelle adaptiert von Weiß (2009, S. 35).

\subsubsection{Die Funktion von PrPC}

Das Prionprotein ist im Lauf der Evolution ein hoch konserviertes Protein geworden, so dass sich eine wichtige biologische Rolle vermuten lässt (Rivera-Milla et al. 2006). Allerdings konnte bis zum heutigen Tage die eindeutige Funktion des PrPC nicht zufriedenstellend geklärt werden. Experimente mit Prnp ${ }^{0 / 0}$-Tieren gaben 
diesbezüglich keinen Aufschluss, da bei den Tieren keine gravierenden phänotypischen Auffälligkeiten festzustellen waren (Bueler et al. 1992). Lediglich eine geringe Beeinträchtigung der Reizweiterleitung (Collinge et al. 1994) und des zirkadianen Rhythmus (Tobler et al. 1997) wurden beobachtet. PrPC wird hauptsächlich im Gehirn und Rückenmark exprimiert, wurde aber auch in Lunge, Herz, Niere, im Gastrointestinaltrakt, Muskeln, Milchdrüsen und lymphatischen Geweben gefunden (Zomosa-Signoret et al. 2008). Ziemlich sicher scheint die Rolle von PrPC in der Neuroprotektion, beziehungsweise Apoptose zu sein. Bei Experimenten mit murinen Neuronen, denen nach Kultivierung das Serum entzogen wurde, zeigte sich ein stärkerer Zelluntergang bei Prnp ${ }^{0 / 0}$ ZZellen, als im Vergleich zur Kontrollgruppe. Als man in einem 2. Ansatz das PRNP-Gen wieder einbrachte, konnte die Dauer bis zum Eintreten des Zelltodes verlängert werden (Kuwahara et al. 1999). $\operatorname{PrPC}$ schützt auch vor oxidativem Stress. In einem Experiment mit neokortikalen Neuronen von Prnp ${ }^{0 / 0}$-Mäusen wurde eine erhöhte Anfälligkeit für oxidativen Stress induzierende Substanzen wie Wasserstoffperoxid und Xanthinoxidase beobachtet (Brown DR et al. 2002). In einem weiteren Experiment konnte gezeigt werden, dass hypoxische Hirninfarktareale bei PrP-knockoutMäusen deutlich größer waren als bei Mäusen vom Wildtyp (McLennan et al. 2004). Anlass zur weiteren Diskussion und Forschung geben aber Experimente die im Zusammenhang mit einer PrPC_Überexpression eine apoptotische Wirkungen zeigen konnten (Paitel et al. 2002). Der größte Teil der PrPC-Moleküle ist an der Zelloberfläche lokalisiert, wo es durch den GPI-Anker des C-terminalen Endes an die Lipiddoppelschicht angeheftet ist (Stahl et al. 1987). Dennoch scheint PrPC in der Lage $\mathrm{zu}$ sein, durch Interaktion mit transmembranen Proteinen Signale ins Zytoplasma zu senden (Westergard et al. 2007). PrPC interagiert mit Synapsin Ib, welches an Synapsenbildung und Neurotransmitterregulation beteiligt ist (Spielhaupter and Schatzl 2001). PrPC hat durch die Interaktion mit Tubulin, welches der Hauptbestandteil der Mikrotubuli ist, außerdem Einfluss auf das Zytoskelett (Nieznanski et al. 2005). Das Prionprotein bindet auch an Phosphatidylinositol-3Kinasen (PI3K), Enzyme mit einer Vielzahl von zellulären Schlüsselfunktionen, wie Zellwachstum, Zellproliferation und Differenzierung (Vassallo et al. 2005). 


\subsubsection{Unterschiede zwischen PrPC und PrPsc}

Das zelluläre Prionprotein $(\mathrm{PrPC})$ und das Scrapie-Prionprotein $\left(\mathrm{PrPsc}^{\mathrm{C}}\right)$ haben die identische Primärstruktur (Aminosäuresequenz), unterscheiden sich aber in ihrer Sekundär- und Tertiärstruktur (Stahl et al. 1993). PrPC besitzt einen hohen Anteil an $\alpha$-helikalen Abschnitten, PrPsc hingegen einen signifikant größeren Anteil an $\beta$ Faltblatt-Struktur (Pan et al. 1993). Durch eine Konformationsänderung ändern sich die chemischen und physikalischen Eigenschaften von PrPC und PrPsc. PrPSc neigt zur Bildung großer, unlöslicher Aggregate (Prusiner et al. 1983). Weitere wichtige Unterscheidungsmerkmale sind die Sensitivität gegenüber dem Abbau durch Proteinase K und die Löslichkeit in Detergenzien. Während $\operatorname{PrPC}$ durch Proteinase K vollständig abgebaut und in Detergenzien gelöst werden kann, wird PrPSc nur partiell verdaut, beziehungsweise gelöst (Bolton et al. 1984; Meyer et al. 1986) (Abb. 5 und Tab. 1).

\begin{tabular}{ccc} 
Isomere & $\operatorname{PrP}^{\mathrm{C}}$ & $\operatorname{PrP}^{\mathrm{Sc}}$ \\
\hline Infektiosität & nein & ja \\
Struktur & $\alpha$-Helices-reich & $\beta$-Faltblatt-reich \\
Löslichkeit & ja & nein \\
PK-Sensitivität & ja & nein
\end{tabular}

Tabelle 1. Die Unterschiede der chemischen und physikalischen Eigenschaften von PrPC und PrPsc. Unterschiede bestehen in der Infektiosität, Struktur, Löslichkeit und ProteinaseK-Sensitivität. 


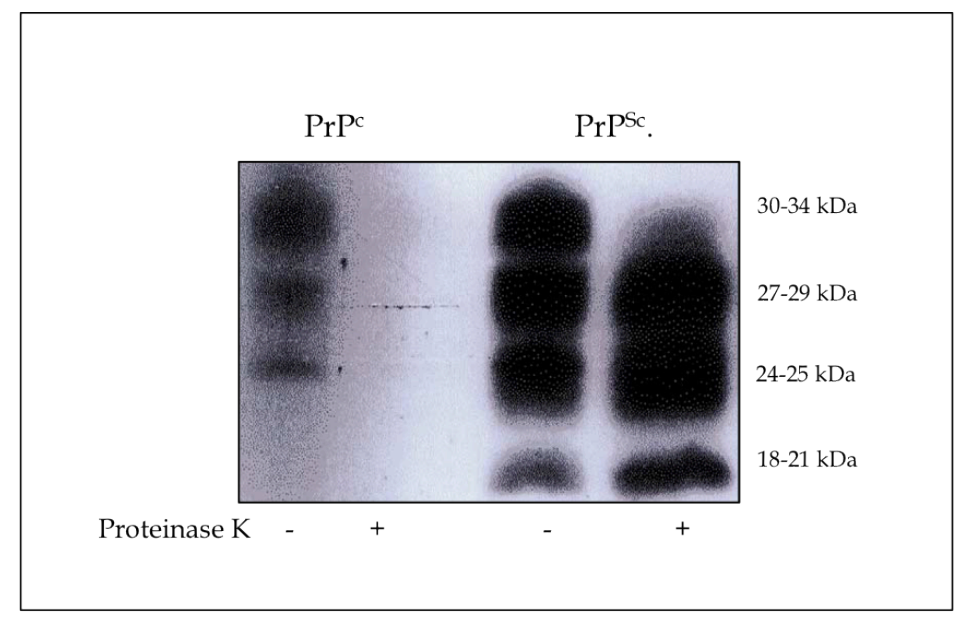

Abbildung 5. Western-Blot-Profil von PrPC und PrPsc nach Behandlung mit Proteinase K. Auf der linken Seite sieht man den kompletten Verdau von PrPC und rechts PrPsc, was durch die Behandlung mit Proteinase $\mathrm{K}$ nicht vollständig verdaut werden kann. Bildquelle adaptiert von Dormont (2002, S. 18).

\subsection{Prionenerkrankungen bei Menschen}

Entsprechend der Ätiologie unterscheidet man klassisch zwischen 3 verschiedenen Formen der TSE beim Menschen (Brown K and Mastrianni 2010):

1. sporadische Creutzfeldt-Jakob-Krankheit (sCJK)

2. familiäre Formen: familiäre Creutzfeldt-Jakob-Krankheit (fCJK), GerstmannSträussler-Scheinker-Syndrom (GSS) und die letale familiäre Insomnie (FFI)

3. übertragene Formen: neue Variante der Creutzfeldt-Jakob-Krankheit (vCJK), iatrogene Creutzfeldt-Jakob-Krankheit (iCJK) und Kuru

Die sporadische Creutzfeldt-Jakob-Krankheit ist die weltweit häufigste aller Prionenerkrankungen beim Menschen. Sie gehört aber mit einer jährlichen Inzidenz von ca. 1-2 zu einer Million generell zu den seltenen Krankheiten (Masters et al. 1979). Die zweifelsfreie Diagnosestellung der CJK ist bislang nur neuropathologisch möglich. Um dennoch eine möglichst genaue Aussage machen zu können, wird das Gesamtbild aus klinischem Erscheinungsbild, EEG, MRT und Liquor-Biomarkern bewertet. Leitsymptom ist die rasch fortschreitende Demenz, wobei zu Beginn der Erkrankung eine Wesensänderung und zerebelläre Symptome im Vordergrund stehen. Das EEG zeigt im späten Stadium abhängig vom Subtyp starke, typisch periodische, sogenannte sharp-wave-Komplexe. Im MRT des Kopfes sind in der 
Protonen- und T2-Wichtung oft Hyperintensitäten der Basalganglien erkennbar (Meissner et al. 2009). Etabliert hat sich ebenfalls die Proteinuntersuchung des Liquors. Dabei weisen das 14-3-3-Protein und das Tau-Protein (> 1300pg/ml) die größte Sensitivität und Spezifität auf (Sanchez-Juan et al. 2007).

\subsubsection{Sporadische Formen}

Mit ca. 85\% hat die sporadische Form der CJK den größten Anteil. Bis heute ist die Ursache der Krankheit noch unbekannt, sodass sie auch als idiopathische Krankheit bezeichnet wird. Begünstigender Faktor für eine schnellere Erkrankung, scheint eine Homozygotie für Valin oder Methionin bei Codon 129 des humanen PrP-Genes $(P R N P)$ zu sein. Patienten, mit Heterozygotie an diesem Genort, erkranken weitaus später (Baker et al. 1991; Palmer et al. 1991; Lewis et al. 2006). Der Erkrankungsgipfel liegt zwischen dem 60. und 70. Lebensjahr. Es handelt sich um eine rasch fortschreitende Erkrankung mit einer medianen Überlebenszeit von ca. 6 Monaten (Sturzenegger 2001). Klinisch stehen häufig eine rasch fortschreitende Demenz, die sich innerhalb weniger Wochen bis Monate entwickelt, sowie eine progrediente Ataxie im Vordergrund. Im Verlauf bilden sich extrapyramidal-motorische Störungen, Myoklonien und Pyramidenbahnzeichen aus. Zum Ende der Krankheit wird bei vielen Patienten ein akinetischer Mutismus beobachtet. 90\% der Patienten sterben innerhalb eines Jahres nach Krankheitsausbruch. Genauer betrachtet lässt sich die sporadische CJK in die 6 Subtypen MM1, MV1, MM2, MV2, VV1, VV2 unterteilen, wodurch ein heterogenes Bild entsteht. Diese molekulare Einteilung ist abhängig vom Codon-129-Genotyp des Prionproteingens, entweder homozygot für Methionin (MM), Valin (VV) oder heterozygot (MV), und abhängig vom WesternBlot-Profil, des abnormen Prionproteins PrPsc, nach Behandlung mit Proteinase K. Die Einteilung in Typ 1 oder 2 beruht auf der unterschiedlichen Wanderungsgeschwindigkeit der unglykolysierten PrP-Bande des PrPsc im Western Blot (Parchi et al. 1999; Cali et al. 2006) (Abb. 6). 


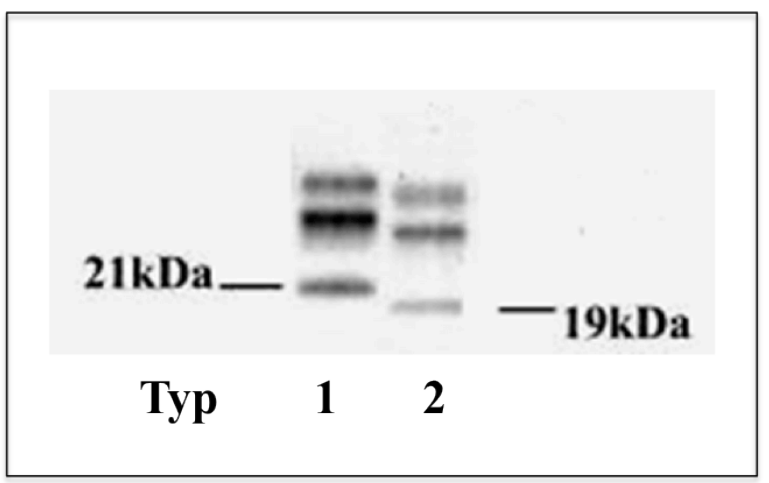

Abbildung 6. Darstellung des Western-Blot-Profils von PrPsc nach Verdau mit Proteinase K. Abhängig von der Wanderungsgeschwindigkeit der unglykolysierten Bande des PrPSc, ergeben sich für Typ 1 eine Bande bei 21 kDa und für Typ 2 eine Bande bei 19 kDa.

Unterschiede zwischen den 6 Subtypen äußern sich in der Häufigkeit, sowie im klinischen und im neuropathologischen Erscheinungsbild (Bishop et al. 2010). Ein Überblick der Häufigkeit zeigt Tabelle 2.

\begin{tabular}{cc} 
Subtypen der sCJK & $\begin{array}{c}\text { Häufigkeit } \\
\text { in } \%\end{array}$ \\
\hline MM1/MV1 & $60-70$ \\
VV2 & 16 \\
MV2 & 9 \\
MM2 & $2-8$ \\
VV1 & $<1$ \\
\hline
\end{tabular}

Tabelle 2. Übersicht über die Häufigkeit des Auftretens der verschieden Subtypen der sCJK. Quelle adaptiert von Gambetti et al. (2003, S. 217-224).

Im Weiteren werden nur die am häufigsten auftretenden Subtypen MM1/MV1 und VV2 besprochen. MM1 und MV1 werden zusammengefasst, weil sie sehr ähnlich bezüglich der neuropathologischen Merkmale sind. Mit 60-70\% haben sie den größten Anteil. Allerdings macht MV1 nur 5\% der erkrankten Fälle dieser Gruppe aus. Der Durchschnitt der Menschen erkrankt ab einem Alter von 65 Jahren mit einer durchschnittlichen Überlebenszeit von 4 Monaten. Die häufigsten klinischen Merkmale sind Demenz, Desorientiertheit, Ataxie, psychiatrische Auffälligkeiten und Sehstörungen (Parchi et al. 1999). Neuropathologisch zeigt sich eine feine, relativ homogen verteilte spongiforme Degeneration, Astrogliose und ein Untergang 
der Neurone unter anderem im frontalen Kortex und der Sehrinde. Immunhistochemisch spricht man von PrP-Ablagerungen vom synaptischen Typ (Gambetti et al. 2003) (Abb. 7 und 8). Bei Subtyp VV2, der 16\% der sCJK ausmacht, spricht man vom ataktischen Typ. Mittleres Erkrankungsalter sind 60 Jahre, bei einer klinischen Überlebenszeit von 6 Monaten. Zusätzlich zur Ataxie treten zu Beginn der Symptomatik bei einem Drittel der Patienten kognitive Einschränkungen und okulomotorische Störungen auf (Castellani et al. 2004). Neuropathologisch lässt sich oft eine laminar verteilte spongiforme Degeneration, Astrogliose und ein Neuronenuntergang feststellen, allerdings betrifft es mehr die subkortikalen Schichten im Bereich des Thalamus und Neostriatum (Abb. 8). Die Immunhistochemie ist charakterisiert durch plaqueähnliche PrPSc-Aggregate (Abb. 7). Ein weiteres diagnostisches Kriterium ist eine starke Anfärbbarkeit der PurkinjeZellen im Kleinhirn (Gambetti et al. 2003).

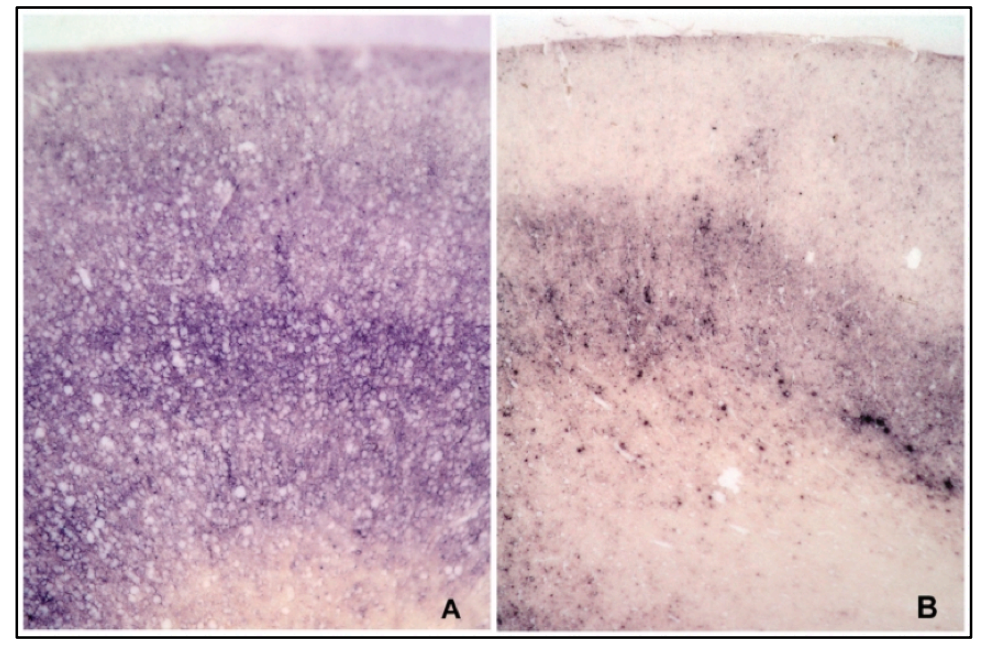

Abbildung 7. Pet-Blot-Darstellung der spezifischen neuropathologischen Verteilungsmuster im frontalen Kortex A) Diffuse synaptische PrPsc-Ablagerung typisch für Subtyp MM1. B) plaqueähnliche PrPsc-Ablagerungen entsprechend für VV2. Bildquelle adaptiert von Parchi et al. (2010, S. 3037). 


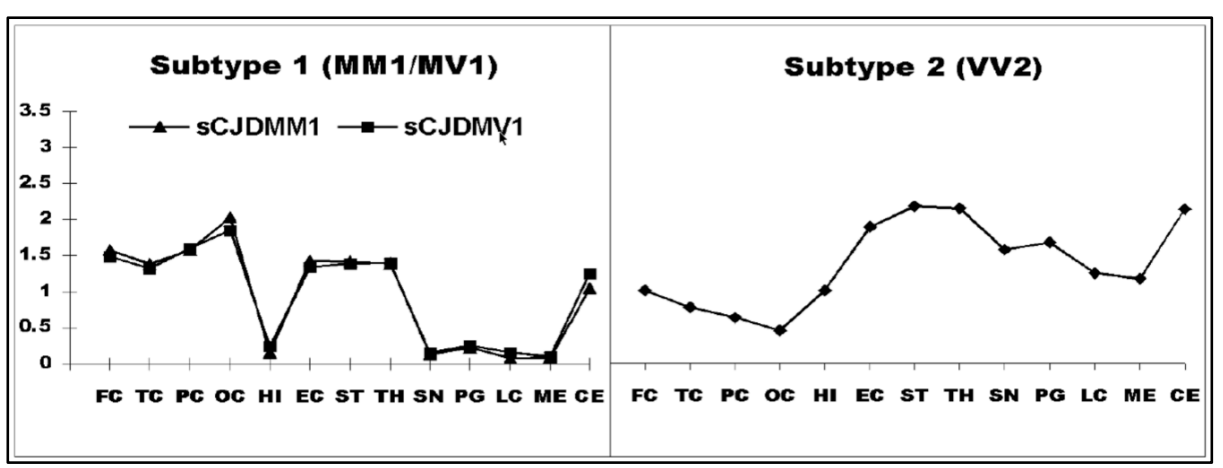

Abbildung 8. Verteilungsmuster der für CJK typischen Veränderungen im Gehirn. Spongiose, Astrogliose und neuronaler Zellverlust wurden jeweils unabhängig von einander untersucht. Spongiose wurde eingeteilt auf einer Skala von 0-4: nicht nachweisbar, wenig, mäßig, schwer und Status spongiosus. Astrogliose und neuronaler Zellverlust wurden eingeteilt auf einer Skala von 0-3: nicht nachweisbar, wenig, mäßig und schwer. Für jede Hirnregion wurde ein Durchschnittswert der 3 Werte gebildet. FC: frontaler Kortex; TC: temporaler Kortex; PC: parietaler Kortex; OC: okzipitaler Kortex; HI: Hippocampus; EC: entorhinaler Kortex; ST: Neostriatum; TH: Thalamus; SN: Substantia nigra, PG: periventrikuläres Grau des Mittelhirns; LC: Locus coeruleus; ME: periventrikuläres Grau und untere Olive der Medulla; CE: Kleinhirn. Bildquelle adaptiert von Gambetti et al. (2003, S. 218).

\subsubsection{Familiäre Formen}

Weitaus seltener sind die familiären Formen der CJK (fCJK), die genetisch bedingt sind und familiär gehäuft auftreten. $\mathrm{Zu}$ den genetisch vererbten Formen gehören auch das Gerstmann-Sträussler-Scheinker-Syndrom (GSS) und die letale familiäre Insomnie (fatale familial insomnia, kurz FFI). Insgesamt haben sie einen Anteil von knapp 10\% aller CJK-Fälle. Als Ursache der Erkrankungen sind das Auftreten mehrerer unterschiedlicher Punktmutationen, sowie einiger Deletions- und Insertionsmutationen im Prion-Proteingen (PRNP) identifiziert worden (Gabizon et al. 1993; Hsiao et al. 1989; Medori et al. 1992) (Abb. 9). 


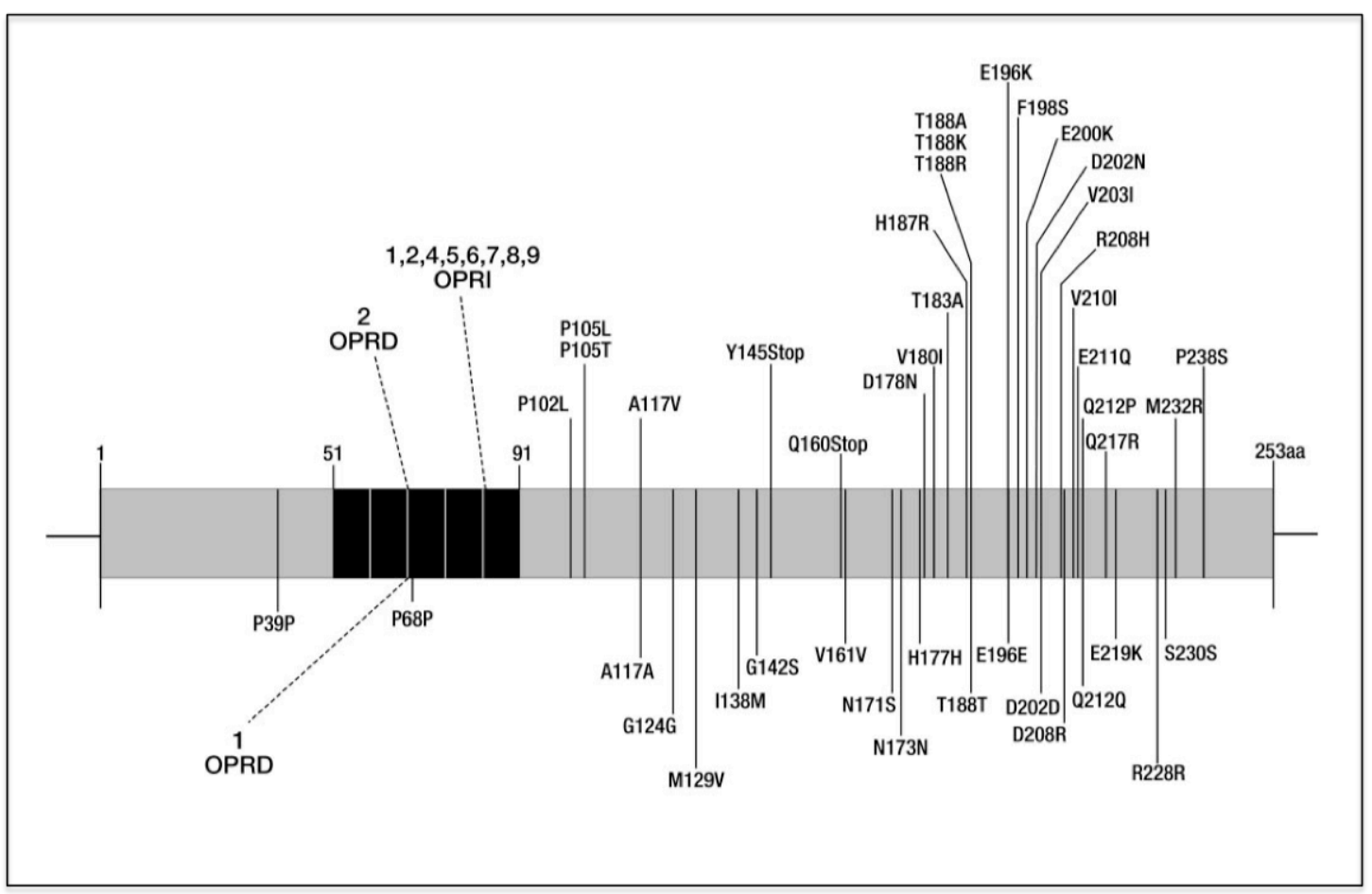

Abbildung 9. Überblick über die Mutationen und Polymorphismen im humanen PrionProteingen (PRNP). Pathogene Mutationen befinden sich über dem Strich. Diese bestehen aus 1,2 oder 4-9 Oktapeptidrepeat-Insertionen zwischen den Codons 51 und 91, einer Deletion von 2 Oktapeptidrepeats und einer Vielzahl von Punktmutationen. Die Polymorphismen sind unterhalb des Striches gekennzeichnet. Bildquelle adaptiert von McKintosh et al. (2003, S. 189).

\subsection{3 Übertragene Formen}

Die Kuru-Krankheit wurde erstmals 1957 beschrieben und zählt zu den infektiös übertragbaren Prionenerkrankungen (Gajdusek and Zigas 1957). Die Krankheit trat nur beim Volksstamm der Fore in Papa-Neuguinea auf. Die Übertragung der Krankheit erfolgte durch einen rituellen Kannibalismus innerhalb des Volksstammes. Die seit 1974 bekannte iCJK wird durch eine unbeabsichtigte Kontamination mit dem Erreger verursacht und macht weniger als 1\% aller CJK-Fälle aus (Duffy et al. 1974). Zur Übertragung kann es durch Transplantation von infizierter Hornhaut oder Dura mater (Duffy et al. 1974), Gebrauch von ungenügend sterilisiertem Operationsbesteck (Bernoulli et al. 1977; Davanipour et al. 1984), durch kontaminierte Hormonpräparate aus der Hirnanhangsdrüse (Brown P 1988; Billette de Villemeur et al. 1992), sowie durch eine Übertragung von mit vCJK 
kontaminierten Blutkonserven kommen (Llewelyn et al. 2004). Fälle der neuen Variante der CJK traten erstmals 1995 in Großbritannien und kurz danach in Frankreich auf (Chazot et al. 1996; Brown P et al. 2001; Zou and Gambetti 2009). Bei der vCJK kam es erstmals zu einer Übertragung von Tieren auf den Menschen, durch den Verzehr von BSE-kontaminiertem Fleisch (Ricketts 2004).

\subsection{Neurodegenerative Prozesse und Prionen}

\subsubsection{Gewinn, Verlust oder Änderung der Funktion des PrP?}

Die Mechanismen der von Prionen ausgelösten Neurotoxizität und der daraus folgenden Neurodegeneration sind bis heute noch nicht eindeutig erklärt. Man geht davon aus, dass allein die Anwesenheit von PrPsc nicht zur Entstehung von TSEs ausreicht. Wahrscheinlich ist es ein Zusammenspiel von $\operatorname{PrPC}$ und $\operatorname{PrPsc}$, wodurch Prionen ihre neurotoxischen Eigenschaften entfalten (Mallucci et al. 2003). 3 Hypothesen versuchen, dies zu erklären. Die am häufigsten diskutierte Variante beschreibt eine Zunahme der toxischen Einflüsse durch das gebildete PrPsc, welches innerhalb der Zelle schädigend wirkt. PrPSc könnte dabei die synaptische Funktion stören, den axonalen Transport blockieren oder apoptotische Signalwege triggern. Andererseits könnte die Neurotoxizität das Ergebnis des Funktionsverlusts von PrPC sein, wobei dessen neuroprotektive Eigenschaften verloren gehen. Die 3 . Möglichkeit beschreibt eine Funktionsänderung von $\mathrm{PrPC}$ unter dem Einfluss von PrPSc. Dabei gehen zytoprotektive Funktionen zugunsten zytotoxischer verloren (Westergard et al. 2007; Winklhofer et al. 2008). PrPSc kann in verschiedenen Formen vorkommen, als lösliche Monomere/Oligomere oder unlösliche Aggregate. Jedoch ist bis heute unklar, von welcher Form die Toxizität ausgeht. Einerseits sind PrPsc_ Aggregate charakteristisch für die Erkrankung und deren neurotoxischen Wirkungen wurden beschrieben. Man vermutet jedoch, dass die höchste Infektiosität von PrPSc_Oligomeren ausgeht (Caughey et al. 2009). Neue Überlegungen gehen davon aus, dass PrPsc-Aggregate ein Reservoir der infektiösen Oligomere sein könnten und durch die Bindung der Oligomere eine Schutzfunktion ausüben 
könnten (Fontaine and Brown 2009).

\subsubsection{Krankheitsbeginn an den Synapsen}

Schon vor über 10 Jahren wurde von Mark Mattson und seinen Mitarbeitern die Hypothese aufgestellt, dass speziell die Apoptose bei Neuronen durch einen vorangegangen Untergang der Synapsen ausgelöst werden kann (Mattson and Duan 1999). Mittlerweile gelten Funktionsstörungen der Synapse als Schlüsselereignisse in der Entstehung von vielen neurodegenerativen Erkrankungen wie zum Beispiel der Schizophrenie und Morbus Alzheimer (Waites and Garner 2011). Dieses Merkmal lässt sich auch bei der CJK beobachten, wo der Untergang der Synapsen weit vor dem ersten Auftreten der typischen klinischen Symptome eintritt (Gray BC et al. 2009). An einem Tiermodell, bei dem Hirnproben entnommen wurden, um die Anzahl der Synapsen, Neurone und Axone zu bestimmen, konnte gezeigt werden, dass die Anzahl der Synapsen bereits zu Beginn der Erkrankungszeit deutlich abnahm. Erst im späteren Verlauf kam es zum Untergang der Neurone und zum Auftreten der klinischen Symptome (Jeffrey et al. 2000). Im Detail ist noch unklar wie die synaptische Dysfunktion zum Untergang der Neuronen führt. So erhofft man sich in den Krankheitsprozess eingreifen zu können, wenn die Mechanismen der synaptischen Dysfunktion verstanden sind (Mallucci et al. 2007; Mallucci 2009).

\subsubsection{Synaptosomen}

Synaptosomen sind isolierte Nervenendigungen der Neurone, welche durch eine Kombination aus Zentrifugation und Fraktionierung mit Hilfe eines Saccharosegradienten aus homogenisiertem Hirngewebe gewonnen werden. Sie beinhalten mit Neurotransmittern beladene Vesikel, Golgi-Apparate, Endoplasmatische Retikula, Mikrofilamente und Mitochondrien. Der Vorteil dieser Isolation ist, dass sie eine präzise Untersuchung der synaptischen Funktion unabhängig von der restlichen Hirnsubstanz möglich macht (De Robertis et al. 1961; Gray EG and Whittaker 1962). In Kombination mit Proteomuntersuchungen sind 
dies sehr nützliche Techniken, um einen Überblick über Proteine zu bekommen, welche im Zusammenhang mit pathologischen Veränderungen der synaptischen Funktionen und Plastizität stehen (Bai and Witzmann 2007). Experimente mit diesem Aufbau wurden bereits bei Morbus Alzheimer angewendet. Die Erkrankung zeigt in ähnlicher Art, dass synaptische Veränderungen frühe Ereignisse in der Krankheitsentwickelung sind (Gillardon et al. 2007; Yang et al. 2011)

\subsection{Zielsetzung}

Diese Arbeit untersucht das synaptische Proteom bei Patienten mit sporadischer Creutzfeldt-Jakob-Krankheit. Dies soll dem besseren Verständnis der Prozesse dienen, die am Verlauf der Krankheit beteiligt sind. Gleichzeitig werden Gemeinsamkeiten und subtypspezifische Unterschiede der am häufigsten auftretenden Subtypen MM1 und VV2 der sCJK untersucht. 


\section{Material}

\subsection{Chemikalien}

\begin{tabular}{|l|l|}
\hline Bezeichnung & Hersteller \\
\hline Aceton & Sigma-Aldrich (München, Deutschland) \\
\hline Acetonitril & Sigma-Aldrich (München, Deutschland) \\
\hline Ammoniumbikarbonat & Sigma-Aldrich (München, Deutschland) \\
\hline Ammoniumperoxidsulfat & Roth (Karlsruhe, Deutschland) \\
\hline Ampholyte & Bio-Rad (Hercules, CA, USA) \\
\hline Biorad Protein Assay & Bio-Rad (Hercules, CA, USA) \\
\hline Bovines Serumalbumin & Roth (Karlsruhe, Deutschland) \\
\hline Bromophenol blau & Sigma-Aldrich (München, Deutschland) \\
\hline Coomassie-Brilliant-Blau G-250 & Roth (Karlsruhe, Deutschland) \\
\hline CHAPS & Bio-Rad (Hercules, CA, USA) \\
\hline Dithiothreitol & Merck (Darmstadt, Deutschland) \\
\hline Essigsäure & Merck (Darmstadt, Deutschland) \\
\hline Ethanol & Merck (Darmstadt, Deutschland) \\
\hline Fötales Bovines Serum & Biochrom (Berlin, Deutschland) \\
\hline Glycerol & Sigma-Aldrich (München, Deutschland) \\
\hline Guanidiniumthiocyanat & Roth (Karlsruhe, Deutschland) \\
\hline Iodacetamid & Bio-Rad (Hercules, CA, USA) \\
\hline Isopropanol & Merck (Darmstadt, Deutschland) \\
\hline Kalziumchlorid & Sigma-Aldrich (München, Deutschland) \\
\hline Luminol & Sigma-Aldrich (München, Deutschland) \\
\hline Lysin & Sigma-Aldrich (München, Deutschland) \\
\hline Methanol & Merck (Darmstadt, Deutschland) \\
\hline Milchpulver & Roth (Karlsruhe, Deutschland) \\
\hline Mineräöl & Bio-Rad (Hercules, CA, USA) \\
\hline Natriumlaurylsulfat & Sigma-Aldrich (München, Deutschland) \\
\hline Natriumcarbonat & Roth (Karlsruhe, Deutschland) \\
\hline & \\
\hline
\end{tabular}




\begin{tabular}{|l|l|}
\hline Bezeichnung & Hersteller \\
\hline Natriumdodecylsulfat & Merck (Darmstadt, Deutschland) \\
\hline p-Coumarsäure & Sigma-Aldrich (München, Deutschland) \\
\hline Roti®Load & Roth (Karlsruhe, Deutschland) \\
\hline Rotiphorese® Gel 40 & Sigma-Aldrich (München, Deutschland) \\
\hline Tetramethylethylendiamin & Roth (Karlsruhe, Deutschland) \\
\hline Thiourea & Sigma-Aldrich (München, Deutschland) \\
\hline Trifluoressigsäure & Sigma-Aldrich (München, Deutschland) \\
\hline Tris & Roth (Karlsruhe, Deutschland) \\
\hline Tris-Hydrochlorid & Roth (Karlsruhe, Deutschland) \\
\hline Trypsin & Promega (Madison, WI, USA) \\
\hline Tween-20 & Merck (Darmstadt, Deutschland) \\
\hline Urea & Roth (Karlsruhe, Deutschland) \\
\hline
\end{tabular}

\subsection{Materialien}

\begin{tabular}{|l|l|l|}
\hline Bezeichnung & Spezifizierung & Hersteller \\
\hline ECL-Hyperfilm & $\begin{array}{l}\text { Amersham Biosciences } \\
\text { (Buckinghamshire, UK) }\end{array}$ \\
\hline Filterpapier (gefaltet) & $3 \mathrm{hw}$ & Sartorius (Göttingen, Deutschland) \\
\hline Küvetten & $10 \times 4 \times 45 \mathrm{~mm}$ & Sarstedt (Nümbrecht, Deutschland) \\
\hline Pipetten & $5 \mathrm{ml}, 10 \mathrm{ml}, 25 \mathrm{ml}$ & Sarstedt (Nümbrecht, Deutschland) \\
\hline $\begin{array}{l}\text { PVDF-Transfer- } \\
\text { Membran }\end{array}$ & Hybond-P & GE Healthcare (Freiburg, Deutschland) \\
\hline Ready Strip IPG 17 cm & $\mathrm{pH} 3-10$ linear & Bio-Rad (München, Deutschland) \\
\hline
\end{tabular}

\subsection{Instrumente}

\begin{tabular}{|l|l|l|}
\hline Anwedung & Modell & Hersteller \\
\hline $\begin{array}{l}\text { Automatischer } \\
\text { Blotprozessierer }\end{array}$ & BioLane ${ }^{\mathrm{TM}}$ HTI & $\begin{array}{l}\text { Hölle und Hüttner AG } \\
\text { (Tübingen, Deutschalnd) }\end{array}$ \\
\hline Elektrophorese & PowerPac 3000 & $\begin{array}{l}\text { Bio-Rad (München, } \\
\text { Deutschland) }\end{array}$ \\
\hline
\end{tabular}




\begin{tabular}{|c|c|c|}
\hline Anwedung & Modell & Hersteller \\
\hline $\begin{array}{l}\text { ESI TOF } \\
\text { Massenspektrometer }\end{array}$ & $\begin{array}{l}\text { Ultima Global coupled } \\
\text { with CapLC system }\end{array}$ & Micromass (Manchester, UK) \\
\hline Filmprozessor & Konica SRX-101A & Konica (Taiwan) \\
\hline Fluoreszenz-Scanner & Fuji FLA 5100 & $\begin{array}{l}\text { Fujifilm (Düsseldorf, } \\
\text { Deutschland) }\end{array}$ \\
\hline $\begin{array}{l}\text { Gelkammern und } \\
\text { Zubehör }\end{array}$ & $\begin{array}{l}\text { Mini Protean II TM System } \\
\text { Protean II XL Cell }\end{array}$ & $\begin{array}{l}\text { Bio-Rad (München, } \\
\text { Deutschland) }\end{array}$ \\
\hline Homogenisator & ATM Falc & $\begin{array}{l}\text { Falc Instruments S.r.L. } \\
\text { (Treviglio, Italien) }\end{array}$ \\
\hline Inkubator & Cellstar & $\begin{array}{l}\text { Nunc (Wiesbaden, } \\
\text { Deutschland) }\end{array}$ \\
\hline $\begin{array}{l}\text { Isofokussierung und } \\
\text { Zubehör }\end{array}$ & Protean IEF Cell & $\begin{array}{l}\text { Bio-Rad (München, } \\
\text { Deutschland) }\end{array}$ \\
\hline Magnetrührer & RCT & $\begin{array}{l}\text { IKA-Combimag (Staufen, } \\
\text { Deutschland) }\end{array}$ \\
\hline pH-Meter & MP-220 & $\begin{array}{l}\text { Mettler-Toledo (Steinbach, } \\
\text { Deutschland) }\end{array}$ \\
\hline Scanner & CanoScan8400F & Canon (Krefeld, Deutschland) \\
\hline Spektralphotometer & Ultrospec 2100 pro & $\begin{array}{l}\text { GE Healthcare (Freiburg, } \\
\text { Deutschland) }\end{array}$ \\
\hline Ultraschallwasserbad & Transsonic 310/H & $\begin{array}{l}\text { Elma }{ }^{\circledR} \text { (Pforzheim, } \\
\text { Deutschland) }\end{array}$ \\
\hline Ultrazentrifuge & XL-70 & $\begin{array}{l}\text { Beckham Coulter (Krefeld, } \\
\text { Deutschland) }\end{array}$ \\
\hline Vakuumtrockner & SVC 100 & $\begin{array}{l}\text { Savant Instruments (Farming } \\
\text { Dale, NY, USA) }\end{array}$ \\
\hline Vortexer & REAX 200 & $\begin{array}{l}\text { Heidolph (Schwabach, } \\
\text { Deutschland) }\end{array}$ \\
\hline Waagen & $\begin{array}{l}\text { BL } 150 \mathrm{~S} \\
\text { CP } 3202 \mathrm{P}\end{array}$ & $\begin{array}{l}\text { Sartorius ( Göttingen, } \\
\text { Deutschland) }\end{array}$ \\
\hline
\end{tabular}




\begin{tabular}{|l|l|l|}
\hline Anwedung & Modell & Hersteller \\
\hline Wasserbad & & GFL (Burgwedel, Deutschland) \\
\hline Wasserkühlung & DC1 & ThermoFisher Scientific \\
\hline $\begin{array}{l}\text { Western Blot } \\
\text { Transfer Cell }\end{array}$ & $\begin{array}{l}\text { Trans Blot DS Semi-Dry } \\
\text { Transfer Cell }\end{array}$ & $\begin{array}{l}\text { Bio-Rad (München, } \\
\text { Deutschland) }\end{array}$ \\
\hline Zentrifugen & $5810 \mathrm{R}, 5415$ & $\begin{array}{l}\text { Eppendorf (Hamburg, } \\
\text { Deutschland) }\end{array}$ \\
\hline
\end{tabular}

\subsection{Antikörper}

\subsubsection{Primäre Antikörper}

\begin{tabular}{|l|l|l|l|}
\hline Antikörper & Spezifizierung & Verdünnung & Hersteller \\
\hline $\begin{array}{l}\text { Anti-Synaptophysin } \\
\text { (clone SY38) }\end{array}$ & Maus, & $1: 2000$ & $\begin{array}{l}\text { Dako Cytomation } \\
\text { (Hamburg, } \\
\text { monoklonal }\end{array}$ \\
& & & Deutschland) \\
\hline
\end{tabular}

\subsubsection{Sekundäre Antikörper}

\begin{tabular}{|l|l|l|l|}
\hline Antikörper & Spezifizierung & Verdünnung & Hersteller \\
\hline Anti-Maus-IgG- & Ziege & $1: 5000$ & Jackson \\
Antikörper & & $1: 2000$ & ImmunoResearch \\
& & & Laboratories, Inc. \\
& & & (Newmarket, UK) \\
\hline
\end{tabular}

\subsection{Gehirnproben}

Für das Projekt wurde Hirnmaterial aus dem präfrontalen Kortex von jeweils 5 Patienten mit Subtyp MM1, VV2 und der Kontrollgruppe entnommen. Diese Region wurde gewählt, weil sie bei allen Subtypen der sCJK betroffen ist. Die Patienten, die an sporadischer Creutzfeldt-Jakob-Krankheit erkrankt waren, wurden als pathologisch gesicherte Fälle entsprechend den WHO-Kriterien eingeordnet. 


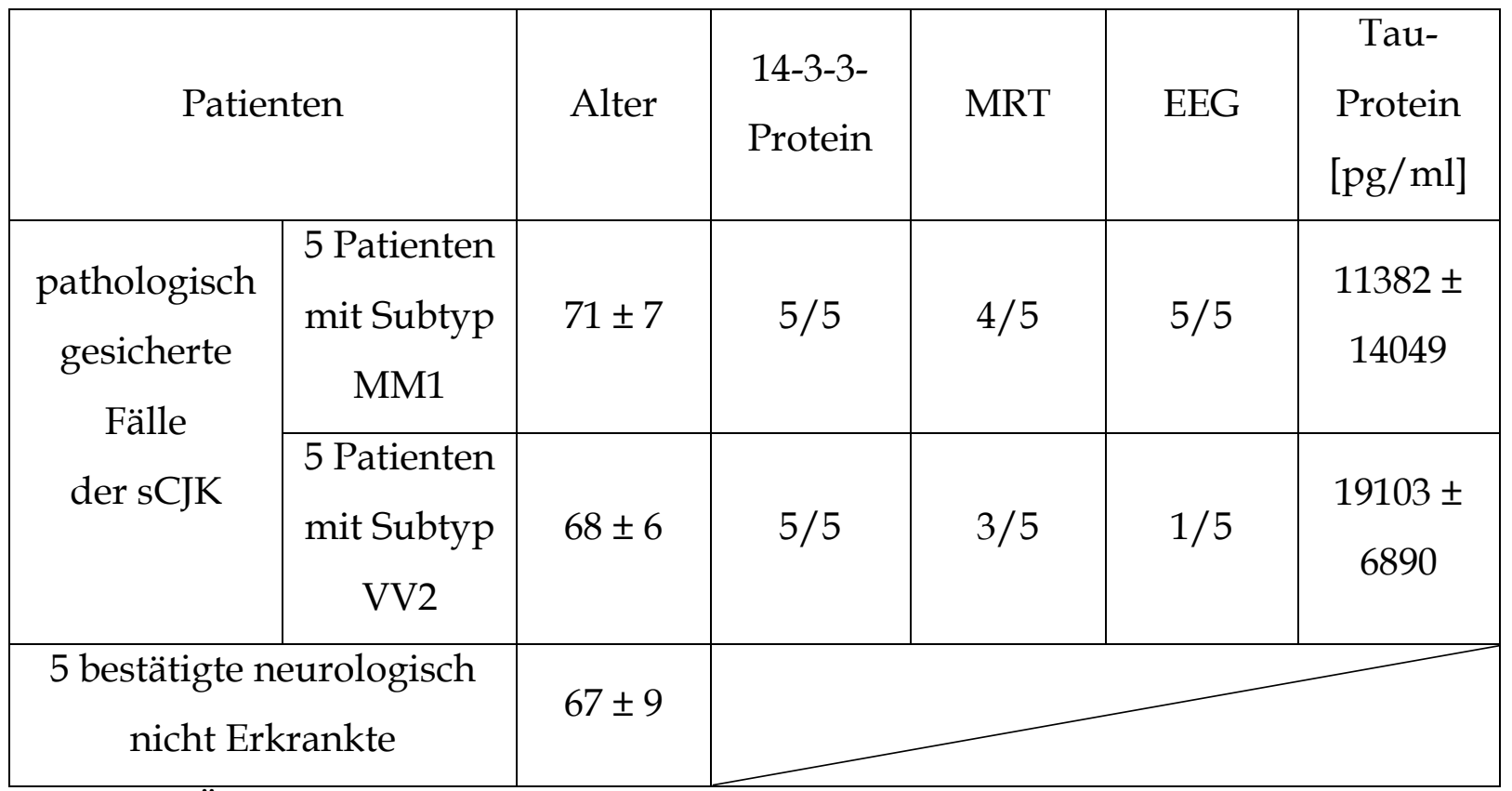

Tabelle 3. Überblick über das Alter, 14-3-3-, MRT-, EEG- und Tau-Protein-Befunde der ausgewählten Patienten

Dafür erfolgte eine neuropathologische Untersuchung aller CJK-Patienten, wobei bei allen spongiforme Veränderungen und Ablagerungen der Prionproteins gefunden werden konnten. Um eine klinische Diagnose zu stellen, wurde das 14-3-3-Protein und Tau-Protein (Konzentration $>1300 \mathrm{pg} / \mathrm{ml}$ ist hinweisend auf CJK) im Liquor bestimmt, sowie eine Magnetresonanztomographie (Hyperintensitäten der Basalganglien) und Elektroenzephalographie (Präsenz von starken, typisch periodischen sharp-wave-Komplexen) durchgeführt (Otto et al. 2002). Die Patienten der Kontrollgruppe zeigten neuropathologisch dem Alter entsprechende Veränderungen, keine Demenz und wurden dem Alter der Patientengruppe angepasst. Todesursache der 5 Patienten war Multiorganversagen, chronische Niereninsuffizienz, Lungen-Krebs oder Herzinfarkt. Spätestens 24 Stunden nach Eintritt des Todes wurden Hirnproben entnommen (Tab. 3). 
2.6 Puffer und Lösungen

Aceton/Methanol: 8:1 (Vol:Vol)

Äquilibrationspuffer I: 6M Urea, 2\% SDS, 30\% Glycerin, 75mM Tris $\mathrm{pH}=8,8$, mit $2 \%(w / v)$ DTT in ${ }_{d d} \mathrm{H}_{2} \mathrm{O}$

Äquilibrationspuffer II: 6M Urea, 2\% SDS, 30\% Glycerin, 75mM Tris $\mathrm{pH}=8,8$, mit 2,5\% (w/v) Iodacetamid, Bromphenolblau für eine leicht blaue Lösung in ${ }_{d d} \mathrm{H}_{2} \mathrm{O}$ Blockierungspuffer für Western Blot: $5 \%$ Milchpulver in PBS-T

ECL-Lösung 1: $250 \mathrm{mM}$ Luminol, $90 \mathrm{mM}$ p-Coumarsäure, $1 \mathrm{M}$ Tris- $\mathrm{HCl} \mathrm{pH}=8,5$ in ${ }_{\mathrm{d}} \mathrm{H}_{2} \mathrm{O}$

ECL-Lösung 2: 0,018\% $\mathrm{H}_{2} \mathrm{O}_{2}, 1 \mathrm{M}$ Tris $\mathrm{pH}=8,5$ in ${ }_{\mathrm{d}} \mathrm{H}_{2} \mathrm{O}$

Guanidinium-Lösung: 4M Guanidinium

Homogenisationspuffer: 20mM HEPES pH 7,4, 0,32M Saccharose, $1 \mathrm{mM}$ Natriumorthovanadat, Proteaseinhibitoren, $1 \mathrm{mM}$ EDTA in $\mathrm{dd}_{\mathrm{H}} \mathrm{H}_{2} \mathrm{O}$

Kolloidale Coomassie-Brilliant-Blau-Färbelösung: 0,12\% Coomassie-Brilliant-Blau G-250, 10\% Phosphorsäure, 10\% Ammoniumsulfat, 20\% Methanol in ${ }_{d d} \mathrm{H}_{2} \mathrm{O}$

Lysepuffer: $7 \mathrm{M}$ Urea, $2 \mathrm{M}$ Thiourea, $4 \%$ CHAPS, $1 \mathrm{M}$ Tris- $\mathrm{HCl} \mathrm{pH}=8,8,5 \mathrm{mM}$ Magnesiumacetat in ${ }_{\mathrm{dd}} \mathrm{H}_{2} \mathrm{O}$

PBS: 9,55g PBS-Pulver in $11_{\mathrm{dd}} \mathrm{H}_{2} \mathrm{O}$

PBS-T: 0,1\% Tween-20 in PBS

SDS-Laufpuffer (Elektrophoresepuffer): 192mM Glycin, 0,1\% SDS, 25mM Tris- $\mathrm{HCl}$ $\mathrm{pH}=8,3$ in ${ }_{\mathrm{dd}} \mathrm{H}_{2} \mathrm{O}$

SDS-Sammelgel für 1D-Elektrophorese: 0,49M Tris $\mathrm{HCl} \mathrm{pH}=6,8,0,1 \% \mathrm{SDS}$,

7,4\% Acrylamid, 0,1\% APS, 0,11\% TEMED in ${ }_{\mathrm{d}} \mathrm{H}_{2} \mathrm{O}$

SDS-Trenngel für 1D-Elektrophorese: $0,37 \mathrm{M}$ Tris $\mathrm{HCl} \mathrm{pH}=8,8,0,1 \% \mathrm{SDS}$, $12 \%$ Acrylamid, 0,1\% APS, 0,04\% TEMED in ${ }_{d} \mathrm{H}_{2} \mathrm{O}$

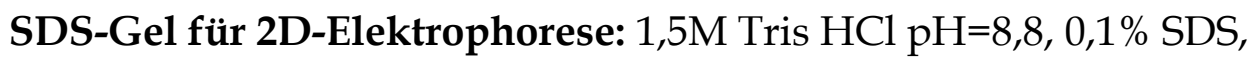
12,5\% Acrylamid, 0,05\% APS, 0,026\% TEMED in $\mathrm{dd}_{\mathrm{H}} \mathrm{H}_{2} \mathrm{O}$

Transferpuffer für Western Blot: 39mM Glycin, 20\% Methanol, $48 \mathrm{mM}$ Tris- $\mathrm{HCl}$ $\mathrm{pH}=8,3$ in ${ }_{\mathrm{d}} \mathrm{H}_{2} \mathrm{O}$

OKANO: 0,1M Tris-Base, 0,2M NaCl, 0,5\% Triton X 100, 0,1mM EDTA, $0,002 \%$ SDS, $0,1 \%$ BSA in ${ }_{d} \mathrm{H}_{2} \mathrm{O}$ 
Rehydrierungspuffer: 7M Urea, 2M Thiourea, 4\% CHAPS, 66mM DTT,

0,2\% Ampholyte in $\mathrm{dd}_{2} \mathrm{O}$

2-facher Rehydrierungspuffer: 7M Urea, 2M Thiourea, 4\% CHAPS, 135mM DTT, $0,4 \%$ Ampholyte in $\mathrm{dd}_{2} \mathrm{O}$

Verdaupuffer ohne Trypsin: 0,5\% 1M CaCl $2,2,5 \% 1 \mathrm{M}$ Ammoniumbikarbonat in $\mathrm{dd}_{2} \mathrm{O}$

Verdaupuffer mit Trypsin: 1,25\% Trypsin, 0,5\% $1 \mathrm{M} \mathrm{CaCl}_{2}, 2,5 \% 1 \mathrm{M}$

Ammoniumbikarbonat in ${ }_{d d} \mathrm{H}_{2} \mathrm{O}$ 


\section{Methoden}

\subsection{Isolation von Synaptosomen aus humanem Gehirngewebe}

Alle Schritte/Lösungen wurden, falls nicht anders angegeben, bei $4^{\circ} \mathrm{C}$ durchgeführt/gelagert. Die Hirnproben wurden mit dem 5-fachen Volumen an Homogenisations-Puffer versetzt und anschließend mit 20 Hüben bei $300 \mathrm{rpm}$ mit dem Glas-Teflon-Homogenisator zerkleinert. Anschließend wurde bei $1500 \times g 10$ Minuten zentrifugiert. Der Überstand, in dem sich die Proteine befanden, wurde abpipettiert und nochmals bei 15000 × g 10 Minuten zentrifugiert, um weitere Zelltrümmer zu entfernen. Das nun entstandene Pellet, in dem sich Membranbestandteile und die Nervenendigungen (Synaptosomen) befanden, wurde mit Homogenisations-Puffer resuspendiert. Zur Isolation wurde die aufgereinigte Membranfraktion auf einen Stufengradient von $0,85 \mathrm{M}, 1 \mathrm{M}$ und 1,2M Saccharose geladen und bei $82.500 \times$ g für 1 Stunde zentrifugiert. Nach dieser Zentrifugation sedimentierten die Synaptosomen in der Interphase zwischen $1 \mathrm{M}$ und 1,2M Saccharose (Abb. 10). Die Synaptosomen wurden abgenommen und mit dem 5fachen Volumen an 0,32M Saccharose wieder gelöst. Es folgte eine Zentrifugation mit $20.000 \times g$ für 20 Minuten. Das Pellet, mit den Synaptosomen, wurde erneut in Homogenisations-Puffer resuspendiert. Danach wurden die Proben aliquotiert und bei $-80^{\circ} \mathrm{C}$ eingefroren. Vor der weiteren Verwendung wurden die Proteinkonzentrationen aller Patientenproben nach der Bradford-Methode bestimmt. Zusätzlich wurden Western Blots angefertigt, bei denen Antikörper gegen Synaptophysin benutzt wurden, um die korrekte Isolation der Synaptosomen zu bestätigen. Synaptophysin gilt als Marker für präsynaptische Endigungen.

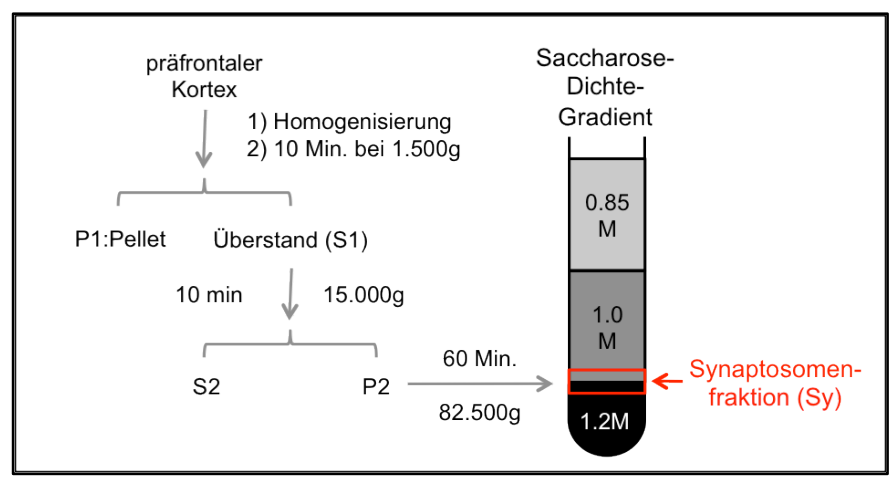

Abbildung 10. Protokoll der Isolierung der Synaptosomen. 


\subsection{Proteinbestimmung nach Bradford}

Um die Proteinkonzentration der Synaptosomen zu bestimmen, wurde die Methode nach Bradford (Bradford 1976) benutzt. Der Bradford-Test ist eine photometrische Methode zur quantitativen Bestimmung von Proteinkonzentrationen. Der Farbstoff, der für den Test genutzt wird, ist Coomassie-Brilliant-Blau G-250 (CBBG). Abhängig von der Lösung und Bindung hat der Farbstoff unterschiedliche Absorptionsmaxima. Die ungebundene Form von Coomassie-Brillant-Blau G-250 hat in saurer Lösung ein Absorptionsmaximum von 465nm. Durch Komplexbildung mit Proteinen verschiebt sich das Absorptionsmaximum hin zu 595nm. Proportional zur Konzentration der Proteine steigt das Signal, welches durch das Photometer detektiert werden kann. Als Ausgangslösung wurde ein Farbstoff-Konzentrat (Biorad Protein Assay) im Verhältnis 1:4 mit $\mathrm{dd}_{2} \mathrm{H}_{2} \mathrm{O}$ verdünnt und anschließend mit Filterpapier filtriert. Als Proteinstandard wird Bovines Serumalbumin verwendet.

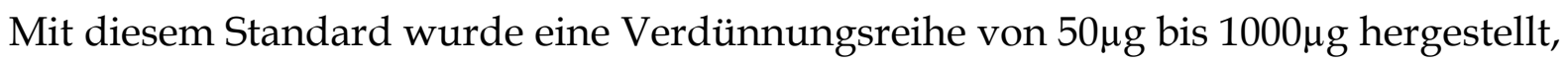
wodurch man eine Eichkurve erhielt. Die Proteine, die analysiert werden sollten, wurden zwischen 1:2 und 1:8 verdünnt, um im Linearkonzentrationsraum von $200 \mu \mathrm{g} / \mathrm{ml}$ - $750 \mu \mathrm{g} / \mathrm{ml}$ des Tests zu sein. Danach wurden jeweils $10 \mu 1$ der verschiedenen Proteinstandards und der zu analysierenden Proben mit $490 \mu \mathrm{l}$ der verdünnten Farbstofflösung gemischt. Nach einer Inkubationszeit von 15 Minuten wurden die Absorptionen der Proben bei einer Wellenlänge von 595nm im Photometer gemessen. Anschließend wurde die Proteinkonzentration aus der Eichkurve mit Hilfe von Microsoft Office 2003 Excel Software abgelesen.

\subsection{SDS-Polyacrylamidgelelektrophorese (SDS-PAGE)}

Die SDS-Polyacrylamidgelelektrophorese ist eine Technik, um Proteine bezüglich ihrer Größe, beziehungsweise ihres Molekulargewichtes aufzutrennen. Die Mischung aus Proteinen wandert unter Einfluss eines elektrischen Feldes durch ein Gel aus Acrylamid, welches sich in ionischer Pufferlösung befindet. Kleine Proteinmoleküle wandern dementsprechend schneller als größere. Die kontinuierlich quervernetzte Polymermatrix wirkt dabei wie ein Sieb, deren 
Porengröße durch die Konzentration an Polyacrylamid/Bisacrylamid verändert werden kann. Gele bestehen aus einer Mischung aus ${ }_{d} \mathrm{H}_{2} \mathrm{O}$, Polyacrylamid/Bisacrylamid, SDS und TRIS-Puffer. Als Polymerisationsinitiator dient APS, welches die für die Polymerisationsreaktion benötigten Radikale bildet. Als Katalysator der Reaktion dient TEMED. Ein Gel selbst besteht aus 2 Komponenten. Die Proteine durchliefen erst das 4,5\% Sammelgel und danach erfolgte die Aufteilung im 12,5\% Trenngel. Gele mit der Größe 8 x 10cm, Dicke 1,0mm wurden im Mini Protean II TM System (Bio-Rad) hergestellt. Als erstes wurde das Trenngel gegossen und danach mit Isopropanol beschichtet. Isopropanol vermischt sich nicht mit Gel. Dadurch erhält man eine glatte Trenngelkante und gleichzeitig dient es als Schutz vor Sauerstoff. Sauerstoff würde die für die Polymerisation notwendigen Radikale abfangen. Nach der Auspolymerisation, die ca. 45 Minuten dauert, wurde Isopropanol restlos abgegossen und das Sammelgel auf das Trenngel gegossen. In das Sammelgel wurde ein Kamm mit 10 Taschen eingesetzt. Die Polymerisationszeit für das Sammelgel betrug 30 Minuten. Die Proteine wurden vor dem Auftragen mit reduzierendem Probenpuffer (Roti®Load) gemischt (Verhältnis 3:1) und für 15 Minuten auf $95^{\circ} \mathrm{C}$ erhitzt. Roti®Load hat mehrere Inhaltsstoffe und dient so zur Reduzierung der Disulfidbrücken zu Thiolen (2-Mercaptoethanol), Denaturierung und Negativierung der Ladung des Proteins (SDS), als Ballastmittel (Glycerol) und als Farbstoff (Bromphenolblau). Durch das Erhitzen wurden die Quartär- und Tertiärstrukturen aufgebrochen. Anschließend wurden die Proben auf die Gele aufgetragen. Damit die Proteinbanden später ihrem molekularen Gewicht zugeordnet werden konnten, wurde zusätzlich ein Molekulargewichts-Marker (Dual-Marker) aufgetragen. Die Elektrophorese lief bei konstanter Amperezahl von 35mA, etwa 45 Minuten, bis der Farbstoff Bromphenolblau den unteren Rand des Gels erreicht hatte.

\subsection{Western Blot}

Nach der oben beschriebenen Auftrennung der Proteine durch SDS-PAGE folgte die Übertragung der Proteine auf eine Trägermembran. Für den halbtrockenen Transfer wurde ein elektrisches Feld senkrecht zum Polyacrylamid-Gel angelegt. An der 
Membranoberfläche bleiben die Proteine auf Grund hydrophober Wechselwirkungen haften. Die Polyvinyliden-Difluorid-Membranen (PVDFMembranen) wurden zuerst in Methanol für ca. 45 Sekunden inkubiert und anschließend in Transfer-Puffer gelegt. Die Blots liefen für 70 Minuten bei konstanter Amperezahl von $135 \mathrm{~mA}$ bei Raumtemperatur. Um die Infektiosität der Gele zu reduzieren, wurden Sie anschließend 30 Minuten mit 4M Guanidiniumthiocyanat behandelt. Dadurch wurden die infektiösen Prionenpartikel denaturiert. Dann wurden die Membranen für 1 Stunde in Blockierungspuffer bei Raumtemperatur fixiert. Zur Immundetektion wurden die Membranen antikörperabhängig bei Raumtemperatur 1-2 Stunden mit dem ersten Antikörper inkubiert. Daraufhin wurde dreimal mit PBS-T für 10 Minuten gründlich gewaschen. Der antispeziesspezifische zweite Antikörper wurde für 1 Stunde inkubiert. Abschließend wurde zweimal 10 Minuten mit PBS-T gewaschen, einmal 5 Minuten mit OKANO und nochmals dreimal 5 Minuten mit PBS-T. OKANO dient zur Reduzierung des Hintergrundes bei der Entwicklung. Während der ganzen Inkubationszeit wurden die Membranen auf den Schüttler gestellt und vor Austrocknung geschützt. Die Antikörper wurden in 5\% Milchpulver und mit PBS-T verdünnt. Die zweiten Antikörper waren mit dem Enzym Peroxidase konjugiert. Durch das Eintauchen der Membranen in ECL-Entwicklungslösungen für 1 Minute, konnte anschließend auf dem ECL-Hyperfilm eine Immunreaktion nachgewiesen werden.

\subsection{Zweidimensionale Gelelektrophorese}

Die 2D-Gelelektrophorese ist eine Methode, die Proteine in zwei aufeinander folgenden Schritten trennt, wobei diese Trennungen auf zwei voneinander unabhängigen Parametern beruhen. Im ersten Schritt (1. Dimension) werden Proteine aufgrund ihres isoelektrischen Punktes (pI) durch isoelektrische Fokussierung (IEF) horizontal voneinander getrennt. Im zweiten Schritt (2.Dimension) werden die Proteine nach ihrem Molekulargewicht durch SDS-PAGE vertikal aufgelöst. Das nun entstandene zweidimensionale Bild zeigt eine hoch auflösende Trennung der Proteine unter Erhalt der quantitativen Verhältnisse. 


\subsubsection{Probenvorbereitung für die erste Dimension}

\subsubsection{Präzipitation}

Die Präzipitation ist eine Fällungsreaktion, bei der gelöste Stoffe aus Lösungen in Form von Niederschlag ausgefällt werden. Das Ziel der Fällung ist es, die Proteine zu reinigen und zu konzentrieren. Für die Synapsenproteine wurde ein Gemisch aus Aceton/Methanol im Verhältnis 8:1 (Vol:Vol) benutzt. Das Gemisch wurde in 3facher Menge zu den Proteinen in der Lösung gegeben und bei $-20^{\circ} \mathrm{C}$ über Nacht gelagert.

\subsubsection{Proteinmarkierung mit CyDyes}

CyDye ist ein Fluoreszenzfarbstoff, der sich an die Lysinseitenketten der Proteine anlagert. Es gibt verschiede CyDyes, die in ihrer chemischen Struktur sehr ähnlich sind, sich aber in ihren spektralen Eigenschaften unterscheiden. Sie fluoreszieren in unterschiedlichen Wellenlängen, wodurch mehrere Protein-gekoppelte CyDyes in einem Gel verglichen werden können, welches die gleichen Laufeigenschaften besitzt. Dies wird als DIGE bezeichnet. Damit werden Unterschiede in der experimentellen Durchführung minimiert. Es wurden 3 verschiedene CyDyes benutzt (Cy2, Сy3 und Cy5). Cy2 wurde immer für den Internal Standard (IS) verwendet. Der IS ist ein Mix aus allen vorhandenen Proben und wurde auf jedes Gel aufgetragen. Das bedeutet, dass jedes Protein als Kontrolle aufgetragen wurde und so mit sich selbst und in Bezug auf die Laufeigenschaften verglichen werden konnte. Cy3 und Cy5 wurden abwechselnd der nicht erkrankten Kontrollgruppe und der erkrankten Patientengruppe zugeordnet. Dadurch konnten Unterschiede in der Bindung der beiden Fluoreszenzfarbstoffe zu den Proteinen minimiert werden. Die CyDyes sind bei starkem Lichteinfluss instabil, deshalb wurden alle folgenden Schritte bei abgedimmten Licht, beziehungsweise im Dunkeln, durchgeführt. Für ein Gel wurden jeweils $25 \mu \mathrm{g}$ Protein vom IS, von einer Probe aus der Kontrollgruppe und von einer Probe aus der Patientengruppe benutzt. Da das Volumen an $\mu \mathrm{l}$, das $25 \mu \mathrm{g}$ entsprach, von Probe zu Probe variierte, wurden die Proteine über Nacht präzipitiert. Das entsprechende Volumen an Proteinen wurde in Eppendorf-Cups 
pipettiert und die 3fache Aceton/Methanol-Mischung hinzugefügt. Am nächsten Tag wurden die Proteine 15 Minuten bei 13000 × $g$ zentrifugiert, das Aceton/Methanol-Gemisch abpipettiert und das sich am Boden befindende

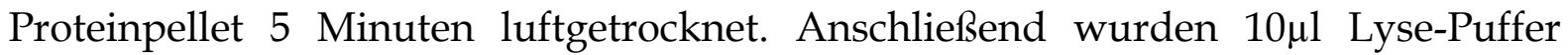
hinzugefügt und das Pellet wieder gelöst. Danach wurde $1 \mu$ l des entsprechenden CyDyes hinzugefügt und 30 Minuten auf Eis inkubiert. Die Reaktion wurde danach mit $1 \mu 1$ Lysin gestoppt und weitere 10 Minuten auf Eis inkubiert. Für weitere 10 Minuten auf Eis wurden $10 \mu \mathrm{l} 2 \mathrm{fach}$ konzentrierter Proben-Puffer dazugegeben. Abschließend wurden $89 \mu$ l Rehydration-Puffer hinzugegeben und alle Proben

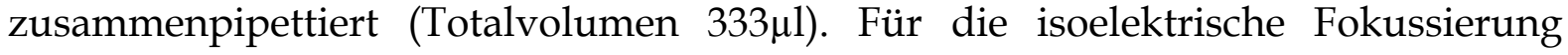
wurden $17 \mathrm{~cm}$ lange Gelstreifen (Ready Strip IPG) mit einem linearen $\mathrm{pH}$-Bereich von 3-10 verwendet. Das Probengemisch wurde in die Isofokussierungskasette pipettiert und der Gelstreifen blasenfrei mit der Gelseite nach unten darauf gelegt. Es folgte eine Stunde Inkubation bei Raumtemperatur. Danach wurden die Gelstreifen mit Mineralöl überschichtet, um die Verdunstung der Probe zu verhindern.

\subsubsection{Erste Dimension: Isoelektrische Fokussierung}

Die isoelektrische Fokussierung ist ein Verfahren, bei dem Proteine aufgrund ihres relativen Gehalts an sauren und basischen Aminosäuren getrennt werden. Die Proteine wandern im elektrischen Feld durch einen $\mathrm{pH}$-Gradienten, bis sie an den pH-Wert gelangen, an dem ihre Nettoladung und damit auch ihre Wanderungsgeschwindigkeit Null ist. Dies ist ihr isoelektrischer Punkt. Aufgrund der amphoteren Eigenschaften von Aminosäuren sind Proteine bei $\mathrm{pH}-W e r t e n$ unterhalb ihres $\mathrm{pI}$ positiv und bei $\mathrm{pH}-$ Werten oberhalb ihres $\mathrm{pI}$ negativ geladen. Die isoelektrische Fokussierung lief nach folgendem Schema ab:

1. Schritt: 12 Stunden Rehydratation bei $20^{\circ} \mathrm{C}$ und $50 \mathrm{~V}$ pro Gel

2. Schritt: 500V für 1 Stunde

3. Schritt: 1000V für 1 Stunde

4. Schritt: 5000V für 2 Stunden

5. Schritt: 8000V bis 60000Vh. 
Nach Abschluss der Isofokussierung (ca. 24 Stunden) wurden die IPG-Streifen für die SDS-PAGE äquilibriert.

\subsection{3 Äquilibrierung der Proteine für die zweite Dimension}

Für die zweite Dimension der Gelelektrophorese musste eine Umpufferung (Äquilibrierung), der durch die IEF aufgetrennten Proteine, durchgeführt werden. Dieser Vorgang wurde benötigt, um die Proteine aus dem IPG-Streifen zu lösen und auf das SDS-Gel übertragen zu können. Disulfidbrücken mussten mit DTT reduziert werden und die entstehenden Sulfhydrylgruppen der Cysteinreste mit IAA alkyliert werden. SDS bindet die Proteine, sodass die Eigenladungen der Proteine überdeckt werden und sie danach eine konstant negative Ladungsverteilung aufweisen. Als Erstes wurden die IPG-Streifen in $\mathrm{dd}_{\mathrm{H}} \mathrm{H}_{2} \mathrm{O}$ vorsichtig gewaschen. Anschließend wurde 20 Minuten in Äquilibrations-Puffer 1 und ebenfalls 20 Minuten in ÄquilibrationsPuffer 2 auf dem Schüttler inkubiert.

\subsubsection{Zweite Dimension: SDS-PAGE}

Für die Gelektrophorese wurden $12 \%$ Gele $(17 \mathrm{~cm} \times 18 \mathrm{~cm} \times 1 \mathrm{~mm})$ am Vortag im Protean II XL Cell (Bio-Rad) gegossen. Die äquilibrierten IPG-Streifen wurden vorsichtig und luftblasenfrei auf die Gele gelegt. Zusätzlich wurde ein Molekulargewichtsmarker auf Filterpapierstreifen aufgetragen und am linken Rand der Gele eingefügt. Die Elektrophorese lief bei konstanten 20mA ca. 17 Stunden lang über Nacht unter Wasserkühlung bei $10^{\circ} \mathrm{C}$ im SDS-Laufpuffer. Die Elektrophorese wurde beendet, als das Bromphenolblau des Äquilibrierungs-Puffers 2 den unteren Rand der Gele erreicht hatte. Anschließend wurde 30 Minuten mit 4M Guanidiniumthiocyanat behandelt.

\subsection{Scannen der Gele}

Um die Gele mit der Software vergleichen zu können, wurden sie mit dem Fuji FLA 5100 Fluoreszenz-Scanner eingelesen. In einem Gel befanden sich nun 3 Proben, die mit unterschiedlichen CyDyes angefärbt waren. Den CyDyes entsprechend wurden dafür im Scanner manuell die passenden Filter eingesetzt (510nm für Cy2, 575nm für 
Cy3 und 665nm für Cy5). Die Filter sind so hergestellt, dass sie nur die Wellenlänge durchlassen, welche die einzelnen CyDyes emittieren und den Rest des Spektrums blockieren. Die Glasplatten zwischen denen sich die Gele befanden, wurden gründlich mit Ethanol gesäubert und anschließend die Gele dreimal gescannt.

\subsection{Kolloidale Coomassie-Brilliant-Blau-Färbung}

Die Coomassie-Brilliant-Blau-Färbung wird benutzt, um die durch 2DGelelektrophorese aufgetrennten Proteine, im SDS-Gel sichtbar zu machen. Danach können Proteine, die untersucht werden sollen, ausgeschnitten werden und mit Hilfe der Massenspektrometrie identifiziert werden. Nach der Auftrennung der Proteine wurden sie 48 Stunden unter leichtem Schütteln in der Coomassie-

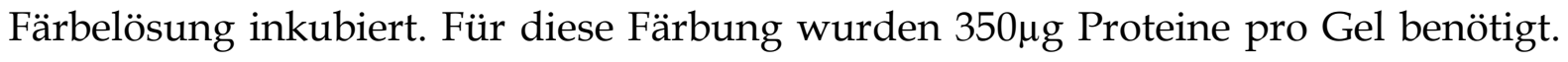
Dazu wurden Proteine aller Patientenproben benutzt. Nach der Inkubation wurden die Gele mit ${ }_{d d} \mathrm{H}_{2} \mathrm{O}$ dreimal gewaschen, 1 Stunde mit $4 \mathrm{M}$ Urea inkubiert und danach in ${ }_{\mathrm{d}} \mathrm{H}_{2} \mathrm{O}$ belassen, bis die Proteinspots ausgeschnitten wurden. Urea baut Keratin ab, was zu falschen Ergebnisse bei der Analyse führen kann.

\subsection{Trypsinverdau}

Um die relevanten Proteine mittels massenspektrometrischer Bestimmung untersuchen zu können, mussten diese aus den Coomassie-Brilliant-Blau gefärbten Gelen ausgeschnitten und mit Trypsin vorbehandelt werden. Trypsin ist ein Enzym, das Eiweiße spaltet, aber dabei nicht spezifisch für ein bestimmtes Eiweiß ist. Es ist vielmehr in der Lage Strukturmerkmale von Eiweißen zu erkennen und spaltet sehr viele Proteine direkt unterhalb der Aminosäuren Lysin und Arginin. Die relevanten Spots wurden mit einem sterilen Skalpell aus den Coomassie-Brilliant-Blau gefärbten Gelen ausgeschnitten und in einen sterilen 0,5ml Eppendorf-Cup gegeben. Nach einem Waschschritt wurden für 20 Minuten 100mM AMBIC dazugegeben um die Gelstücke restlos zu entfärben. Für weitere 15 Minuten wurde $A C N$ in jeden Eppendorf-Cup zusätzlich pipettiert. ACN dehydriert die Gelstücke, um sie so besser für Trypsin zugänglich zu machen. Danach wurden die Lösungen verworfen und die Gelstücke mit dem Vakuumtrockner für 15 Minuten getrocknet. Nach dem 
Trocknen wurden die Gelstücke auf Eis mit trypsinhaltigen Verdauungspuffer rehydriert und für 45 Minuten inkubiert. Hinterher folgte die Inkubation mit Verdaupuffer ohne Trypsin über Nacht bei $37^{\circ} \mathrm{C}$. Am nächsten Tag wurde der Überstand, in dem sich die Peptide befanden, in neue 0,5ml Eppendorf-Cups gegeben und die verbleibenden Peptide in zwei Schritten aus den Gelstücken extrahiert. Zunächst wurden die Peptide mit 30\% ACN in 0,1\% TFA für 30 Minuten im Ultraschallwasserbad aus den Gelstücken gelöst. Danach wurde der Überstand zum restlichen Überstand in die Eppendorf-Cups pipettiert und im Vakuumtrockner 15 Minuten getrocknet. Dieser Schritt wurde anschließend mit 70\% ACN in 0,1\% TFA wiederholt. Die getrockneten Überstande wurden abschließend bei $-20^{\circ} \mathrm{C}$ eingefroren. Zur Analyse wurden die Peptide in 0,1\% Ameisensäure gelöst.

\subsection{Massenspektrometrische Untersuchung}

Bei der ESI-Q-TOF (electrospray ionization quadripole time-of-flight) Massenspektrometrie werden die Peptide mit geladenen Substanzen besprüht und anschließend ionisiert. Die feinen Tropfen trocknen und bleiben auf den Peptiden zurück. Danach werden die ionisierten Peptide anhand ihres Masse-zu-LadungVerhältnis im nächsten Schritt getrennt. Bei dieser Art von Massenspektrometer unterscheidet man die Flugzeit der Ionen im elektrischen Feld. Beim Eintritt in den Analysator haben alle Ionen die gleiche Energie. Leichte Ionen erreichen beim Flug durch das elektrische Feld den Detektor eher als die schwereren Ionen. Die erhaltenen Daten werden mit Datenbanken verglichen und man erhält letztendlich die Aminosäuresequenz des Peptidfragments. Die massenspektrometrische Untersuchung der Peptide und die Proteinidentifikation erfolgte in der Abteilung für Klinische Chemie der Universitätsmedizin Göttingen. Für die Analyse wurde ein ESI-Q-TOF Ultima Global Massenspektrometer (Micromass, Manchester, UK) benutzt. Die Datenerfassung erfolgte mit MassLynx (Version 4.0) Software mit einem Windows NT PC. Anschließend wurden die Daten mit dem Protein-LynxGlobal-Server (Version 2.1), (Micromass, Manchester, UK) weiterverarbeitet. Die Proteine wurden dann durch die MSDB und Swiss-Prot Datenbanken mittels Mascot Search Engine identifiziert. 


\subsection{Vergleich und statistische Auswertung}

Die Analyse und statistische Auswertung der Gele erfolgte mit der Software Delta 2D (Version 3.6) von Decodon (Greifswald, Deutschland). Es wurden insgesamt 25 Gele (fünfmal Subtyp MM1, fünfmal Subtyp VV2, siebenmal Kontrollen, achtmal IS) eingelesen. Für den besseren Vergleich der beiden Subtypen der sporadischen Creutzfeldt-Jakob-Krankheit mit der Kontrollgruppe wurde die 100\%-spot-matchingTechnologie von Delta 2D benutzt, wodurch Unterschiede in den Laufeigenschaften der Gele ausgeglichen werden konnten. Proteine wurden als signifikant reguliert angesehen, wenn sie im Vergleich zur Kontrollgruppe mindestens 2fach hoch- oder herunterreguliert waren und einen $p$-Wert $<0,05$ hatten. 


\section{Ergebnisse}

\subsection{Nachweis der korrekten Isolierung der Synaptosomen}

Die Synaptosomen wurden aus den präfrontalen Kortizes von MM1- und VV2-sCJKPatienten und der Kontrollgruppe extrahiert. Diese Gehirnregion wurde für unsere Versuche gewählt, da sie in jedem sCJK-Subtyp betroffen ist, allerdings in unterschiedlich starker Ausprägung (Gambetti et al. 2003). Um die Grundvoraussetzung der folgenden 2-DE-Experimente $\mathrm{zu}$ sichern, musste der Nachweis erbracht werden, dass die Isolation der Synaptosomen korrekt durchgeführt wurde (Methoden 3.1). Dafür wurde Synaptophysin mit einem spezifischen monoklonalen Antikörper im Western Blot nachgewiesen. Die für Synaptophysin spezifischen Banden, lokalisiert bei $34 \mathrm{kDa}$, konnten bei allen 5 Synaptosomenfraktionen (Sy) der Kontrollgruppe (NDK), sowie bei MM1-sCJK und VV2-sCJK nachgewiesen werden. Im Gegensatz sind auf allen Positionen, der nicht berücksichtigten zytosolischen Proteinfraktionen (S2), keine eindeutigen Banden nachweisbar (Abb. 11).

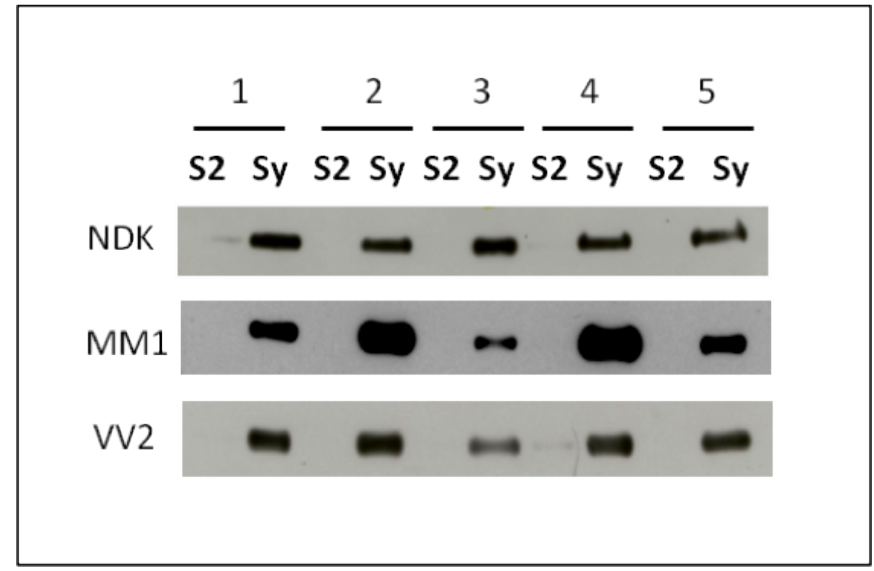

Abbildung 11. Western-Blot-Analyse der isolierten Synptosomenfraktionen (Sy), von der Kontrollgruppe (NDK), MM1-sCJK und VV2-sCJK mithilfe des spezifischen monoklonalen anti-Synaptophysin Antikörpers. Für alle aufgetragenen Synaptosomenfraktionen (Sy) sind Banden bei $34 \mathrm{kDa}$ sichtbar. Im Gegensatz dazu sind bei den nicht isolierten zytosolischen Proteinfraktionen (S2) keine eindeutigen Banden nachweisbar.

\subsection{Ergebnisse der Proteomanalyse: allgemeine Bemerkungen}

Für die Proteomanalyse der isolierten Synaptosomen aus den präfrontalen Kortizes der Kontrollgruppe, MM1-sCJK und VV2-sCJK wurde die 2D-DIGE- 
Technologie benutzt (Methoden 3.5 - 3.10). Nach der 2D-Gelelektrophorese, densitometrischen und statistischen Analyse war es möglich, 257 Proteinspots aufzutrennen. Eine Übersicht aller gefundenen Proteinspots ist in der Abbildung 12 zu sehen.

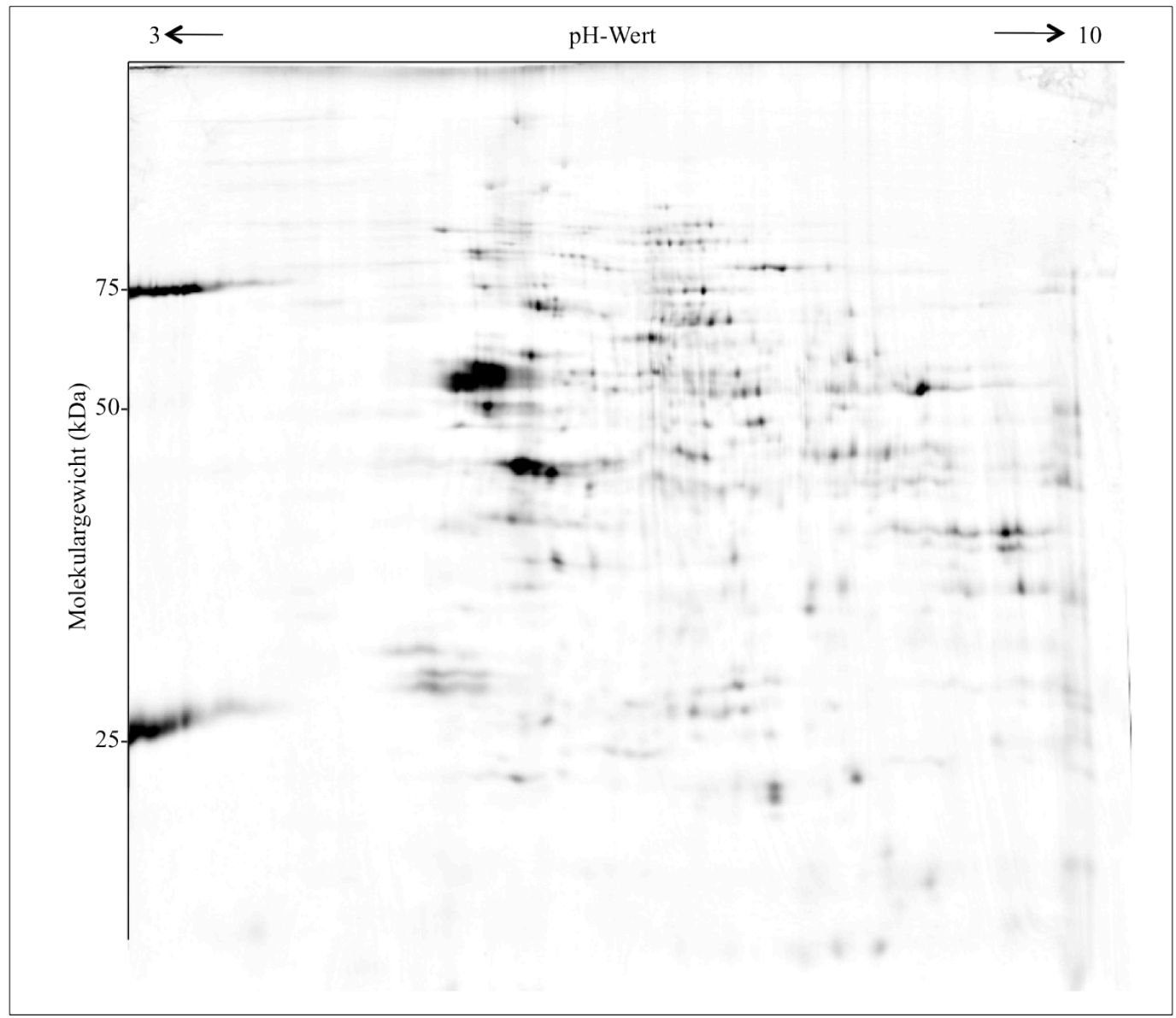

Abbildung 12. Synaptosomen-Proteom-Muster.

Ein Proteinspot wurde als signifikant hoch- oder herunterreguliert angesehen, wenn die Regulierung der CJK-Gruppe im Vergleich zur Kontrollgruppe größer oder kleiner gleich 2 fach betrug und der $p$-Wert $<0,05$ war. Insgesamt waren 40 Proteinspots im Vergleich zur Kontrollgruppe signifikant hoch- oder herunterreguliert. Die Abbildung 13 zeigt die für MM1-sCJK 29 signifikanten Proteinspots, die Abbildung 14 zeigt 12 Proteinspots, welche für VV2-sCJK signifikant sind. Der Proteinspot ID 6805 ist signifikant für beide Subtypen. 


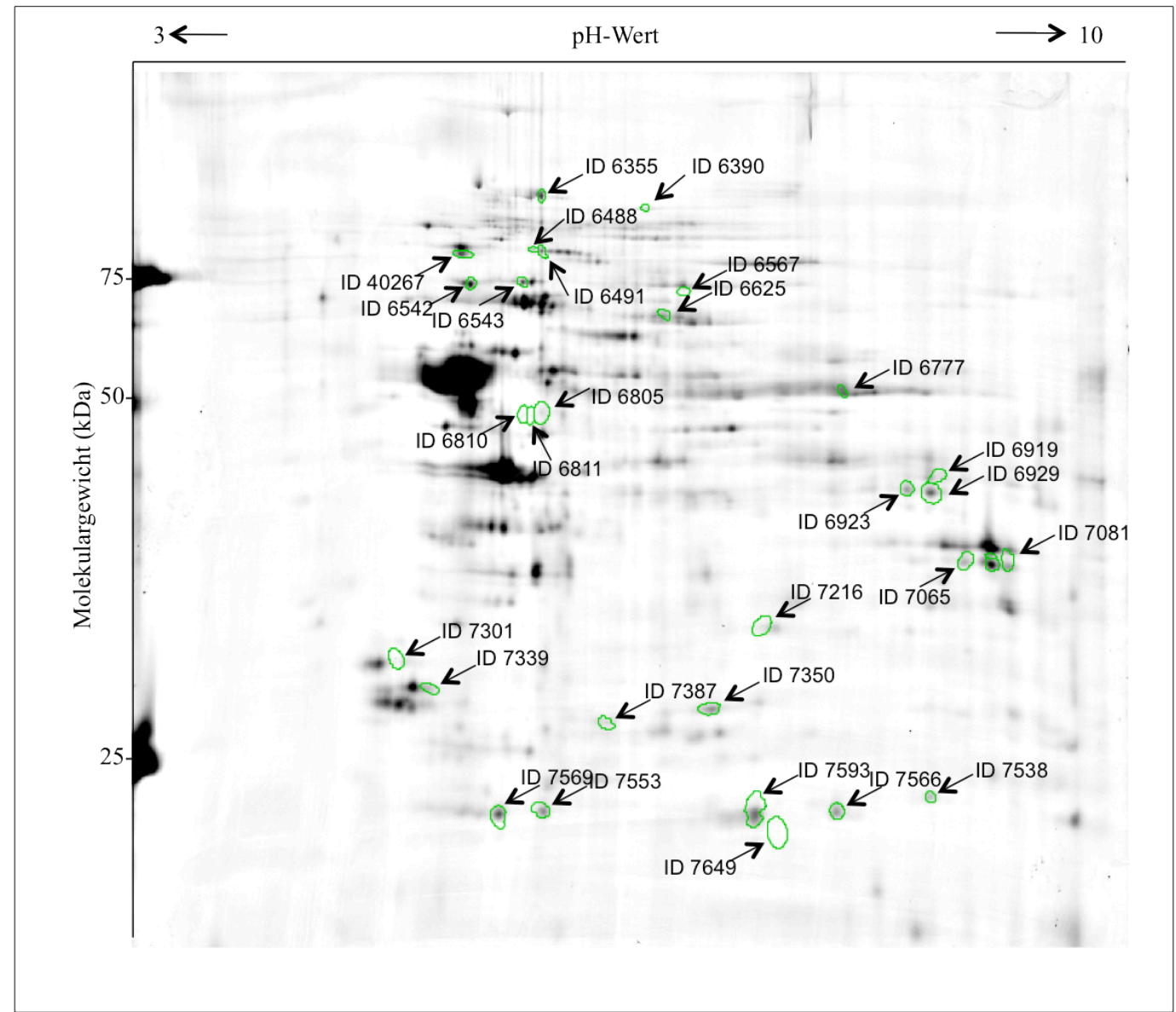

Abbildung 13. Die Übersicht der signifikanten Proteinspots, für MM1 nach Analyse mit der Software Delta 2D. Die nummerierten Spots zeigen eine signifikante Hoch- und Herunterregulation für den Subtyp MM1 im Vergleich zur Kontrollgruppe. 


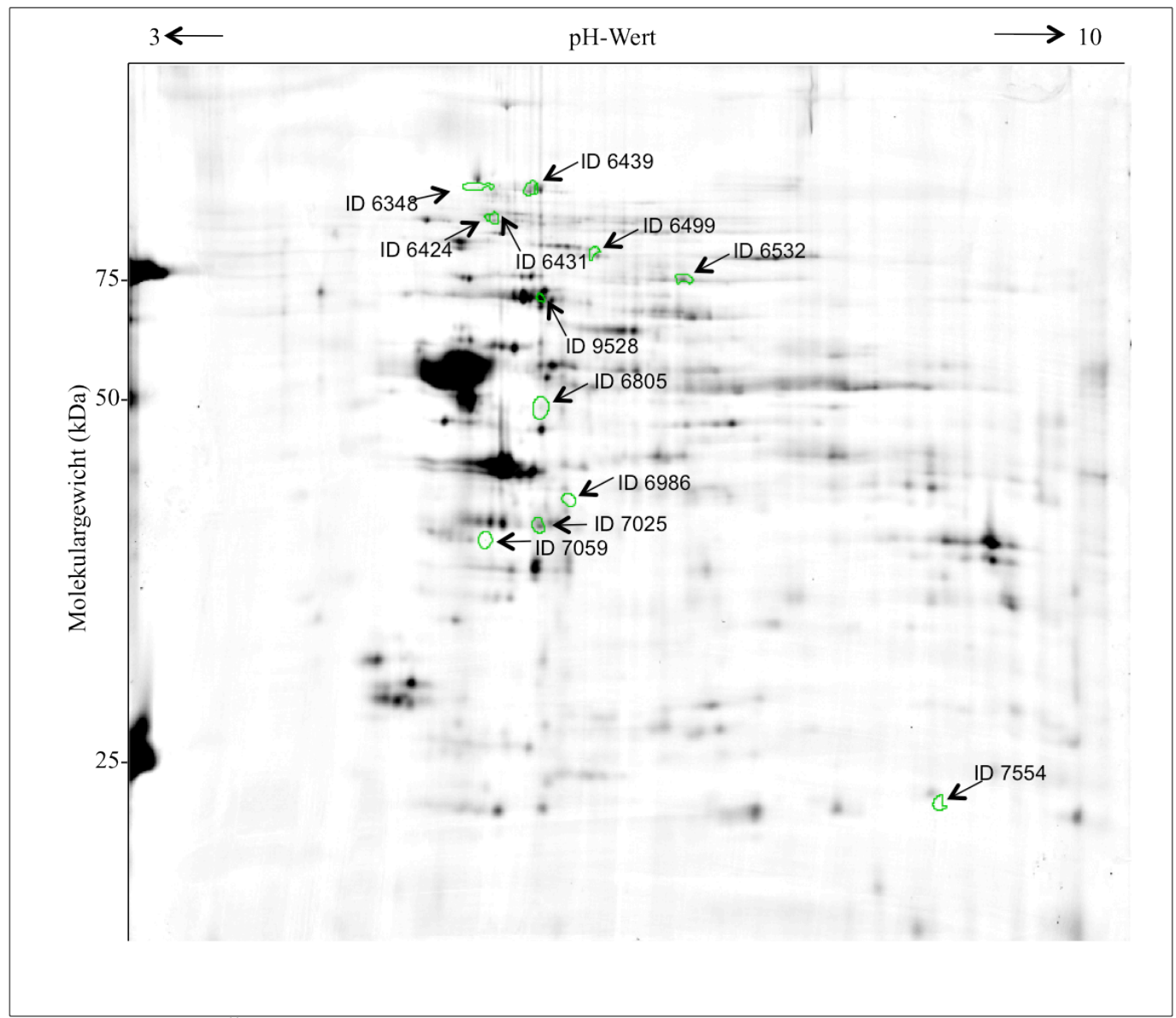

Abbildung 14. Die Übersicht der signifikanten Proteinspots für VV2 nach Analyse mit der Software Delta 2D. Die nummerierten Spots zeigen eine signifikante Hoch- und Herunterregulation für den Subtyp VV2 im Vergleich zur Kontrollgruppe.

Durch die massenspektrometrische Untersuchung war es möglich, 29 der 40 Proteinspots zu identifizieren. Dabei wurden mehrfach Isoformen identifiziert, sodass es letztlich 23 Proteinen entsprach (Tab. 4). Die verbliebenen Spots konnten nicht identifiziert werden, aufgrund von nicht sicherer Nachweisbarkeit oder zu schwacher Färbung der Coomassie-Brilliant-Blau-gefärbten Gele. Im Vergleich der beiden Subtypen war nur eine der 3 Isoformen des Proteins Glial Fibrillary Acidic Protein (GFAP) für beide Subtypen signifikant hochreguliert. Eine Sonderrolle zeigte sich bei dem Protein Spectrin alpha chain, brain. Spectrin alpha chain, brain ließ sich in 2 Formen identifizieren. Das komplette Protein war für MM1 herunterreguliert und die geschnittene Form (cleaved form) war für VV2 herunterreguliert. Die 21 weiteren gefundenen Proteine sind jeweils nur für einen Subtyp signifikant. Für den Subtyp MM1 konnten 16 dysregulierte Proteine identifiziert werden und für den Subtyp VV2 5 dysregulierte. Eine Übersicht zeigt die Abbildung 15. Noch weitere 
Proteine/Isoformen (mit * in der Tabelle 4 markiert) zeigen die gleiche Tendenz der Regulation für beide Subtypen, jedoch wurden die Signifikanzkriterien nicht erfüllt. Insgesamt konnten 11 Proteinspots nicht identifiziert werden. Ob es sich hier nach einer Identifikation letztendlich auch um 11 Proteine handeln würde, kann nicht beurteilt werden. 6 der 11 unbekannten Spots sind signifikant für MM1. Auf Grund der räumlichen Nähe auf dem Gel, könnte der Spot (ID 6919) auch eine Isoform von Aspartate aminotransferase, mitochondrial sein. Die restlichen 5 Proteinspots sind signifikant für Subtyp VV2, wobei die Spots ID 6424 und ID 6431 sehr eng beieinander liegen, sodass es ein Protein sein könnte.

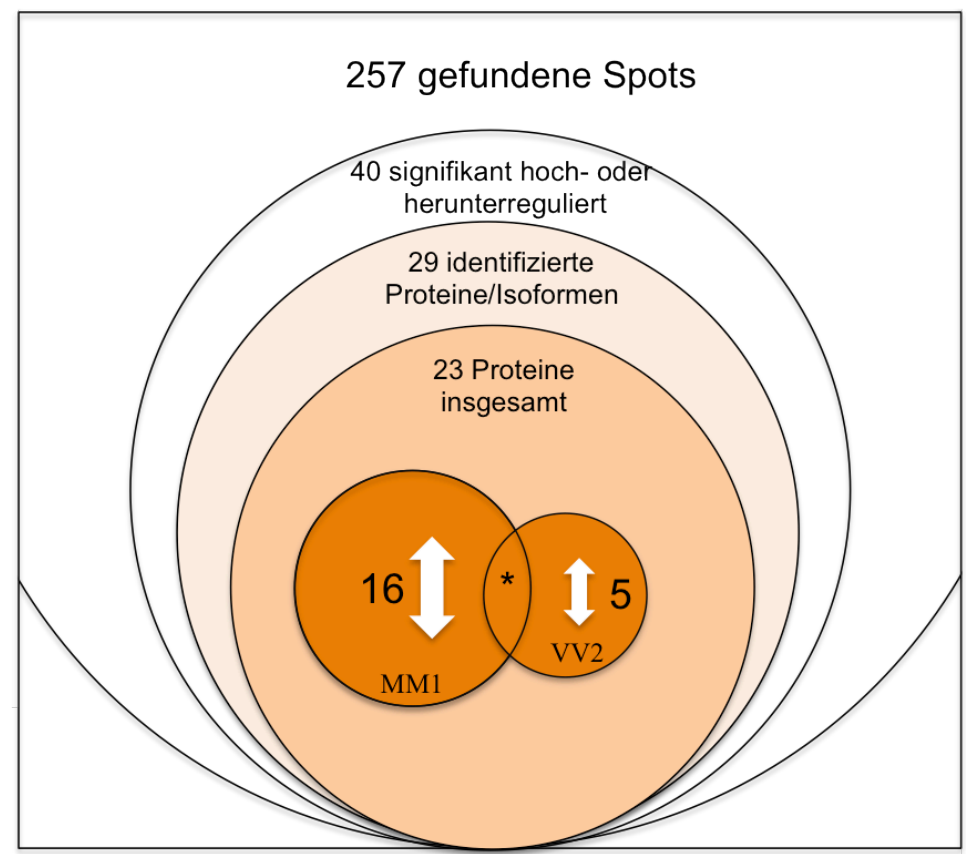

Abbildung 15. Schematische Darstellung der 257 gefundenen Proteinspots und die darauffolgende Reduzierung auf die identifizierten Proteine. 40 hoch- beziehungsweise herunterregulierte signifikante Proteinspots sind mit Hilfe der Softwareanalyse herausgefunden wurden. 29 Spots konnten durch massenspektrometrische Untersuchungen identifiziert werden, dies entsprach 23 Proteinen. 16 Proteine sind signifikant reguliert für den Subtyp MM1, 5 für den Subtyp VV2. * : Eine Isoform von GFAP ist in beiden Subtypen signifikant. Außerdem ließ sich Spectrin alpha chain, brain als Gesamtprotein für MM1 nachweisen und die geschnittene Form für VV2. Noch weitere Proteine/Isoformen zeigen die gleiche Tendenz der Regulation für beide Subtypen, jedoch wurden die Signifikanzkriterien nicht erfüllt. 


\begin{tabular}{|c|c|c|c|c|c|c|c|c|c|}
\hline \multirow{3}{*}{$\frac{\text { ID \# }}{6805}$} & \multirow{2}{*}{ Protein } & \multicolumn{3}{|c|}{ Subtyp MM1 } & \multicolumn{3}{|c|}{ Subtyp VV2 } & \multirow{3}{*}{$\begin{array}{l}\text { UniProt } \\
\text { Eintrag } \\
\text { P14136 }\end{array}$} & \multirow{3}{*}{$\begin{array}{r}\text { Score } \\
487\end{array}$} \\
\hline & & \multicolumn{2}{|c|}{ Regulation } & \multirow{2}{*}{$\begin{array}{c}p \text {-Wert } \\
0,010\end{array}$} & \multicolumn{2}{|c|}{ Regulation } & \multirow{2}{*}{$\frac{p \text {-Wert }}{0,010}$} & & \\
\hline & Glial fibrillary acidic protein & $\uparrow$ & 2,0 & & $\uparrow$ & 2,3 & & & \\
\hline 6355 & Spectrin alpha chain, brain ${ }^{*}$ & $\downarrow$ & 0,3 & 0,043 & $\leftrightarrow$ & 0,3 & 0,053 & Q13813 & 80 \\
\hline 10783 & $\begin{array}{l}\text { Spectrin alpha chain, brain } \\
\text { (cleaved form) }\end{array}$ & $\leftrightarrow$ & 0,8 & 0,492 & $\downarrow$ & 0,4 & 0,028 & Q13813 & 90 \\
\hline 6488 & \multirow{2}{*}{ Gelsolin* } & $\uparrow$ & 3,0 & 0,014 & $\leftrightarrow$ & 2,2 & 0,159 & P06396 & 86 \\
\hline 6491 & & $\uparrow$ & 2,6 & 0,026 & $\leftrightarrow$ & 2,1 & 0,207 & P06396 & 52 \\
\hline 6810 & \multirow{2}{*}{ Glial fibrillary acidic protein * } & $\uparrow$ & 2,8 & 0,029 & $\leftrightarrow$ & 2,0 & 0,059 & P14136 & 198 \\
\hline 6811 & & $\uparrow$ & 3,2 & 0,004 & $\leftrightarrow$ & 2,3 & 0,103 & P14136 & 357 \\
\hline 6499 & Mitofilin $^{*}$ & $\leftrightarrow$ & 3,2 & 0,090 & $\uparrow$ & 2,6 & 0,028 & Q16891 & 75 \\
\hline 9528 & Annexin-A6 * & $\leftrightarrow$ & 0,6 & 0,120 & $\downarrow$ & 0,4 & 0,020 & P08133 & 345 \\
\hline 6542 & $78 \mathrm{kDa}$ glucose-regulated protein & $\uparrow$ & 2,8 & 0,012 & $\leftrightarrow$ & 1,6 & 0,132 & P11021 & 74 \\
\hline 6543 & $\begin{array}{l}\text { NADH-ubiquinone oxidoreductase } 75 \\
\text { kDa subunit }\end{array}$ & $\uparrow$ & 2,7 & 0,042 & $\leftrightarrow$ & 1,0 & 0,937 & P28331 & 109 \\
\hline 7301 & 14-3-3 protein epsilon & $\uparrow$ & 3,7 & 0,003 & $\leftrightarrow$ & 1,0 & 0,915 & P62258 & 265 \\
\hline 7339 & 14-3-3 protein gamma & $\uparrow$ & 3,4 & 0,007 & $\leftrightarrow$ & 0,7 & 0,442 & P61981 & 198 \\
\hline 40267 & Heat shock protein HSP 90-alpha & $\uparrow$ & 2,1 & 0,024 & $\leftrightarrow$ & 1,9 & 0,152 & P07900 & 160 \\
\hline 6625 & Syntaxin-binding protein 1 & $\downarrow$ & 0,5 & 0,029 & $\leftrightarrow$ & 0,7 & 0,089 & P61764 & 176 \\
\hline 6777 & $\begin{array}{l}\text { ATP synthase subunit alpha, } \\
\text { mitochondrial }\end{array}$ & $\downarrow$ & 0,3 & 0,013 & $\leftrightarrow$ & 0,7 & 0,179 & P25705 & 915 \\
\hline 6923 & $\begin{array}{c}\text { Fructose-bisphosphate- } \\
\text { aldolase A }\end{array}$ & $\downarrow$ & 0,4 & 0,011 & $\leftrightarrow$ & 0,8 & 0,332 & P04075 & 50 \\
\hline 6929 & $\begin{array}{c}\text { Aspartate aminotransferase, } \\
\text { mitochondrial }\end{array}$ & $\downarrow$ & 0,4 & 0,002 & $\leftrightarrow$ & 0,7 & 0,157 & P00505 & 1340 \\
\hline 7065 & \multirow{2}{*}{ Malate dehydrogenase, mitochondrial } & $\downarrow$ & 0,4 & 0,040 & $\leftrightarrow$ & 0,9 & 0,680 & P40926 & 413 \\
\hline 7081 & & $\downarrow$ & 0,3 & 0,046 & $\leftrightarrow$ & 0,9 & 0,877 & P40926 & 193 \\
\hline 7216 & Alpha-crystallin B chain & $\downarrow$ & 0,2 & 0,016 & $\leftrightarrow$ & 1,2 & 0,638 & P02511 & 332 \\
\hline 7387 & Enoyl-CoA hydratase, mitochondrial & $\downarrow$ & 0,3 & 0,010 & $\leftrightarrow$ & 1,2 & 0,492 & P30084 & 113 \\
\hline 7553 & Peroxiredoxin-2 & $\downarrow$ & 0,3 & 0,040 & $\leftrightarrow$ & 0,9 & 0,692 & P32119 & 608 \\
\hline 7566 & $\begin{array}{l}\text { Phosphatidylethanolamine-binding } \\
\text { protein } 1 \\
\end{array}$ & $\downarrow$ & 0,3 & 0,008 & $\leftrightarrow$ & 1,1 & 0,854 & P30086 & 721 \\
\hline 7569 & Ferritin heavy chain & $\downarrow$ & 0,4 & 0,044 & $\leftrightarrow$ & 1,0 & 0,937 & P02794 & 122 \\
\hline 7593 & Alpha-crystallin B chain & $\downarrow$ & 0,2 & 0,003 & $\leftrightarrow$ & 1,2 & 0,596 & P02511 & 407 \\
\hline 6986 & Tubulin beta- $2 A$ chain & $\leftrightarrow$ & 0,9 & 0,903 & $\uparrow$ & 2,4 & 0,040 & Q13885 & 39 \\
\hline 6532 & Vesicle-fusing ATPase & $\leftrightarrow$ & 0,9 & 0,890 & $\downarrow$ & 0,4 & 0,004 & P46459 & 78 \\
\hline 7025 & $\begin{array}{l}N(G), N(G) \text { dimethylarginine } \\
\text { dimethylaminohydrolase } 1\end{array}$ & $\leftrightarrow$ & 0,9 & 0,681 & $\downarrow$ & 0,5 & 0,003 & O94760 & 251 \\
\hline 6567 & nicht identifiziert * & $\uparrow$ & 4,1 & 0,043 & $\leftrightarrow$ & 3,2 & 0,089 & & \\
\hline 7649 & nicht identifiziert & $\uparrow$ & 5,2 & 0,023 & $\leftrightarrow$ & 1,3 & 0,634 & & \\
\hline 6390 & nicht identifiziert & $\downarrow$ & 0,3 & 0,038 & $\leftrightarrow$ & 0,8 & 0,629 & & \\
\hline 6919 & nicht identifiziert * & $\downarrow$ & 0,4 & 0,023 & $\leftrightarrow$ & 0,6 & 0,154 & & \\
\hline 7350 & nicht identifiziert & $\downarrow$ & 0,4 & 0,022 & $\leftrightarrow$ & 1,3 & 0,200 & & \\
\hline 7538 & nicht identifiziert & $\downarrow$ & 0,4 & 0,036 & $\leftrightarrow$ & 0,7 & 0,361 & & \\
\hline 7059 & nicht identifiziert & $\leftrightarrow$ & 1,1 & 0,900 & $\uparrow$ & 3,3 & 0,010 & & \\
\hline 7554 & nicht identifiziert & $\leftrightarrow$ & 1,4 & 0,316 & $\uparrow$ & 2,3 & 0,020 & & \\
\hline 6348 & nicht identifiziert * & $\leftrightarrow$ & 0,6 & 0,155 & $\downarrow$ & 0,4 & 0,035 & & \\
\hline 6424 & nicht identifiziert & $\leftrightarrow$ & 1,1 & 0,651 & $\downarrow$ & 0,5 & 0,016 & & \\
\hline 6431 & nicht identifiziert & $\leftrightarrow$ & 0,8 & 0,364 & $\downarrow$ & 0,4 & 0,046 & & \\
\hline
\end{tabular}

Tabelle 4. Überblick der signifikanten hoch- oder herunterregulierten Proteine (dunkelgrau unterlegt für den jeweiligen Subtyp). Die Proteine mit * markiert zeigen die gleiche Richtung der Regulation in beiden Subtypen, verfehlen aber die Signifikanzkriterien (hellgrau unterlegt besonders knapp). 
Die 23 identifizierten Proteine wurden anhand ihrer biologischen Funktionen in 4 Gruppen eingeteilt. 35\% der identifizierten Proteine können der Gruppe Zellstruktur und Stofftransport zugeordnet werden. Mit 30\% ist die zweitgrößte Gruppe Zellund Energiestoffwechsel. Deutlich weniger Proteine gehören der Gruppe Apoptose und oxidativer Stress an. Mit 5 zugeordneten Proteinen hat sie einen Anteil von 22\%. Den prozentual kleinsten Anteil mit 13\% haben die Chaperon-Proteine (Abb. 16).

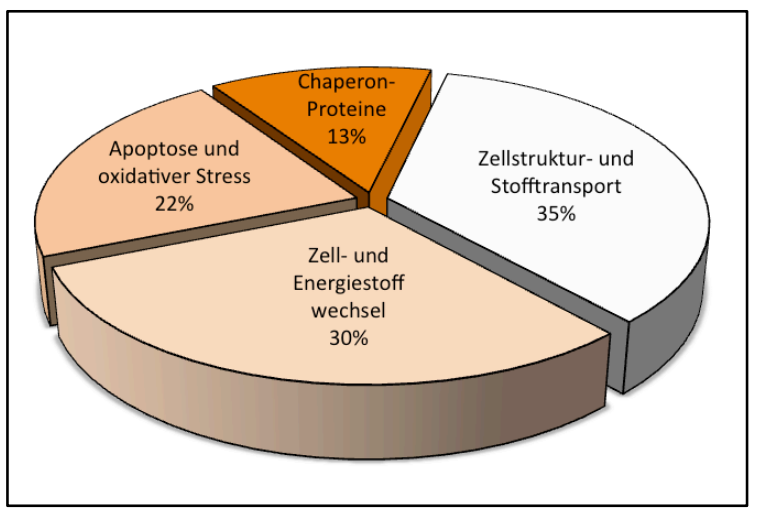

Abbildung 16. Prozentuale Verhältnisse, nachdem alle identifizierten Proteine anhand ihrer biologischen Funktionen eingeteilt wurden.

Um ein präziseres Bild von den Subtypen $\mathrm{zu}$ bekommen, wurden in den Abbildungen 17 und 18 die Proteine den Subtypen entsprechend eingeteilt. Für den Subtyp MM1 ist nun die größte Gruppe Zell- und Energiestoffwechsel mit 33\%. Für den Subtyp VV2 macht Zellstruktur und Stofftransport mit 70\% den Großteil der Proteine aus. Chaperon-Proteine konnten für VV2-sCJK nicht gefunden werden.

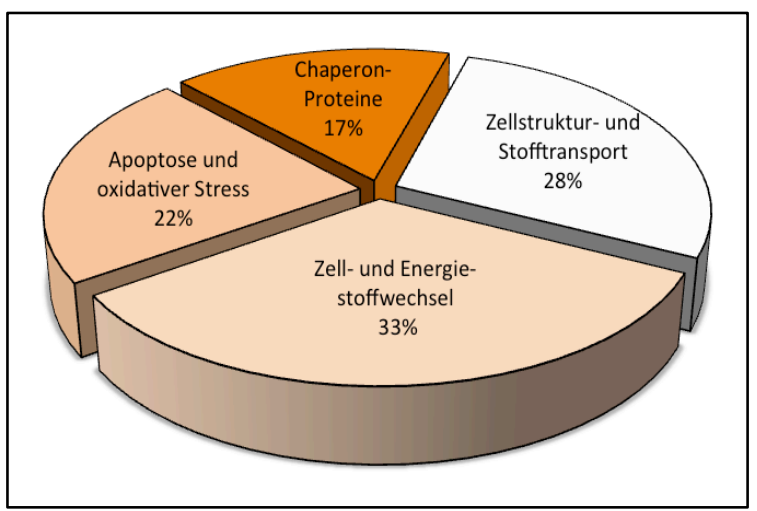

Abbildung 17. Prozentuale Verhältnisse für MM1-sCJK, nachdem die Proteine anhand ihrer biologischen Funktionen eingeteilt wurden. 


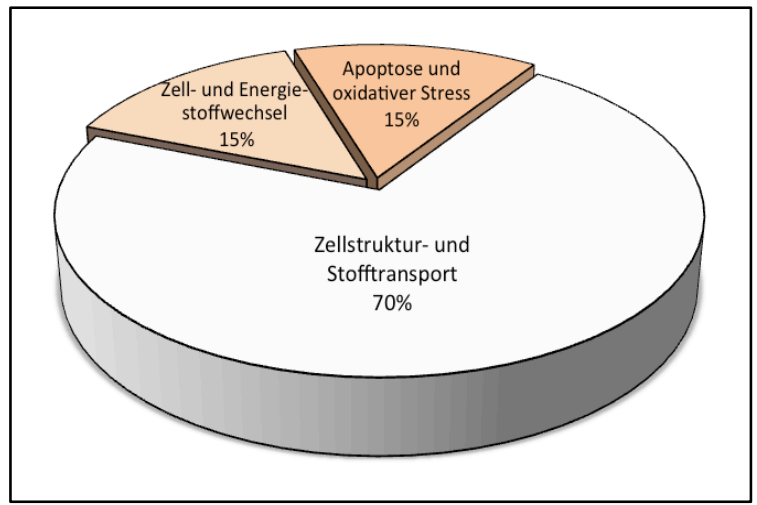

Abbildung 18. Prozentuale Verhältnisse für VV2-sCJK, nachdem die Proteine anhand ihrer biologischen Funktionen eingeteilt wurden.

\subsection{Proteine mit Einfluss auf Zellstruktur und Stofftransport}

$\mathrm{Zu}$ dieser Gruppe gehören die Proteine Annexin-A6, Spectrin alpha chain, brain und ihre gespaltene Form, Syntaxin-binding protein 1, Ferritin heavy chain, die 3 Isoformen von GFAP, die 2 Isoformen von Gelsolin, Tubulin beta-2A chain und Vesicle-fusing ATPase. Insgesamt zeigt sich eine ausgeglichene Verteilung. 5 Proteine sind jeweils signifikant für MM1 und VV2. Eine Isoform von GFAP (ID 6805) ist signifikant für beide Subtypen. Spectrin alpha chain, brain ist signifikant für MM1, verfehlt aber die Signifikanzkriterien für VV2 nur sehr knapp ( $p$-Wert von 0,053). Für MM1 sind alle identifizierten Isoformen von GFAP und Gelsolin hochreguliert. Spectrin alpha chain, brain; Syntaxin-binding protein 1 und Ferritin heavy chain sind herunterreguliert. Für VV2 ist eine Isoform von GFAP und Tubulin beta-2A chain hochreguliert. Annexin-A6, Vesicle-fusing ATPase und die gespaltene Form von Spectrin alpha chain, brain sind herunterreguliert. Weiterhin zeigen die beiden Isoformen des GFAPs ( ID 6810, 6811) und Gelsolin die gleiche Tendenz der Regulation für VV2-sCJK, ohne die Signifikanz zu erreichen. Gleiches gilt für Annexin A6 und MM1-sCJK (Tab. 5). 


\begin{tabular}{|l|l|l|}
\cline { 2 - 3 } \multicolumn{1}{c|}{} & MM1 & VV2 \\
\hline hochreguliert & $\begin{array}{l}\text { GFAP * (und 2 weitere } \\
\text { Isoformen) }\end{array}$ & GFAP \\
\cline { 2 - 3 } & $\begin{array}{l}\text { Gelsolin * (und 1 weitere } \\
\text { Isoform) }\end{array}$ & Tubulin beta-2A chain \\
\hline \multirow{2}{*}{$\begin{array}{l}\text { herunter- } \\
\text { reguliert }\end{array}$} & $\begin{array}{l}\text { Spectrin alpha chain, } \\
\text { brain * }\end{array}$ & Annexin-A6 * \\
\cline { 2 - 3 } & $\begin{array}{l}\text { Syntaxin-binding protein } \\
1\end{array}$ & Vesicle-fusing ATPase \\
\cline { 2 - 3 } & Ferritin heavy chain & $\begin{array}{l}\text { Spectrin alpha chain, brain } \\
\text { (cleaved form) }\end{array}$ \\
\hline
\end{tabular}

Tabelle 5. Verteilung der signifikanten hoch- oder herunterregulierten Proteine zwischen den Subtypen MM1 und VV2, für die Gruppe der Proteine mit Einfluss auf die Zellstruktur und Stofftransport. * Eine Isoform von GFAP (ID 6805) ist signifikant für beide Subtypen. Zusätzlich zeigen die beiden anderen Isoformen des GFAPs, Spectrin alpha chain, brain und Gelsolin die gleiche Tendenz der Regulation auch für VV2-sCJK, die Signifikanzkriterien werden aber verfehlt. Gleiches gilt für Annexin A6 und MM1-sCJK.

\subsection{Proteine mit Einfluss auf Zellstoffwechsel und Energiestoffwechsel}

Den zweitgrößten Anteil hatte die Gruppe der Proteine des Zell- und Energiestoffwechsels. Dazu gehören die Proteine Enoyl-CoA hydratase, mitochondrial; Malate dehydrogenase, mitochondrial; Aspartate aminotransferase, mitochondrial; Fructosebisphosphate aldolase A, NADH-ubiquinone oxidoreductase $75 \mathrm{kDa}$ subunit, ATP synthase subunit alpha, mitochondrial und Mitofilin. Von Malate dehydrogenase, mitochondrial wurden 2 Isoformen identifiziert. Mitofilin ist in dieser Gruppe das einzige Protein, was signifikant für VV2-sCJK reguliert ist. Für den Subtyp MM1 zeigt es ebenfalls eine Hochregulation um das 3,2fache bei einem $p$-Wert von 0,090 (Signifikanzgrenze $p$-Wert < 0,05). Alle anderen Proteine sind signifikant für den Subtyp MM1. NADHubiquinone oxidoreductase $75 \mathrm{kDa}$ subunit ist von diesen Proteinen das einzige hochregulierte Protein. Die verbliebenen 5 Proteine sind herunterreguliert. Somit lässt sich sagen, dass die Gruppe des Zell- und Energiestoffwechsels hauptsächlich gekennzeichnet ist durch herunterregulierte Proteine, signifikant für den Subtyp MM1 (Tab. 6). 


\begin{tabular}{|c|c|c|}
\hline & MM1 & VV2 \\
\hline hochreguliert & $\begin{array}{l}\text { NADH-ubiquinone oxidoreductase } 75 \quad \mathrm{kDa} \\
\text { subunit }\end{array}$ & Mitofilin * \\
\hline \multirow{5}{*}{$\begin{array}{l}\text { herunter- } \\
\text { reguliert }\end{array}$} & Enoyl-CoA hydratase, mitochondrial & \\
\hline & $\begin{array}{l}\text { Malate dehydrogenase, mitochondrial (und } 1 \\
\text { weitere Isoform) }\end{array}$ & \\
\hline & Fructose-bisphosphate aldolase A & \\
\hline & ATP synthase subunit alpha, mitochondrial & \\
\hline & Aspartate aminotransferase, mitochondrial & \\
\hline
\end{tabular}

Tabelle 6. Verteilung der signifikanten hoch- oder herunterregulierten Proteine, zwischen den Subtypen MM1 und VV2, für die Gruppe der Proteine mit Einfluss auf den Zell- und Energiestoffwechsel. * Mitofilin tendiert zur gleichen Regulation auch für MM1sCJK ohne die Signifikanz zu erreichen.

\subsection{Proteine mit Einfluss auf Apoptose und oxidativen Stress}

Den drittgrößten Anteil mit 22\% hat die Gruppe der Proteine, die im Zusammenhang mit Apoptose und oxidativem Stress stehen. Sie beinhaltet die Proteine 14-3-3 protein gamma, 14-3-3 protein epsilon, Peroxiredoxin-2, Phosphatidylethanolamine-binding protein 1 und $N(G), N(G)$ dimethylarginine dimethylaminohydrolase $1 . N(G), N(G)$ dimethylarginine dimethylaminohydrolase 1 ist für den Subtyp VV2 signifikant herunterreguliert (0,5fache, $p$-Wert von 0,003). Die 4 erstgenannten Proteine sind signifikant für den Subtyp MM1. Die beiden 14-3-3Isoformen sind hochreguliert, Peroxiredoxin-2 und Phosphatidylethanolamine-binding protein 1 sind herunterreguliert. Zusammengefasst lässt sich sagen, dass 4 der 5 Proteine sind signifikant für den Subtyp MM1 (Tab. 7). 


\begin{tabular}{|c|c|c|}
\hline & MM1 & VV2 \\
\hline \multirow[t]{2}{*}{ hochreguliert } & 14-3-3 protein gamma & \\
\hline & 14-3-3 protein epsilon & \\
\hline \multirow[t]{2}{*}{$\begin{array}{l}\text { herunter- } \\
\text { reguliert }\end{array}$} & $\begin{array}{l}\text { Phosphatidylethanolamine- } \\
\text { binding protein } 1\end{array}$ & \multirow[t]{2}{*}{$\begin{array}{l}N(G), \quad N(G) \quad \text { dimethylarginine } \\
\text { dimethylaminohydrolase } 1\end{array}$} \\
\hline & Peroxiredoxin-2 & \\
\hline
\end{tabular}

Tabelle 7. Verteilung der signifikanten hoch- oder herunterregulierten Proteine zwischen den Subtypen MM1 und VV2 für die Gruppe der Proteine mit Einfluss auf die Apoptose und oxidativen Stress.

\subsection{Proteine mit Einfluss auf die Proteinfaltung (Chaperon-Proteine)}

Zur kleinsten Gruppe mit 13\% gehören die Proteine Heat shock protein HSP 90-alpha, $78 \mathrm{kDa}$ glucose-regulated protein und 2 Isoformen von Alpha-crystallin B chain. Das Heat shock protein HSP 90-alpha ist für den Subtyp MM1 signifikant hochreguliert um das 2,1fache mit einem $p$-Wert von 0,024. Außerdem zeigt $78 \mathrm{kDa}$ glucose-regulated protein eine Hochregulation um das 2,8fache, bei einem $p$-Wert von 0,012. Beide Isoformen von Alpha-crystallin B chain zeigen eine signifikante Herunterregulation für den Subtyp MM1 (Tab. 8).

\begin{tabular}{|l|l|l|}
\cline { 2 - 3 } \multicolumn{1}{c|}{} & MM1 & VV2 \\
\hline \multirow{2}{*}{ hochreguliert } & Heat shock protein HSP 90-alpha & \multicolumn{2}{|c|}{} \\
\cline { 2 - 3 } & $78 \mathrm{kDa}$ glucose-regulated protein & \\
\hline $\begin{array}{l}\text { herunter- } \\
\text { reguliert }\end{array}$ & $\begin{array}{l}\text { Alpha-crystallin B chain (und 1 weitere } \\
\text { Isoform) }\end{array}$ & \\
\hline
\end{tabular}

Tabelle 8. Verteilung der signifikanten Proteine für MM1-sCJK für die Gruppe der Proteine mit Einfluss auf die Proteinfaltung. 


\section{Diskussion}

In dieser Arbeit wurde das Proteom der Synapse der beiden am häufigsten auftretenden Subtypen der sporadischen Creutzfeldt-Jakob-Krankheit MM1 und VV2 mit einer neurologisch unauffälligen Kontrollgruppe verglichen. Ziel war es, Proteine $\mathrm{zu}$ identifizieren, die eine unterschiedliche Expression zeigen und somit eine Rolle im Pathomechanismus der sporadischen Creutzfeldt-Jakob-Krankheit spielen könnten. Im Vergleich der beiden Subtypen mit der Kontrollgruppe wurden 23 CJK-regulierte Proteine identifiziert. Der Großteil der Proteine lässt sich der Gruppe Zellstruktur und Stofftransport zuordnen. Eine Isoform von GFAP war als einziges Protein signifikant für beide Subtypen. Spectrin alpha chain, brain ließ sich in 2 Formen identifizieren. Das komplette Protein war für MM1 signifikant und die geschnittene Form für VV2. Außerdem zeigten noch weitere Proteine, beziehungsweise Isoformen die gleiche Tendenz der Regulation, verfehlten aber die Signifikanzkriterien. So ist es denkbar, dass unter anderen experimentellen Bedingungen die Signifikanzgrenze erreicht werden könnte. Insgesamt wurden mehr als doppelt soviele Proteine für Subtyp MM1 gefunden. Die Ergebnisse deuten daraufhin, dass verschiedene zelluläre Prozesse in der Synapse gestört sein könnten.

\subsection{Proteine mit Einfluss auf Zellstruktur und Stofftransport}

Mit Tubulin beta-2A chain und Gelsolin sind 2 Proteine hochreguliert, die durch ihre Funktion unter anderem zum Erhalt der Stabilität der Nervenzelle dienen. Tubulin beta- $2 A$ chain ist wichtig für den Aufbau von Axonen während der Gehirnentwickelung und Regeneration (Hoffman 1988; Joshi and Cleveland 1989; Hoffman and Luduena 1996). Zusätzlich scheint es auch am Umbau von Dendriten (remodeling) beteiligt zu sein (Paden et al. 1995). Gelsolin ist ein calciumabhängiges, ein Aktin-bindendes Protein und hat eine Schlüsselrolle im Bereich der AktinSynthese und Abbau (Sun HQ et al. 1999). Außerdem werden Gelsolin eine antiapoptotische, anti-amyloide und eine anti-oxidative Wirkung zugeschrieben (Koya et al. 2000; Harms et al. 2004; Sadzynski et al. 2010). Die Proteine Spectrin alpha chain, brain; Syntaxin-binding protein, sowie Annexin A6 sind herunterreguliert und könnten Einfluss auf die Zellkommunikation haben. Spectrin alpha chain, brain ist eine 
Untereinheit des Spectrins. Spectrin hat eine direkte Verbindung zu Aktin, welches ein wichtiger Bestandteil und Stabilitätsfaktor des Zytoskeletts ist und die Aktinfilamente aufbaut (Bennett et al. 1982; Fox et al. 1987; Bennett and Baines 2001). Gleichzeitig wird die Fähigkeit Calcium zu binden diskutiert, da strukturelle Ähnlichkeiten zu Calmodulin gefunden wurden (Bennett and Baines 2001). Calcium wird benötigt für die aktive Bewegung des Zytoskeletts. Die Vermutung, dass Spectrin alpha chain, brain Calcium binden kann, wird bekräftigt durch eine direkte Verbindung zum NMDA-Rezeptorder, der durch calciumabhängige Regulierung eine wichtige Schlüsselrolle für die synaptische Plastizität ausübt (Wechsler and Teichberg 1998). Außerdem wurde eine direkte Verbindung zu Proteinen der Syntaxin-Familie gefunden, das vermuten lässt, dass Spectrin eine regulatorische Funktion bei der Exozytose ausüben könnte (Nakano et al. 2001). Es konnte außerdem gezeigt werden, dass Spectrin alpha chain, brain bei alkoholinduzierter Neurodegeneration durch die Aktivierung von Calpain selbst abgebaut wird (Rajgopal and Vemuri 2002). Syntaxin-binding protein 1 spielt eine Schlüsselrolle in der synaptischen Aktivität bei der Fusion und Neurotransmitterfreisetzung aus den Vesikeln (Swanson et al. 1998; Burgoyne et al. 2009; Han GA et al. 2010). Durch Bindung an Syntaxin 1 stabilisiert es das Protein in seinen Konformationsformen und vermittelt gleichzeitig das Binden von Syntaxin 1 an den SNARE-Komplex. Außerdem unterstützt es den SNARE-Komplex bei der Membranfusion (Deak et al. 2009; Han GA et al. 2010). Das Fehlen von Syntaxin-binding protein 1 führt zum kompletten Ausfall der Neurotransmittersekretion, welches zwangsläufig zum Funktionsverlust der Neurone führt (Verhage et al. 2000; Heeroma et al. 2004). Weiterhin zeigt Syntaxin-binding protein 1 eine aktivierende Wirkung auf Cdk5 (Shetty et al. 1995; Rajgopal and Vemuri 2001). Cdk5 ist hauptsächlich aktiv im ZNS und beteiligt an neuronaler Entwicklung. Interessanterweise scheint Cdk5 eine Schlüsselrolle in der Neuropathologie von vielen neurodegenerativen Erkrankungen zu spielen und könnte eine molekulare Verbindung zwischen synaptischer Dysfunktion und neuronalem Zelltod sein (Lopes and Agostinho 2011). Annexin A6 ist ein calciumabhängiges Protein, das mit den Phospholipiden der Membranen interagiert. Es ist in der Regulation des Stofftransports (Endozytose und Exozytose) zwischen Golgi-Apparat und Plasmamembran involviert, insbesondere von 
Cholesterin und Caveolin (Grewal et al. 2000; Cubells et al. 2007). Außerdem ist es Bestandteil der clathrin-coated-pits (Lin et al. 1992). Es interagiert auch mit dem Protein Fyn, das zusammen mit PrP und Caveolin ein Signalkomplex bildet (Chow A et al. 2000; Mouillet-Richard et al. 2000). Weiterhin bindet Annexin A6 an das synaptische Vesikel Protein Synapsin I, das die Menge der vorhandenen präsynaptischen Vesikel für die Freisetzung von Neurotransmittern reguliert (Inui et al. 1994). Das außerdem herunterregulierte Protein Ferritin heavy chain ist eine Untereinheit des Ferritins (Han J et al. 2000). Ferritin bindet Eisen und reguliert durch eine pufferähnliche Wirkung den Eisenhaushalt, abhängig vom zellulären Bedarf. Störungen des Eisenhaushalts können durch Bewegungsstörungen und Verhaltensstörungen auffällig werden (Johnstone and Milward 2010). Der Funktionsverlust von $\mathrm{PrPC}$, beziehungsweise die Aggregation von PrPsc, führt zu einem Dysregulation des Eisenhaushalts (Singh et al. 2009). Dabei freiwerdende Eisenionen führen zu Neurotoxizität in der Nervenzelle (Das et al. 2010) und zu oxidativem Stress (Kim et al. 2000). Herausstechend aus dieser Gruppe sind Spectrin alpha chain, brain; Syntaxin-binding protein 1 und Annexin A6. Möglicherweise könnte die gestörte Funktion dieser 3 Proteine für eine fehlerhafte Kommunikation zwischen den Neuronen sprechen. Hinweise lassen sich für beide Subtypen finden, sodass dies auf eine Fehlfunktion im Rahmen des allgemeinen Pathomechanismus der sporadischen Creutzfeldt-Jakob-Krankheit hinweisen könnte. Ein erniedrigtes Vorkommen von Spectrin alpha chain, brain konnte ebenfalls im Rahmen des betaAmyloid-induzierten Zelluntergangs bei Morbus Alzheimer gefunden werden (Wei et al. 2008). Syntaxin-binding protein 1 steht in Verbindung zu Cdk5, dessen Funktionsstörungen im Pathomechanismus von Morbus Alzheimer und Morbus Parkinson von Bedeutung sind. (Lopes and Agostinho 2011; Shetty et al. 1995; Rajgopal and Vemuri 2001). Unser Studiendesign lässt keine Aussage zu, wann genau die Änderung der Proteinexpression auftritt. Um einen genaueren Überblick über den Beginn der Änderung dieser involvierten Proteine zu bekommen, sind bereits weitere Experimente im Tiermodell geplant. Dabei sollen transgene Mäuse, die menschliches PrPC exprimieren und mit den Subtypen MM1 und VV2 der sCJK infiziert werden, mit einer Kontrollgruppe zu verschiedenen Zeitpunkten mittels Proteomanalyse verglichen werden. 


\subsection{Proteine mit Einfluss auf Zellstoffwechsel und Energiestoffwechsel}

Für den Subtyp MM1 zeigt sich, dass im Bereich des Mitochondrienmetabolismus viele Schlüsselenzyme herunterreguliert sind, die an lebenswichtigen Kreisläufen für die Energiegewinnung aus Fetten, Proteinen und Kohlenhydraten in der Zelle beteiligt sind. Enoyl-CoA hydratase, mitochondrial ist ein Enzym der $\beta$-Oxidation, welches eine Hydratationsreaktion katalysiert (Janssen et al. 1997; Bahnson et al. 2002). In einem Experiment mit humanen Brustkrebszellen MCF-7 zeigte sich, dass die durch das Protein PP2 (kinase inhibitor) induzierte Apoptose zu einer Herunterregulation von Enoyl-CoA hydratase, mitochondrial führte (Liu et al. 2010). Das Enzym Malate dehydrogenase, mitochondrial ist Bestandteil des Zitratzyklus und im Malat-Aspartat-Shuttle, welches ein System zum indirekten Transfer des NADHs vom Zytosol in die Matrix der Mitochondrien ist. NADH wird in Mitochondrien in der Atmungskette für die Synthese des ATPs benötigt (Rassow et al. 2006a). Ebenfalls beteiligt am Malat-Aspartat-Shuttle ist das Enzym Aspartate aminotransferase, mitochondrial (Rassow et al. 2006b). Fructose-bisphosphate aldolase A ist ein Enzym der Glykolyse und ist daher unentbehrlich für die Verwertung von Kohlenhydraten. (Rassow et al. 2006c). ATP synthase subunit alpha, mitochondrial ist das einzige herunterregulierte Protein, was nicht direkt eine Reaktion katalysiert. Es ist eine Untereinheit der ATP-Synthase. Die ATP-Synthase ist in der mitochondrialen Innenmembran verankert und regeneriert ATP. ATP ist der zentrale und entscheidende Energieträger aller Organismen (Rassow et al. 2006d). Die Hochregulation von NADH-ubiquinone oxidoreductase 75 kDa subunit (MM1) und Mitofilin (VV2) könnte ein Indiz für den Schutz und Erhalt der korrekten Mitochondrienfunktion sein. Die NADH-ubiquinone oxidoreductase $75 \mathrm{kDa}$ subunit ist der größte Bestandteil des Komplexes 1 der Atmungskette in Mitochondrien (Chow W et al. 1991; Duncan et al. 1992). Fehlfunktion des Komplexes 1 können sich störend auf die Homöostase von Gehirn, Skelettmuskeln und Herz auswirken (Smeitink et al. 2004). Das Vorhandensein von Mitofilin scheint essentiell wichtig für die Funktion der Mitochondrien, sowie die korrekte Formation der inneren Mitochondrienmembran zu sein (Mun et al. 2010). Zusammenfassend lassen sich die Konsequenzen der herunterregulierten Proteine im Einzelnen nur schwer beurteilen. Das Gesamtbild dieser Proteine deutet darauf hin, dass es im Verlauf der 
sCJK für Subtyp MM1 zu einer mitochondrialen Dysfunktion innerhalb der Synapsen kommen könnte. Dies wird bestätigt durch Experimente, wo ultrastrukturell gezeigt werden konnte, dass es bei sCJK-Patienten im Bereich des Gehirns zu mitochondrialer Degeneration kommt (Liberski et al. 2005). Allerdings scheint die Degeneration der Mitochondrien nicht gleichbedeutend mit einem grundsätzlichen Mitochondrienverlust zu sein. Experimente mit Scrapie-infizierten Mäusen, welche die Anzahl und Funktion der Mitochondrien im Verlauf der Erkrankung untersuchten, zeigten, dass am Anfang der Erkrankung die Anzahl der Mitochondrien relativ konstant blieb, obwohl es auch $\mathrm{zu}$ morphologischen Veränderungen der inneren Mitochondrienmembran kam. Dementsprechend könnte die Dysfunktion zu Beginn im Vordergrund stehen und diese erst im späteren Verlauf zum Untergang der Neurone führen (Siskova et al. 2010). Auch ein Experiment der Alzheimer-Forschung zeigte, dass die Ablagerung von aggregierten Proteinen, wie $\beta$-Amyloid oder dem Tau-Protein, oxidativen Stress induziert, welcher zu mitochondrialer Dysfunktion führte (Grimm et al. 2011).

\subsection{Proteine mit Einfluss auf Apoptose und oxidativen Stress}

Im Bereich dieser Gruppe sind die Proteine Phosphatidylethanolamine-binding protein 1 und $N(G), N(G)$ dimethylarginine dimethylaminohydrolase 1 herunterreguliert. Bei Morbus Alzheimer kommt es vermutlich durch A $\beta$-induzierte Toxizität zur Herunterregulation von Phosphatidylethanolamine-binding protein 1, was zu einer erhöhten Aktivität der Stickstoffmonoxid-Synthase führt (George et al. 2006; Szego et al. 2011). $N(G), N(G)$ dimethylarginine dimethylaminohydrolase 1 ist eine Enzym was die Synthese von Inhibitoren der NOS katalysiert (Wang et al. 2009). Die Funktion des Enzyms kann durch aufkommenden oxidativen Stress in der Zelle negativ beeinflusst werden (Tain et al. 2010). Die steigende Stickstoffmonoxid-Konzentration könnte dann durch Cytochrom-c-Oxidase-Inhibition neuronalen Zelltod induzieren (Brown GC and Neher 2010). So könnte eine pathologisch erhöhte Konzentration von Stickstoffmonoxid in der Zelle ein Merkmal von neurodegenerativen Veränderungen sein (Garcao et al. 2006). 


\subsection{Proteine mit Einfluss auf Proteinfaltung (Chaperon-Proteine)}

Mit HSP 90-alpha und $78 \mathrm{kDa}$ glucose-regulated protein sind 2 Proteine für Subtyp MM1 hochreguliert, die unter anderem eine anti-apoptotische Funktion gemeinsam haben. HSP 90-alpha ist ein ATP-abhängiges Chaperon-Protein, dessen Expression durch zellulären Stress erhöht wird. Durch eine Interaktion mit einer Vielzahl an Proteinen, hat es eine ausgeprägte anti-apoptotische Funktion (Parcellier et al. 2003; Lanneau et al. 2007). Ebenfalls konnte eine Erhöhung von Hsp90-positiven Purkinjezellen im Cerebellum von Scrapie-infizierten Schafen gefunden werden (Serrano et al. 2011). Außerdem scheint Hsp90 die Fähigkeit zu haben, fehlgefaltete Proteine wieder neu zu organisieren, wie bei der Alzheimer Krankheit (Muchowski 2002; Lu et al. 2009). Weiterhin wurde die Hypothese aufgestellt, dass Mutationen im HSP90AA1 Gen dazu führen, dass Schafe anfälliger für Scrapie-Infektionen werden (Marcos-Carcavilla et al. 2008). Hsp90 scheint auch Einfluss auf die korrekte synaptische Funktion und Plastizität zu nehmen, durch das Vermitteln des kontinuierlichen Transports von AMPA-Rezeptoren in die Synapsen (Gerges et al. 2004). $78 \mathrm{kDa}$ glucose-regulated protein ist das wichtigste calciumbindende Chaperon des ERs. Es wirkt unterstützend bei Faltung und Zusammenbau der Proteine. Außerdem gilt es als potentes anti-apoptotisches Protein (Ni et al. 2011). Es wird auch als Stressmarker des ERs angesehen (Hardy and Raiter 2010). Erhöhte Konzentrationen von $78 \mathrm{kDa}$ glucose-regulated protein wurden auch bei mit BSEinfizierten Kühen gefunden. Eine andere mögliche Erklärung wäre, dass dies mit erhöhtem Stress des ERs korreliert, was zu unkontrollierter Proteinfaltung führen könnte und somit zur Entstehung der Krankheit (Tang et al. 2010). Alpha-crystallin B chain ist ein Beispiel für ein Protein, dessen Herunterregulation negative Auswirkungen für die Zelle zur Folge haben könnte. Das Protein ist eine Untereinheit der Alpha-Crystalline. Diese haben Chaperon-ähnliche Eigenschaften, indem sie die Präzipitation von denaturierten Proteinen verhindern und die Toleranz gegenüber zellulärem Stress erhöhen (Augusteyn 2004). Außer in Synapsen kommen sie auch in Astrozyten vor. Anscheinend kann Alpha-crystallin B chain Einfluss auf die synaptische Plastizität nehmen, welche durch physiologischen Stress durch kognitive Aufgaben ausgelöst wurde (Hu et al. 2009). In Experimenten mit Aggregaten aus amyloiden Peptiden A $\beta$, den Auslösern des Morbus Alzheimers, 
konnte durch die Wirkung von Alpha-Crystallin B chain das Wachstum von A $\beta_{1-40}$ eingeschränkt und die spontane Formation von $A \beta_{1-42}$ unterbunden werden (Raman et al. 2005; Dehle et al. 2010). In ähnlicher Weise wird dies durch Experimente bestätigt, in denen Alpha-Crystallin B chain PrP-Aggregate fragmentieren konnte (Sun Y et al. 2008).

\subsection{Gemeinsamkeiten und Unterschiede zwischen den Subtypen}

Für unsere Experimente wurden die beiden am häufigsten auftretenden Subtypen MM1 und VV2 gewählt. Obwohl sie Subtypen der sporadischen Creutzfeldt-JakobKrankheit darstellen, differieren sie deutlich im klinischen und neuropathologischen Erscheinungsbild. Bei Subtyp MM1 spricht man vom myoklonischen Typ, welcher $\mathrm{zu}$ Beginn mit kognitiven Auffälligkeiten und Sehstörungen einhergeht. Neuropathologisch ist die Degeneration der Neurone im Neocortex und der Sehrinde am stärksten ausgeprägt. Immunhistochemisch spricht man von PrPAblagerungen vom synaptischen Typ (Gambetti et al. 2003). Subtyp VV2 wird als ataktischer Typ beschrieben. Dementielle Veränderungen treten dabei meist in späteren Stadien auf (Parchi et al. 1996; Parchi et al. 1999; Castellani et al. 2004). Neuropathologisch ist hauptsächlich Thalamus und Neostriatum betroffen. Die Immunhistochemie ist charakterisiert durch eine plaqueähnliche Anordnung der PrPSc-Aggregate (Gambetti et al. 2003). Um eine bessere Vergleichbarkeit zu erlangen, wurden die Hirnproben aus dem präfrontalen Kortex entnommen, welcher bei beiden Subtypen in ähnlicher Ausprägung betroffen ist (Abb. 8) (Gambetti et al. 2003). Nur eine Isoform von GFAP war bei unseren Experimenten für beide Subtypen herunterreguliert. GFAP ist ein Typ III-Intermediärfilamentprotein, welches im Zytoplasma von Gliazellen, vor allem in Astrozyten, im ZNS vorkommt. Als reaktive Antwort auf Erkrankungen des ZNS ist es hochreguliert (Brenner 1994). Mittlerweile sind mehrere Isoformen und Funktionen von GFAP bekannt. Diskutiert wird eine Beteiligung an der Regeneration von Nervenzellen und synaptischen Plastizität (Middeldorp and Hol 2011). Ein erhöhtes Vorkommen von GFAP wurde bereits bei Scrapie-infizierten Hamstern nachgewiesen (Tian et al. 2008). Insgesamt konnten mehr als doppelt so viele Proteine für Subtyp MM1 gefunden werden. Die größten Gemeinsamkeiten 
beider Subtypen gab es hinsichtlich Struktur und Stofftransport, die größten Differenzen bezüglich Zell- und Energiestoffwechsel. Proteine aus den Gruppen Apotose/oxidativer Stress und Chaperon-Proteine konnten außerdem mehrheitlich Subtyp MM1 zugeordnet werden. Ursächlich dafür könnten unterschiedliche Signalwege, beziehungsweise die Interaktion mit verschiedenen molekularen Partnern sein, die anschließend zur Ausprägung des jeweiligen Phänotyps führen. Nach Infektion von transgenen Mäusen mit menschlichen Prionen von sCJKErkrankten ergab sich, in Abhängigkeit des jeweiligen PrPsc-Typen, ein unterschiedliches Läsionsmuster im Gehirn (Bishop et al. 2010). Die Unterschiede zwischen den Subtypen könnten auch Ausdruck der verschiedenen Formen von PrPSc sein. Sehr wahrscheinlich besitzt PrPsc subtypspezifische Eigenschaften. So zeigen die PrPSc-Typen biochemische Unterschiede bezüglich der Größe nach Proteinase-K-Abbau, dem Glykosylierungsmuster, der Widerstandsfähigkeit gegen Denaturierung und in der Größe der PrPSc-Aggregate (Parchi et al. 1996; Parchi et al. 1997; Kobayashi et al. 2005; Wemheuer et al. 2009). Andererseits konnte eine Studie zeigen, dass Subtyp MM1 und Subtyp VV2 im Vergleich zu einer Kontrollgruppe zwar ein unterschiedliches Muster der Genexpression besitzt, allerdings ließ sich den Subtypen im Vergleich untereinander kein spezifisches Muster an Genen zuordnen. Unterschiedlich war die Aktivität der auffälligen Gene. Dabei war Subtyp MM1 charakterisiert durch eine Induktion der Genaktivität, Subtyp VV2 hingegen durch eine eher senkende Genaktivität beschrieben. So korrelierte das Ausmaß der Expression auch mit den neuropathologischen Veränderungen, die gefunden wurden (Xiang et al. 2005). 


\section{Zusammenfassung}

Die Creutzfeldt-Jakob-Krankheit ist eine neurodegenerative Erkrankung, die histologisch durch charakteristische Veränderungen im Gehirn gekennzeichnet ist. Der Großteil der Erkrankten leidet an der sporadischen Form, die sich in 6 verschiedene Subtypen gliedert. Dabei treten die Subtypen MM1 und VV2 am häufigsten auf und lassen sich klinisch und neuropathologisch unterscheiden. Die Ursachen, die zur Entstehung der Erkrankung beitragen, konnten bisher nicht eindeutig geklärt werden. Allerdings wird vermutet, dass die Erkrankung von den Synapsen ausgeht und sich im Gehirn ausbreitet. Das Ziel der Arbeit war es, Proteine $\mathrm{zu}$ identifizieren, die an den pathologischen Prozessen der sporadischen Creutzfeldt-Jakob-Krankheit beteiligt sind. Dafür wurde das synaptische Proteom von sCJK-Erkrankten mit einer neurologisch gesunden Kontrollgruppe verglichen. Außerdem wurden die Subtypen MM1 und VV2 hinsichtlich ihrer Gemeinsamkeiten und Unterschiede untersucht. Nach Auftrennung der Proteine durch zweidimensionale Gelelektrophorese und anschließender quantitativer und massenspektrometrischer Analyse war es möglich, 23 Proteine zu identifizieren, die unterschiedlich reguliert sind. Diese konnten den Bereichen Zellstruktur und Stofftransport, Zell- und Energiestoffwechsel, Apoptose und oxidativer Stress, sowie Chaperon-Proteinen zugeordnet werden. Mit einer Isoform von GFAP wurde nur 1 Protein identifiziert, das für beide Subtypen gemeinsam hochreguliert war. Allerdings zeigen noch weitere Proteine die gleiche Tendenz der Dysregulation, verfehlten aber die Signifikanzkriterien. Insgesamt wurden mehr als doppelt soviele Proteine für Subtyp MM1 gefunden. Die Ergebnisse dieser Arbeit deuten daraufhin, dass verschiedene zelluläre Prozesse in der Synapse gestört sind. Bei beiden Subtypen könnte es zu einer Störung der Zellkommunikation zwischen den Neuronen und zu strukturellen Veränderungen kommen. Zusätzlich ergaben sich für Subtyp MM1 Hinweise auf eine mitochondriale Dysfunktion innerhalb der Synapsen. Ursächlich dafür könnten unterschiedliche Signalwege, beziehungsweise die Interaktion mit verschiedenen molekularen Partnern sein. Diese Arbeit ist Grundlage für neue Ansatzpunkte und weiterführende Experimente in der Erforschung der Creutzfeldt-Jakob-Krankheit. 


\section{Literaturverzeichnis}

Alper T, Cramp WA, Haig DA, Clarke MC (1967). "Does the agent of scrapie replicate without nucleic acid?" Nature 214(5090): 764-766.

Alper T, Haig DA, Clarke MC (1966). "The exceptionally small size of the scrapie agent." Biochem Biophys Res Commun 22(3): 278-284.

Augusteyn RC (2004). "alpha-crystallin: a review of its structure and function." Clin Exp Optom 87(6): 356-366.

Bahnson BJ, Anderson VE, Petsko GA (2002). "Structural mechanism of enoyl-CoA hydratase: three atoms from a single water are added in either an E1cb stepwise or concerted fashion." Biochemistry 41(8): 2621-2629.

Bai F, Witzmann FA (2007). "Synaptosome proteomics." Subcell Biochem 43: 77-98.

Baker HE, Poulter M, Crow TJ, Frith CD, Lofthouse R, Ridley RM (1991). "Aminoacid polymorphism in human prion protein and age at death in inherited prion disease." Lancet 337(8752): 1286.

Basler K, Oesch B, Scott M, Westaway D, Walchli M, Groth DF, McKinley MP, Prusiner SB, Weissmann C. (1986). "Scrapie and cellular PrP isoforms are encoded by the same chromosomal gene." Cell 46(3): 417-428.

Bellinger-Kawahara C, Cleaver JE, Diener TO, Prusiner SB (1987). "Purified scrapie prions resist inactivation by UV irradiation." J Virol 61(1): 159-166.

Bennett V, Baines AJ (2001). "Spectrin and ankyrin-based pathways: metazoan inventions for integrating cells into tissues." Physiol Rev 81(3): 1353-1392.

Bennett V, Davis J, Fowler WE (1982). "Brain spectrin, a membrane-associated protein related in structure and function to erythrocyte spectrin." Nature 299(5879): 126-131.

Bernoulli C, Siegfried J, Baumgartner G, Regli F, Rabinowicz T, Gajdusek DC, Gibbs CJ Jr. (1977). "Danger of accidental person-to-person transmission of Creutzfeldt-Jakob disease by surgery." Lancet 1977,1(8009): 478-479.

Billette de Villemeur T, Gourmelen M, Beauvais P, Rodriguez D, Vaudour G, Deslys JP, Dormont D, Richard P, Richardet JM (1992). "[Creutzfeldt-Jakob disease in 4 children treated with growth hormone]." Rev Neurol (Paris) 148(5): 328-334.

Bishop MT, Will RG, Manson JC 2010). "Defining sporadic Creutzfeldt-Jakob disease strains and their transmission properties." Proc Natl Acad Sci U S A 107(26): 12005-12010. 
Bolton DC, McKinley MP, Prusiner SB (1982). "Identification of a protein that purifies with the scrapie prion." Science 218(4579): 1309-1311.

Bolton DC, McKinley MP, Prusiner SB (1984). "Molecular characteristics of the major scrapie prion protein." Biochemistry 23(25): 5898-5906.

Bradford MM (1976). "A rapid and sensitive method for the quantitation of microgram quantities of protein utilizing the principle of protein-dye binding." Anal Biochem 72: 248-254.

Brenner M (1994). "Structure and transcriptional regulation of the GFAP gene." Brain Pathol 4(3): 245-257.

Brown DR, Nicholas RS, Canevari L. (2002). "Lack of prion protein expression results in a neuronal phenotype sensitive to stress." J Neurosci Res 67(2): 211-224.

Brown GC, Neher JJ (2010). "Inflammatory neurodegeneration and mechanisms of microglial killing of neurons." Mol Neurobiol 41(2-3): 242-247.

Brown K, Mastrianni JA (2010). "The prion diseases." J Geriatr Psychiatry Neurol 23(4): 277-298.

Brown P (1988). "The decline and fall of Creutzfeldt-Jakob disease associated with human growth hormone therapy." Neurology 38(7): 1135-1137.

Brown P, Will RG, Bradley R, Asher DM, Detwiler L (2001). "Bovine spongiform encephalopathy and variant Creutzfeldt-Jakob disease: background, evolution, and current concerns." Emerg Infect Dis 7(1): 6-16.

Bueler H, Fischer M, Lang Y, Bluethmann H, Lipp HP, DeArmond SJ, Prusiner SB, Aguet M, Weissmann C (1992). "Normal development and behaviour of mice lacking the neuronal cell-surface PrP protein." Nature 356(6370): 577-582.

Burgoyne RD, Barclay JW, Ciufo LF, Graham ME, Handley MT, Morgan A (2009). "The functions of Munc18-1 in regulated exocytosis." Ann N Y Acad Sci 1152: 76-86.

Cali I, Castellani R, Yuan J, Al-Shekhlee A, Cohen ML, Xiao X, Moleres FJ, Parchi P, Zou WQ, Gambetti P (2006). "Classification of sporadic Creutzfeldt-Jakob disease revisited." Brain 129(Pt 9): 2266-2277.

Castellani RJ, Colucci M, Xie Z, Zou W, Li C, Parchi P, Capellari S, Pastore M, Rahbar MH, Chen SG, Gambetti P (2004). "Sensitivity of 14-3-3 protein test varies in subtypes of sporadic Creutzfeldt-Jakob disease." Neurology 63(3): 436-442. 
Caughey B, Baron GS, Chesebro B, Jeffrey M. (2009). "Getting a grip on prions: oligomers, amyloids, and pathological membrane interactions." Annu Rev Biochem 78: 177-204.

Chazot G, Broussolle E, Lapras C, Blattler T, Aguzzi A, Kopp N (1996). "New variant of Creutzfeldt-Jakob disease in a 26-year-old French man." Lancet 347(9009): 1181.

Chesebro B, Race R, Wehrly K, Nishio J, Bloom M, Lechner D, Bergstrom S, Robbins K, Mayer L, Keith JM, et al. (1985). "Identification of scrapie prion proteinspecific mRNA in scrapie-infected and uninfected brain." Nature 315(6017): 331-333.

Chow A, Davis AJ, Gawler DJ (2000). "Identification of a novel protein complex containing annexin VI, Fyn, Pyk2, and the p120(GAP) C2 domain." FEBS Lett 469(1): 88-92.

Chow W, Ragan I, Robinson BH (1991). "Determination of the cDNA sequence for the human mitochondrial 75-kDa Fe-S protein of NADH-coenzyme Q reductase." Eur J Biochem 201(3): 547-550.

Collinge J (2001). "Prion diseases of humans and animals: their causes and molecular basis." Annu Rev Neurosci 24: 519-550.

Collinge J, Whittington MA, Sidle KC, Smith CJ, Palmer MS, Clarke AR, Jefferys JG (1994). "Prion protein is necessary for normal synaptic function." Nature 370(6487): 295-297.

Cubells L, Vila de Muga S, Tebar F, Wood P, Evans R, Ingelmo-Torres M, Calvo M, Gaus K, Pol A, Grewal T, Enrich C (2007). "Annexin A6-induced alterations in cholesterol transport and caveolin export from the Golgi complex." Traffic 8(11): 1568-1589.

Das D, Luo X, Singh A, Gu Y, Ghosh S, Mukhopadhyay CK, Chen SG, Sy MS, Kong Q, Singh N (2010). "Paradoxical role of prion protein aggregates in redox-iron induced toxicity." PLoS One 5(7): e11420.

Davanipour Z, Goodman L, Alter M, Sobel E, Asher D, Gajdusek DC (1984). "Possible modes of transmission of Creutzfeldt-Jakob disease." N Engl J Med 311(24): 1582-1583.

Deak F, Xu Y, Chang WP, Dulubova I, Khvotchev M, Liu X, Sudhof TC, Rizo J (2009). "Munc18-1 binding to the neuronal SNARE complex controls synaptic vesicle priming." J Cell Biol 184(5): 751-764.

Dehle FC, Ecroyd H, Musgrave IF, Carver JA (2010). "alphaB-Crystallin inhibits the cell toxicity associated with amyloid fibril formation by kappa-casein and the amyloid-beta peptide." Cell Stress Chaperones 15(6): 1013-1026. 
De Robertis E, Pellegrino De Iraldi A, Rodriguez G, Gomez CJ (1961). "On the isolation of nerve endings and synaptic vesicles." J Biophys Biochem Cytol 9: 229-235.

Dormont D (2002). "Prion diseases: pathogenesis and public health concerns." FEBS Lett 529(1): 17-21.

Duffy P, Wolf J, Collins G, DeVoe AG, Streeten B, Cowen D (1974). "Letter: Possible person-to-person transmission of Creutzfeldt-Jakob disease." N Engl J Med 290(12): 692-693.

Duncan AM, Chow W, Robinson BH (1992). "Localization of the human 75-kDal Fe-S protein of NADH-coenzyme Q reductase gene (NDUFS1) to 2q33----q34." Cytogenet Cell Genet 60(3-4): 212-213.

Endo T, Groth D, Prusiner SB, Kobata, A. (1989). "Diversity of oligosaccharide structures linked to asparagines of the scrapie prion protein." Biochemistry 28(21): 8380-8388.

Fontaine SN, Brown DR (2009). "Mechanisms of prion protein aggregation." Protein Pept Lett 16(1): 14-26.

Fox JE, Reynolds CC, Morrow JS, Phillips DR (1987). "Spectrin is associated with membrane-bound actin filaments in platelets and is hydrolyzed by the Ca2+dependent protease during platelet activation." Blood 69(2): 537-545.

Gabizon R, Rosenmann H, Meiner Z, Kahana I, Kahana E, Shugart Y, Ott J, Prusiner SB (1993). "Mutation and polymorphism of the prion protein gene in Libyan Jews with Creutzfeldt-Jakob disease (CJD)." Am J Hum Genet 53(4): 828-835.

Gajdusek DC, Zigas V (1957). "Degenerative disease of the central nervous system in New Guinea; the endemic occurrence of kuru in the native population." N Engl J Med 257(20): 974-978.

Gajdusek DC, Gibbs CJ, Alpers M (1966). "Experimental transmission of a Kuru-like syndrome to chimpanzees." Nature 209(5025): 794-796.

Gambetti P, Kong Q, Zou W, Parchi P, Chen SG (2003). "Sporadic and familial CJD: classification and characterisation." Br Med Bull 66: 213-239.

Garcao P, Oliveira CR, Agostinho P (2006). "Comparative study of microglia activation induced by amyloid-beta and prion peptides: role in neurodegeneration." J Neurosci Res 84(1): 182-193. 
George AJ, Holsinger RM, McLean CA, Tan SS, Scott HS, Cardamone T, Cappai R, Masters CL, Li QX (2006). "Decreased phosphatidylethanolamine binding protein expression correlates with Abeta accumulation in the Tg2576 mouse model of Alzheimer's disease." Neurobiol Aging 27(4): 614-623.

Gerges NZ, Tran IC, Backos DS, Harrell JM, Chinkers M, Pratt WB, Esteban JA (2004). "Independent functions of hsp90 in neurotransmitter release and in the continuous synaptic cycling of AMPA receptors." J Neurosci 24(20): 4758-4766.

Gillardon F, Rist W, Kussmaul L, Vogel J, Berg M, Danzer K, Kraut N, Hengerer B (2007). "Proteomic and functional alterations in brain mitochondria from Tg2576 mice occur before amyloid plaque deposition." Proteomics 7(4): 605616.

Glatzel M, Aguzzi A (2001). "The shifting biology of prions." Brain Res Brain Res Rev 36(2-3): 241-248.

Gray BC, Siskova Z, Perry VH, O'Connor V (2009). "Selective presynaptic degeneration in the synaptopathy associated with ME7-induced hippocampal pathology." Neurobiol Dis 35(1): 63-74.

Gray EG, Whittaker VP (1962). "The isolation of nerve endings from brain: an electron-microscopic study of cell fragments derived by homogenization and centrifugation." J Anat 96: 79-88.

Grewal T, Heeren J, Mewawala D, Schnitgerhans T, Wendt D, Salomon G, Enrich C, Beisiegel U, Jackle S (2000). "Annexin VI stimulates endocytosis and is involved in the trafficking of low density lipoprotein to the prelysosomal compartment." J Biol Chem 275(43): 33806-33813.

Griffith JS (1967). "Self-replication and scrapie." Nature 215(5105): 1043-1044.

Grimm S, Hoehn A, Davies KJ, Grune T (2011). "Protein oxidative modifications in the ageing brain: consequence for the onset of neurodegenerative disease." Free Radic Res 45(1): 73-88.

Han GA, Malintan NT, Collins BM, Meunier FA, Sugita S (2010). "Munc18-1 as a key regulator of neurosecretion." J Neurochem 115(1): 1-10.

Han J, Day JR, Thomson K, Connor JR, Beard JL (2000). "Iron deficiency alters H- and L-ferritin expression in rat brain." Cell Mol Biol (Noisy-le-grand) 46(3): 517528.

Hardy B, Raiter A (2010). "Peptide-binding heat shock protein GRP78 protects cardiomyocytes from hypoxia-induced apoptosis." J Mol Med 88(11): 11571167. 
Harms C, Bosel J, Lautenschlager M, Harms U, Braun JS, Hortnagl H, Dirnagl U, Kwiatkowski DJ, Fink K, Endres M (2004). "Neuronal gelsolin prevents apoptosis by enhancing actin depolymerization." Mol Cell Neurosci 25(1): 6982.

Heeroma JH, Roelandse M, Wierda K, van Aerde KI, Toonen RF, Hensbroek RA, Brussaard A, Matus A, Verhage M. (2004). "Trophic support delays but does not prevent cell-intrinsic degeneration of neurons deficient for munc18-1." Eur J Neurosci 20(3): 623-634.

Hoffman PN (1988). "Distinct roles of neurofilament and tubulin gene expression in axonal growth." Ciba Found Symp 138: 192-204.

Hoffman PN, Luduena RF (1996). "Changes in the isotype composition of betatubulin delivered to regenerating sensory axons by slow axonal transport." Brain Res 742(1-2): 329-333.

Hsiao K, Baker HF, Crow TJ, Poulter M, Owen F, Terwilliger JD, Westaway D, Ott J, Prusiner SB. (1989). "Linkage of a prion protein missense variant to Gerstmann-Straussler syndrome." Nature 338(6213): 342-345.

Hu S, Ying Z, Gomez-Pinilla F, Frautschy SA (2009). "Exercise can increase small heat shock proteins (sHSP) and pre- and post-synaptic proteins in the hippocampus." Brain Res 1249: 191-201.

Inui M, Watanabe T, Sobue K (1994). "Annexin VI binds to a synaptic vesicle protein, synapsin I." J Neurochem 63(5): 1917-1923.

Janssen U, Davis EM, Le Beau MM, Stoffel W (1997). "Human mitochondrial enoylCoA hydratase gene (ECHS1): structural organization and assignment to chromosome 10q26.2-q26.3." Genomics 40(3): 470-475.

Jeffrey M, Halliday WG, Bell J, Johnston AR, MacLeod NK, Ingham C, Sayers AR, Brown DA, Fraser JR (2000). "Synapse loss associated with abnormal PrP precedes neuronal degeneration in the scrapie-infected murine hippocampus." Neuropathol Appl Neurobiol 26(1): 41-54.

Johnstone D, Milward EA (2010). "Molecular genetic approaches to understanding the roles and regulation of iron in brain health and disease." J Neurochem 113(6): 1387-1402.

Joshi HC, Cleveland DW (1989). "Differential utilization of beta-tubulin isotypes in differentiating neurites." J Cell Biol 109(2): 663-673.

Kim NH, Park SJ, Jin JK, Kwon MS, Choi EK, Carp RI, Kim YS (2000). "Increased ferric iron content and iron-induced oxidative stress in the brains of scrapieinfected mice." Brain Res 884(1--2): 98-103. 
Kobayashi A, Satoh S, Ironside JW, Mohri S, Kitamoto T (2005). "Type 1 and type 2 human PrPSc have different aggregation sizes in methionine homozygotes with sporadic, iatrogenic and variant Creutzfeldt-Jakob disease." J Gen Virol 86(Pt 1): 237-240.

Koya RC, Fujita H, Shimizu S, Ohtsu M, Takimoto M, Tsujimoto Y, Kuzumaki N. (2000). "Gelsolin inhibits apoptosis by blocking mitochondrial membrane potential loss and cytochrome c release." J Biol Chem 275(20): 15343-15349.

Kuwahara C, Takeuchi AM, Nishimura T, Haraguchi K, Kubosaki A, Matsumoto Y, Saeki K, Yokoyama T, Itohara S, Onodera T (1999). "Prions prevent neuronal cell-line death." Nature 400(6741): 225-226.

Lanneau D, de Thonel A, Maurel S, Didelot C, Garrido C (2007). "Apoptosis versus cell differentiation: role of heat shock proteins HSP90, HSP70 and HSP27." Prion 1(1): 53-60.

Levin J: Prionerkrankungen: Analyse von Aggregationsprozessen des Prionproteins auf Einzelmolekülebene. Med. Diss. LMU München 2007

Lewis PA, Tattum MH, Jones S, Bhelt D, Batchelor M, Clarke AR, Collinge J, Jackson GS (2006). "Codon 129 polymorphism of the human prion protein influences the kinetics of amyloid formation." J Gen Virol 87(Pt 8): 2443-2449.

Liberski PP, Streichenberger N, Giraud P, Soutrenon M, Meyronnet D, Sikorska B, Kopp N (2005). "Ultrastructural pathology of prion diseases revisited: brain biopsy studies." Neuropathol Appl Neurobiol 31(1): 88-96.

Lin HC, Sudhof TC, Anderson RG (1992). "Annexin VI is required for budding of clathrin-coated pits." Cell 70(2): 283-291.

Liu X, Feng R, Du L (2010). "The role of enoyl-CoA hydratase short chain 1 and peroxiredoxin 3 in PP2-induced apoptosis in human breast cancer MCF-7 cells." FEBS Lett 584(14): 3185-3192.

Llewelyn CA, Hewitt PE, Knight RS, Amar K, Cousens S, Mackenzie J, Will RG (2004). "Possible transmission of variant Creutzfeldt-Jakob disease by blood transfusion." Lancet 363(9407): 417-421.

Lopes JP, Agostinho P (2011). "Cdk5: multitasking between physiological and pathological conditions." Prog Neurobiol 94(1): 49-63.

Lu Y, Ansar S, Michaelis ML, Blagg BS (2009). "Neuroprotective activity and evaluation of Hsp90 inhibitors in an immortalized neuronal cell line." Bioorg Med Chem 17(4): 1709-1715. 
Mallucci GR (2009). "Prion neurodegeneration: starts and stops at the synapse." Prion 3(4): 195-201.

Mallucci GR, Dickinson A, Linehan J, Klohn PC, Brandner S, Collinge J (2003). "Depleting neuronal PrP in prion infection prevents disease and reverses spongiosis." Science 302(5646): 871-874.

Mallucci GR, White MD, Farmer M, Dickinson A, Khatun H, Powell AD, Brandner S, Jefferys JG, Collinge J (2007). "Targeting cellular prion protein reverses early cognitive deficits and neurophysiological dysfunction in prion-infected mice." Neuron 53(3): 325-335.

Marcos-Carcavilla A, Calvo JH, Gonzalez C, Moazami-Goudarzi K, Laurent P, Bertaud M, Hayes H, Beattie AE, Serrano C, Lyahyai J, Martin-Burriel I, Serrano M (2008). "Structural and functional analysis of the HSP90AA1 gene: distribution of polymorphisms among sheep with different responses to scrapie." Cell Stress Chaperones 13(1): 19-29.

Masters CL, Harris JO, Gajdusek DC, Gibbs CJ, Jr., Bernoulli C, Asher DM (1979). "Creutzfeldt-Jakob disease: patterns of worldwide occurrence and the significance of familial and sporadic clustering." Ann Neurol 5(2): 177-188.

Mattson MP, Duan W (1999). "Apoptotic" biochemical cascades in synaptic compartments: roles in adaptive plasticity and neurodegenerative disorders." J Neurosci Res 58(1): 152-166.

McKintosh E, Tabrizi SJ, Collinge J (2003). "Prion diseases." J Neurovirol 9(2): 183-193.

McLennan NF, Brennan PM, McNeill A, Davies I, Fotheringham A, Rennison KA, Ritchie D, Brannan F, Head MW, Ironside JW, Williams A, Bell JE (2004). "Prion protein accumulation and neuroprotection in hypoxic brain damage." Am J Pathol 165(1): 227-235.

Medori R, Montagna P, Tritschler HJ, LeBlanc A, Cortelli P, Tinuper P, Lugaresi E, Gambetti P (1992). "Fatal familial insomnia: a second kindred with mutation of prion protein gene at codon 178." Neurology 42(3 Pt 1): 669-670.

Meissner B, Kallenberg K, Sanchez-Juan P, Collie D, Summers DM, Almonti S, Collins SJ, Smith P, Cras P, Jansen GH, Brandel JP, Coulthart MB, Roberts H, Van Everbroeck B, Galanaud D, Mellina V, Will RG, Zerr I (2009). "MRI lesion profiles in sporadic Creutzfeldt-Jakob disease." Neurology 72(23):1994-2001.

Meyer RK, McKinley MP, Bowman KA, Braunfeld MB, Barry RA, Prusiner SB (1986). "Separation and properties of cellular and scrapie prion proteins." Proc Natl Acad Sci U S A 83(8): 2310-2314.

Middeldorp J, Hol EM (2011). "GFAP in health and disease." Prog Neurobiol 93(3): 421-443. 
Mouillet-Richard S, Ermonval M, Chebassier C, Laplanche JL, Lehmann S, Launay JM, Kellermann O (2000). "Signal transduction through prion protein." Science 289(5486): 1925-1928.

Muchowski PJ (2002). "Protein misfolding, amyloid formation, and neurodegeneration: a critical role for molecular chaperones?" Neuron 35(1): 912.

Mun JY, Lee TH, Kim JH, Yoo BH, Bahk YY, Koo HS, Han SS (2010). "Caenorhabditis elegans mitofilin homologs control the morphology of mitochondrial cristae and influence reproduction and physiology." J Cell Physiol 224(3): 748-756.

Nakano M, Nogami S, Sato S, Terano A, Shirataki H (2001). "Interaction of syntaxin with alpha-fodrin, a major component of the submembranous cytoskeleton." Biochem Biophys Res Commun 288(2): 468-475.

Ni M, Zhang Y, Lee AS (2011). "Beyond the endoplasmic reticulum: atypical GRP78 in cell viability, signalling and therapeutic targeting." Biochem J434 (2): 181188.

Nieznanski K, Nieznanska H, Skowronek KJ, Osiecka KM, Stepkowski D (2005). "Direct interaction between prion protein and tubulin." Biochem Biophys Res Commun 334(2): 403-411.

Oesch B, Westaway D, Walchli M, McKinley MP, Kent SB, Aebersold R, Barry RA, Tempst P, Teplow DB, Hood LE (1985). "A cellular gene encodes scrapie PrP 27-30 protein." Cell 40(4): 735-746.

Otto M, Wiltfang J, Cepek L, Neumann M, Mollenhauer B, Steinacker P, Ciesielczyk B, Schulz-Schaeffer W, Kretzschmar HA, Poser S (2002). "Tau protein and 143-3 protein in the differential diagnosis of Creutzfeldt-Jakob disease." Neurology 58(2): 192-197.

Paden CM, Zhou X, Watt JA, Burton R, Pickett J, Oblinger MM (1995). "Distribution of growth-associated class I alpha-tubulin and class II beta-tubulin mRNAs in adult rat brain." J Comp Neurol 362(3): 368-384.

Paitel E, Alves da Costa C, Vilette D, Grassi J, Checler F (2002). "Overexpression of PrPc triggers caspase 3 activation: potentiation by proteasome inhibitors and blockade by anti-PrP antibodies." J Neurochem 83(5): 1208-1214.

Palmer MS, Dryden AJ, Hughes JT, Collinge J (1991). "Homozygous prion protein genotype predisposes to sporadic Creutzfeldt-Jakob disease." Nature 352(6333): 340-342. 
Pan KM, Baldwin M, Nguyen J, Gasset M, Serban A, Groth D, Mehlhorn I, Huang Z, Fletterick RJ, Cohen FE (1993). "Conversion of alpha-helices into beta-sheets features in the formation of the scrapie prion proteins." Proc Natl Acad Sci U S A 90(23): 10962-10966.

Parcellier A, Gurbuxani S, Schmitt E, Solary E, Garrido C (2003). "Heat shock proteins, cellular chaperones that modulate mitochondrial cell death pathways." Biochem Biophys Res Commun 304(3): 505-512.

Parchi P, Castellani R, Capellari S, Ghetti B, Young K, Chen SG, Farlow M, Dickson DW, Sima AA, Trojanowski JQ, Petersen RB, Gambetti P (1996). "Molecular basis of phenotypic variability in sporadic Creutzfeldt-Jakob disease." Ann Neurol 39(6): 767-778.

Parchi P, Capellari S, Chen SG, Petersen RB, Gambetti P, Kopp N, Brown P, Kitamoto T, Tateishi J, Giese A, Kretzschmar H (1997). "Typing prion isoforms." Nature 386(6622): 232-234.

Parchi P, Giese A, Capellari S, Brown P, Schulz-Schaeffer W, Windl O, Zerr I, Budka H, Kopp N, Piccardo P, Poser S, Rojiani A, Streichemberger N, Julien J, Vital C, Ghetti B, Gambetti P, Kretzschmar H (1999). "Classification of sporadic Creutzfeldt-Jakob disease based on molecular and phenotypic analysis of 300 subjects." Ann Neurol 46(2): 224-233.

Parchi P, Cescatti M, Notari S, Schulz-Schaeffer WJ, Capellari S, Giese A, Zou WQ, Kretzschmar H, Ghetti B, Brown P (2010). "Agent strain variation in human prion disease: insights from a molecular and pathological review of the National Institutes of Health series of experimentally transmitted disease." Brain 133(10): 3030-3042.

Pattison IH (1965). "Resistance of the Scrapie Agent to Formalin." J Comp Pathol 75: 159-164.

Porps P: Erhöhte Lebenserwartung und Resistenz gegenuber oxidativem Stress in Maus-Prion-Protein (PrP)-exprimierenden Drosophila melanogaster. Rer. Nat. Diss. Würzburg 2008

Prusiner SB (1982). "Novel proteinaceous infectious particles cause scrapie." Science 216(4542): 136-144.

Prusiner SB (1998). "Prions." Proc Natl Acad Sci U S A 95(23): 13363-13383.

Prusiner SB, McKinley MP, Groth DF, Bowman KA, Mock NI, Cochran SP, Masiarz FR (1981). "Scrapie agent contains a hydrophobic protein." Proc Natl Acad Sci U S A 78(11): 6675-6679. 
Prusiner SB, Bolton DC, Groth DF, Bowman KA, Cochran SP, McKinley MP (1982). "Further purification and characterization of scrapie prions." Biochemistry 21(26): 6942-6950.

Prusiner SB, McKinley MP, Bowman KA, Bolton DC, Bendheim PE, Groth DF, Glenner GG (1983). "Scrapie prions aggregate to form amyloid-like birefringent rods." Cell 35(2 Pt 1): 349-358.

Prusiner SB, Groth DF, Bolton DC, Kent SB, Hood LE (1984). "Purification and structural studies of a major scrapie prion protein." Cell 38(1): 127-134.

Puckett C, Concannon P, Casey C, Hood L (1991). "Genomic structure of the human prion protein gene." Am J Hum Genet 49(2): 320-329.

Rac M (2006). "[Molecular bases of prion diseases]." Ann Acad Med Stetin 52(3): 5-13.

Rajgopal Y, Vemuri MC (2001). "Ethanol induced changes in cyclin-dependent kinase-5 activity and its activators, P35, P67 (Munc-18) in rat brain." Neurosci Lett 308(3): 173-176.

Rajgopal Y, Vemuri MC (2002). "Calpain activation and alpha-spectrin cleavage in rat brain by ethanol." Neurosci Lett 321(3): 187-191.

Raman B, Ban T, Sakai M, Pasta SY, Ramakrishna T, Naiki H, Goto Y, Rao Ch M (2005). "AlphaB-crystallin, a small heat-shock protein, prevents the amyloid fibril growth of an amyloid beta-peptide and beta2-microglobulin." Biochem J 392(Pt 3): 573-581.

Rassow, Hauser, Netzker, Deutzmann: Duale Reihe Biochemie, 1. Auflage; hrsg. v. Bob A, Bob K; Georg Thieme Verlag, Stuttgart 2006a, 118, 179

Rassow, Hauser, Netzker, Deutzmann: Duale Reihe Biochemie, 1. Auflage; hrsg. v. Bob A, Bob K; Georg Thieme Verlag, Stuttgart 2006b, 152, 178-180

Rassow, Hauser, Netzker, Deutzmann: Duale Reihe Biochemie, 1. Auflage; hrsg. v. Bob A, Bob K; Georg Thieme Verlag, Stuttgart 2006c, 77

Rassow, Hauser, Netzker, Deutzmann: Duale Reihe Biochemie, 1. Auflage; hrsg. v. Bob A, Bob K; Georg Thieme Verlag, Stuttgart 2006d, 4-6, 164-165

Ricketts MN (2004). "Public health and the BSE epidemic." Curr Top MicrobiolImmunol 284: 99-119.

Riek R, Hornemann S, Wider G, Billeter M, Glockshuber R, Wuthrich K (1996). "NMR structure of the mouse prion protein domain $\operatorname{PrP}(121-321)$." Nature 382(6587): 180-182. 
Rivera-Milla E, Oidtmann B, Panagiotidis CH, Baier M, Sklaviadis T, Hoffmann R, Zhou Y, Solis GP, Stuermer CA, Malaga-Trillo E (2006). "Disparate evolution of prion protein domains and the distinct origin of Doppel- and prion-related loci revealed by fish-to-mammal comparisons." FASEB J 20(2): 317-319.

Sadzynski A, Kurek K, Kononczuk T, Zendzian-Piotrowska M (2010). "[Gelsolin variety of structure and functions]." Postepy Hig Med Dosw (Online) 64: 303309.

Sanchez-Juan P, Sanchez-Valle R, Green A, Ladogana A, Cuadrado-Corrales N, Mitrova E, Stoeck K, Sklaviadis T, Kulczycki J, Hess K, Krasnianski A, Equestre M, Slivarichova D, Saiz A, Calero M, Pocchiari M, Knight R, van Duijn CM, Zerr I. (2007). "Influence of timing on CSF tests value for Creutzfeldt-Jakob disease diagnosis." J Neurol 254(7): 901-906.

Serrano C, Bolea R, Lyahyai J, Filali H, Varona L, Marcos-Carcavilla A, Acin C, Calvo JH, Serrano M, Badiola JJ, Zaragoza P, Martin-Burriel I (2011). "Changes in HSP gene and protein expression in natural scrapie with brain damage." Vet Res 42(1): 13.

Shetty KT, Kaech S, Link WT, Jaffe H, Flores CM, Wray S, Pant HC, Beushausen S (1995). "Molecular characterization of a neuronal-specific protein that stimulates the activity of Cdk5." J Neurochem 64(5): 1988-1995.

Singh A, Kong Q, Luo X, Petersen RB, Meyerson H, Singh N (2009). "Prion protein $(\mathrm{PrP})$ knock-out mice show altered iron metabolism: a functional role for PrP in iron uptake and transport." PLoS One 4(7): e6115.

Siskova Z, Mahad DJ, Pudney C, Campbell G, Cadogan M, Asuni A, O'Connor V, Perry VH (2010). "Morphological and functional abnormalities in mitochondria associated with synaptic degeneration in prion disease." Am J Pathol 177(3): 1411-1421.

Smeitink JA, van den Heuvel LW, Koopman WJ, Nijtmans LG, Ugalde C, Willems PH (2004). "Cell biological consequences of mitochondrial NADH: ubiquinone oxidoreductase deficiency." Curr Neurovasc Res 1(1): 29-40.

Spielhaupter C, Schatzl HM (2001). "PrPC directly interacts with proteins involved in signaling pathways." J Biol Chem 276(48): 44604-44612.

Stahl N, Borchelt DR, Hsiao K, Prusiner SB (1987). "Scrapie prion protein contains a phosphatidylinositol glycolipid." Cell 51(2): 229-240.

Stahl N, Baldwin MA, Teplow DB, Hood L, Gibson BW, Burlingame AL, Prusiner SB (1993). "Structural studies of the scrapie prion protein using mass spectrometry and amino acid sequencing." Biochemistry 32(8): 1991-2002. 
Sturzenegger: Die Klinik der Prionkrankheiten des Menschen; in: Prionen und Prionkrankheiten; hrsg. v. Hörnlimann B, Riesner, Kretzschmar H; Walter de Gruyter, Berlin 2001, 250-251

Sun HQ, Yamamoto M, Mejillano M, Yin HL (1999). "Gelsolin, a multifunctional actin regulatory protein." J Biol Chem 274(47): 33179-33182.

Sun Y, Makarava N, Lee CI, Laksanalamai P, Robb FT, Baskakov IV (2008). "Conformational stability of PrP amyloid fibrils controls their smallest possible fragment size." J Mol Biol 376(4): 1155-1167.

Swanson DA, Steel JM, Valle D (1998). "Identification and characterization of the human ortholog of rat STXBP1, a protein implicated in vesicle trafficking and neurotransmitter release." Genomics 48(3): 373-376.

Szego EM, Csorba A, Janaky T, Kekesi KA, Abraham IM, Morotz GM, Penke B, Palkovits M, Murvai U, Kellermayer MS, Kardos J, Juhasz GD (2011). "Effects of Estrogen on Beta-Amyloid-Induced Cholinergic Cell Death in the Nucleus Basalis Magnocellularis." Neuroendocrinology 93(2): 90-105.

Tain YL, Kao YH, Hsieh CS, Chen CC, Sheen JM, Lin IC, Huang LT (2010). "Melatonin blocks oxidative stress-induced increased asymmetric dimethylarginine." Free Radic Biol Med 49(6): 1088-1098.

Tang Y, Xiang W, Terry L, Kretzschmar HA, Windl O (2010). "Transcriptional analysis implicates endoplasmic reticulum stress in bovine spongiform encephalopathy." PLoS One 5(12): e14207.

Tian C, Zhang BY, Shi Q, Han J, Gao C, Han L, Dong XP (2008). "Analyses of the expressions of GFAP in the brain tissues of hamsters infected with various amounts of scrapie strain $263 \mathrm{~K}$ at terminal stage." Zhonghua Shi Yan He Lin Chuang Bing Du Xue Za Zhi 22(4): 241-243.

Tobler I, Deboer T, Fischer M (1997). "Sleep and sleep regulation in normal and prion protein-deficient mice." J Neurosci 17(5): 1869-1879.

Turk E, Teplow DB, Hood LE, Prusiner SB (1988). "Purification and properties of the cellular and scrapie hamster prion proteins." Eur J Biochem 176(1): 21-30.

Vassallo N, Herms J, Behrens C, Krebs B, Saeki K, Onodera T, Windl O, Kretzschmar HA (2005). "Activation of phosphatidylinositol 3-kinase by cellular prion protein and its role in cell survival." Biochem Biophys Res Commun 332(1): 75-82.

Verhage M, Maia AS, Plomp JJ, Brussaard AB, Heeroma JH, Vermeer H, Toonen RF, Hammer RE, van den Berg TK, Missler M, Geuze HJ, Sudhof TC (2000). "Synaptic assembly of the brain in the absence ofneurotransmitter secretion." Science 287(5454): 864-869. 
Waites CL, Garner CC (2011). "Presynaptic function in health and disease." Trends Neurosci 34(6): 326-337.

Wang Y, Monzingo AF, Hu S, Schaller TH, Robertus JD, Fast W (2009). "Developing dual and specific inhibitors of dimethylarginine dimethylaminohydrolase-1 and nitric oxide synthase: toward a targeted polypharmacology to control nitric oxide." Biochemistry 48(36): 8624-8635.

Wechsler A, Teichberg VI (1998). "Brain spectrin binding to the NMDA receptor is regulated by phosphorylation, calcium and calmodulin." EMBO J 17(14): 39313939.

Wei Z, Song MS, MacTavish D, Jhamandas JH, Kar S (2008). "Role of calpain and caspase in beta-amyloid-induced cell death in rat primary septal cultured neurons." Neuropharmacology 54(4): 721-733.

Weiß E: Analyse der Proteinexpression zur Untersuchung der physiologischen Funktion des zellulären Prionproteins (PrPc). Med. Diss. Göttingen 2009

Wemheuer WM, Benestad SL, Wrede A, Schulze-Sturm U, Wemheuer WE, Hahmann U, Gawinecka J, Schutz E, Zerr I, Brenig B, Bratberg B, Andreoletti O, Schulz-Schaeffer WJ (2009). "Similarities between forms of sheep scrapie and Creutzfeldt-Jakob disease are encoded by distinct prion types." Am J Pathol 175(6): 2566-2573.

Westergard L, Christensen HM, Harris DA (2007). "The cellular prion protein $(\operatorname{PrP}(\mathrm{C}))$ : its physiological function and role in disease." Biochim Biophys Acta 1772(6): 629-644.

Winklhofer KF, Tatzelt J, Haass C (2008). "The two faces of protein misfolding: gainand loss-of-function in neurodegenerative diseases." EMBO J 27(2): 336-349.

Xiang W, Windl O, Westner IM, Neumann M, Zerr I, Lederer RM, Kretzschmar HA (2005). Cerebral gene expression profiles in sporadic Creutzfeldt-Jakob disease. Ann Neurol Aug;58(2):242-57

Yang H, Qiao H, Tian X (2011). "Proteomic analysis of cerebral synaptosomes isolated from rat model of alzheimer's disease." Indian J Exp Biol 49(2): 118124.

Zahn R, Liu A, Luhrs T, Riek R, von Schroetter C, Lopez Garcia F, Billeter M, Calzolai L, Wider G, Wuthrich K (2000). "NMR solution structure of the human prion protein." Proc Natl Acad Sci U S A 97(1): 145-150.

Zomosa-Signoret V, Arnaud JD, Fontes P, Alvarez-Martinez MT, Liautard JP (2008). "Physiological role of the cellular prion protein." Vet Res 39(4): 9. 
Zou WQ, Gambetti P (2009). "Variant Creutzfeldt-Jakob disease: French versus British." Ann Neurol 65(3): 233-235. 


\section{Danksagung}

Hiermit möchte ich all denjenigen danken, mit deren Unterstützung ich diese Arbeit schreiben konnte.

$\mathrm{Zu}$ Beginn möchte ich besonders meiner Doktormutter Prof. Inga Zerr danken, die es möglich gemacht hat, dass ich ein Mitglied der Prionforschungsgruppe werden konnte. Vielen Dank, dass ich sie jederzeit um Rat fragen konnte und nie lange auf eine Antwort warten musste.

Großer Dank gebührt meinen beiden Betreuerinnen Dr. Julie Carimalo und Dr. Joanna Gawinecka. Eine bessere Betreuung hätte ich mir nicht wünschen können. Vielen Dank an Julie für ihre Unterstützung zu jeder Tageszeit. Vielen Dank auch an Joanna, für die Anleitung und Hilfe bei der experimentellen Durchführung der Versuche. Auf Ihre Erfahrung war immer Verlass.

Ein großer Dank gebührt Dr. Matthias Schmitz, Barbara Ciesielczyk und Katja Hermann, die mir immer halfen, wenn der Laboralltag ins Stocken geriet. Ebenso danke ich mich bei Jolanthe Ehrlich und Maja Schneider-Dominco für die schnelle Hilfe bei allen bürokratischen Hürden.

Herzlicher Dank gilt der Abteilung für Neuropathologie, deren S2-Labor ich benutzen durfte. Vielen Dank an Dr. Wiebke Wemheuer, Jutta Petschenka, Johanna Breyer und Dr. Walter Schulz-Schäffer, die mich in ihren Arbeitsalltag integriert haben.

Dr. A. R. Asif und seinen technischen Assistenten möchte ich für die Durchführung der massenspektrometrischen Analysen danken.

Ebenso danke ich Christian Kuhn für das Korrekturlesen der ersten Version. 